Illinois State University

ISU ReD: Research and eData

Theses and Dissertations

3-5-2015

\title{
A Democracy, If We Can Keep It: Democratic Engagement Policy in Higher Education
}

Maegan Gorham

Illinois State University, maegangorham@gmail.com

Follow this and additional works at: https://ir.library.illinoisstate.edu/etd

Part of the Higher Education Administration Commons, Higher Education and Teaching Commons, and the Public Policy Commons

\section{Recommended Citation}

Gorham, Maegan, "A Democracy, If We Can Keep It: Democratic Engagement Policy in Higher Education" (2015). Theses and Dissertations. 386.

https://ir.library.illinoisstate.edu/etd/386

This Dissertation is brought to you for free and open access by ISU ReD: Research and eData. It has been accepted for inclusion in Theses and Dissertations by an authorized administrator of ISU ReD: Research and eData. For more information, please contact ISUReD@ilstu.edu. 


\title{
A DEMOCRACY, IF WE CAN KEEP IT: DEMOCRATIC ENGAGEMENT POLICY IN HIGHER EDUCATION
}

\author{
Maegan M. Gorham
}

172 Pages

August 2015

Students will be called upon as American citizens to be knowledgeable, engaged, contributing citizens, and higher education plays a part in the development of this role. Engagement must surpass simple volunteerism in order to more fully realize the potential benefit of democracy and democratic engagement activities. In turn, institutions must respond effectively and responsibly, making informed decisions about educating all students in the safest manner possible. This exploratory policy analysis, with embedded legal research, explores the policy issue, "Is higher education the appropriate venue for instruction on democratic engagement and, if so, do the benefits and rewards of instruction on democratic engagement outweigh the possible risks of incurring additional legal liability?" Through my own analysis of this issue, I find that democratic engagement is critical to the preservation of democracy in America, and because higher education is determined to be an ideal environment for civic learning, and because there is a compelling state interest which overrides potential increases in institutional risk and liability, democratic engagement as a priority in higher education should be prioritized nationally and supported through policy. 


\section{A DEMOCRACY, IF WE CAN KEEP IT: DEMOCRATIC ENGAGEMENT POLICY IN HIGHER EDUCATION}

MAEGAN M. GORHAM

A Dissertation Submitted in Partial

Fulfillment of the Requirements for the Degree of

DOCTOR OF PHILOSOPHY

Department of Educational Administration and Foundations

\section{ILLINOIS STATE UNIVERSITY}


(C) 2015 Maegan M. Gorham 


\section{A DEMOCRACY, IF WE CAN KEEP IT: DEMOCRATIC ENGAGEMENT POLICY IN HIGHER EDUCATION}

MAEGAN M. GORHAM

COMMITTEE MEMBERS:

Elizabeth T. Lugg, Chair

Diane R. Dean

John W. Presley

Lance Lippert 


\section{ACKNOWLEDGMENTS}

I want to thank my husband, Nathan, and daughter, Nessa, for supporting me in this journey and for being patient and accommodating during all of my time away from home. Additionally, I want to thank the key people who either supported me or helped me with my family responsibilities during the past four years. To my parents and close family and friends: thank you for watching Nessa for us during class weekends and dedicated writing days. It means a lot to me that she had fun during these days away from home. To my classmates: thank you for your camaraderie and friendship. I appreciate your support, perspectives, and engaging conversation. Cohorts provide an amazing group of like-minded people, and I look forward to communicating with you for in the future. To my committee: thank you for your feedback, suggestions, guidance, and patience. Your expertise and availability helped me to create a better informed paper and prevented me from stumbling into this civic engagement world without the perspective I needed to succeed. To Dr. Lugg: thank you for being such a dedicated and supportive advisor. I appreciate all of your time spent helping me to meet my timeline goals, and I appreciate your support of my future educational endeavors. You inspired me to follow my interest in education law, and for that, I am very grateful. And finally, to Dunn Bros. Coffee in Bettendorf, IA: thank you for my office away from home, for conversations with fellow patrons, and for your interest in my success.

M.M.G. 


\section{CONTENTS}

Page

ACKNOWLEDGMENTS $\quad$ i

CONTENTS

CHAPTER

I. RESEARCH PROBLEM \& BACKGROUND 1

Statement of the Problem 1

Defining Civic Engagement 5

Research Problem 9

$\begin{array}{ll}\text { Policy Issue } & 10\end{array}$

Guiding Questions for Fact-Gathering $\quad 10$

Significance of the Study 11

Limitations of the Study 12

$\begin{array}{ll}\text { II. METHODOLOGY } & 14\end{array}$

$\begin{array}{ll}\text { Introduction } & 14\end{array}$

Forms of Policy Studies $\quad 15$

$\begin{array}{ll}\text { Type of Study } & 17\end{array}$

$\begin{array}{ll}\text { Policy Issue } & 17\end{array}$

$\begin{array}{ll}\text { Structure of the Policy Analysis } & 18\end{array}$

Policy-Relevant Information $\quad 18$

Policy Claim $\quad 20$

Warrant 20

Backing 20

Rebuttal $\quad 21$

Qualifier $\quad 21$

$\begin{array}{ll}\text { Definition of Terms } & 21\end{array}$

$\begin{array}{ll}\text { Definitions } & 21\end{array}$

$\begin{array}{ll}\text { Conclusion } & 27\end{array}$ 
$\begin{array}{ll}\text { Introduction } & 28\end{array}$

$\begin{array}{ll}\text { Theoretical Perspective } & 29\end{array}$

Democratic Theory of Education: Dewey \& Gutmann 29

What is Civic Engagement? 32

The Concept of Citizenship $\quad 33$

The Concept of the University $\quad 38$

Linking Citizenship \& the University 43

How is Civic Engagement Integrated into Higher Education? 56

The Hypothetical Administrator $\quad 60$

Civic Engagement in the Curriculum $\quad 62$

Civic Engagement within the Context of Administration 69

A Focus on Student Development 86

Global Perspective $\quad 91$

Is there a Progression from K-12 to Higher Education? 93

Approaches to K-12 Civics Education 93

Challenges in K-12 Civics Education 95

$\begin{array}{ll}\text { Conclusion } & 98\end{array}$

IV. CURRENT INITIATIVES AND ORGANIZATIONS IN CIVIC ENGAGEMENT

$\begin{array}{ll}\text { Introduction } & 100\end{array}$

Key Organizations, Trends, or Initiatives 101

$\begin{array}{ll}\text { Conclusion } & 110\end{array}$

V. LEGAL REVIEW OF POTENTIAL LIABILITY 112

Introduction $\quad 112$

Higher Education \& the Law 113

$\begin{array}{ll}\text { Liability } & 115\end{array}$

In loco parentis $\quad 116$

Special Relationship $\quad 119$

$\begin{array}{ll}\text { Duty of Care } & 122\end{array}$

The Reasonable Person $\quad 124$

$\begin{array}{ll}\text { Foreseeability } & 125\end{array}$ 
Negligence

Assumption of Risk

128

Voluntary Assumption of Duty

131

Voluntary Participation

Conclusion

VI. POLICY RECOMMENDATION \& CONCLUSIONS

The Policy Issue

135

The Case for Civic Engagement

137

Democratic Engagement in Higher Education

Terminology

The Goal

The Purpose: Why Democratic Engagement in Higher Education

144

Roles \& Responsibilities of the Institution

145

Morals \& Values

145

Democratic Engagement in a Democratic Society

K-12 System: Policy \& Legal Implications

148

Democratic Engagement Policy

The Hypothetical Administrator

Policymaking

The Balance Test

156

Policy Outline

158

Policy-Relevant Information

159

Policy Claim

159

Warrant

159

Backing

160

Rebuttal

160

Qualifier

160

Conclusion 


\section{CHAPTER I}

\section{RESEARCH PROBLEM \& BACKGROUND}

\section{Statement of the Problem}

Justice Sandra Day O'Connor and Congressman Lee Hamilton, in a national report for The Center for Information \& Research on Civic Learning and Engagement (CIRCLE, 2011), tell a compelling story of Dr. Benjamin Franklin during the 1787 Constitutional Convention. When asked if the delegates would create a monarchy or a republic, Dr. Franklin replied, "a republic, if you can keep it" (as cited in CIRCLE, 2011).

As Justice Day O’Connor and Congressman Hamilton note, this phrase captures the need of both the newly formed democracy and our current democratic environment now: an educated, engaged citizenry is necessary and critical to the success of our nation; the people, the true authority, must demand responsiveness from our government at all levels, as they will only perform as well as citizens demand (CIRCLE, 2011).

As more and more accusations of democratic failings are cast, Justice Day O'Connor and Congressman Hamilton claim that these failings and threats to our democratic environment "would be ameliorated by a more knowledgeable and engaged citizenry" (CIRCLE, 2011, p. 5). As they note as well, all Americans must be taught about democracy and developed into engaged, educated citizens; no one is born with 
inherent knowledge about what it means to actively live and participate in a democratic world, and our schools are responsible for teaching students these skills (CIRCLE).

The importance of the democratic citizen in America and the connection to higher education is an enduring ideal for a number of reasons. The concept and relationship is often linked to the political and legal system, noting the importance of having educated citizens contributing to the progress of this nation. The general idea is that educated and informed citizens will contribute at a higher and more useful rate than uneducated citizens.

Civic engagement is relevant specifically to the study of higher education today because young Americans are less involved than ever, both civically and politically, showing low levels of social trust and sense of civic duty, as well as little knowledge of current affairs (Beaumont, 2002). In relation to this claim about the activity of young Americans, Ernest Boyer, in a thorough study of American higher education, concluded that undergraduate education fails to meet the civic and moral goals of higher education (as cited in Beaumont, 2002).

In order to address both the actions of young Americans and this claim of deficiency in training, higher education administrators and policy-makers need the tools necessary to identify and clearly define the civic mission of higher education and understand if and how civic engagement can help rectify this failure, while continuing to best protect the interest of the university.

Naturally, higher education plays a critical role in the formation of educated, democratically engaged citizens, whether or not the institution is formally charged with this task. What happens, however, when higher education institutions and administrators 
do not know how to educate students to be engaged citizens and simultaneously protect the institution from increased liability? Often, the engagement activity is forsaken in order to mitigate risk to the institution - but at what cost to the preservation of democracy and to the development of students?

After establishing and acknowledging that service, in general, is part of the mission of higher education, the question of execution comes into play. Do civic engagement activities belong in higher education? How does an effective program meet the goal of educating engaged citizens? How are morals and values addressed or taught in public and private institutions of higher education? Should civic engagement activities be curricular or extra-curricular? How does the higher education civic engagement experience differ from K-12 civic education and community service? These questions, along with an analysis of risk versus benefit, guide institutions into an arena of uncertainty and potential increases in liability as students are directed towards civic engagement activities.

Civic engagement activities in higher education generate a number of potential legal issues administrators should, but often do not, consider. Maybe even more concerning than the lack of consideration for legal liability, is the administrator who denies permission for civic engagement activity due to a lack of knowledge about the accompanying liability; in other words, it's easier to say 'no' than to examine the potential legal ramifications. Additionally, the faculty member who anticipates a difficult process to gain approval from the university's general council and, instead, decides to ask 'forgiveness, not permission' is also concerning, especially in terms of legal liability. 
Civic engagement activities may be included in the curriculum or designed as cocurricular activities; both scenarios should be examined from a legal liability perspective. Institutions have a responsibility to both the student and the student's safety, as well as a responsibility to protect the interests of the institution itself. Legal theory and precedent set through past court cases helps establish the role of the university and the potential liability.

My study, focused on the connection between civic engagement activities and the associated legal liability, is timely if not in fact tardy, given the widespread phenomenon of civic engagement efforts within higher education. As national civic engagement programs in higher education, such as The American Democracy Project and The Democracy Commitment, continue to reach into evermore institutions to prepare educated and engaged citizens, legal liability issues must be analyzed and addressed in order to safely secure the future of this movement.

These national programs are making significant, real change in organizations through effective civic engagement programming; however, when the programs were formed, legal advice was not solicited and the subject of legal liability in civic engagement was not discussed (G. Mehaffy, personal communication, April 28, 2015; C. Orphan, personal communication, April 20, 2015). In fact, over an 18 month period of strategizing and forming the American Democracy Project by a number of higher education leaders and provosts, the issue of increased liability for institutions did not come up in any capacity (G. Mehaffy). The subject of legal liability for institutions surrounding these activities continues to be absent from civic engagement discourse (J.W. Presley \& L. Lippert, personal communication, April 14, 2015). 
It could be reasoned that legal liability was not considered due to the long history of service activities or because there are already countless reasons why students leave campus and become subject to increase risk, or even because the group forming the American Democracy Project was comprised of academics rather than student affairs personnel (G. Mehaffy, personal communication, April 28, 2015). However, if higher education is the appropriate venue for civic engagement and the goal is to institutionalize the terms and activities associated with the effective education and preparation of engaged citizens, legal liability must be taken into consideration at the policy level and the institutional level. The efforts of the civic engagement movement to achieve these important goals must be protected from potential threats to progress, and institutions must protect the interests of both the student and the university.

When the level and severity of the institution's liability is determined, in regards to students becoming involved in civic engagement activities, the institution must determine the best course of action. Institutions will weigh the benefits of the engagement program against the potential liability risk and determine if the risk is worthwhile to pursue the initiative further; however, it is crucial to provide institutions with a thorough analysis of the purpose and place of civic engagement activities, along with an analysis of case law and liability issues, in order for effective and applicable policy formation to be beneficial to students and the nation's education and citizen development goals.

\section{Defining Civic Engagement}

The idea of civic engagement has become popular enough that the term, by itself, is too inclusive to be useful. Defining civic engagement and the accompanying terms used to describe these activities is troublesome and convoluted; terms are used 
interchangeably and hold varying meaning. Many use Thomas Ehrlich's (2000) definition from his book, Civic Responsibility and Higher Education, "Civic Engagement means working to make a difference in the civic life of our communities and developing the combination of knowledge, skills, values and motivation to make that difference. It means promoting the quality of life in a community, through both political and nonpolitical processes" (Preface, vi).

The Association of American Colleges \& Universities [AACU] (2012) in A Crucible Moment also uses the terms "civic learning" and "democratic learning," stating that this learning cannot simply be learned from books, but must also incorporate the hands-on, active engagement of differing approaches to problem-solving in order to affect the nation's well-being. The Association of American Colleges and Universities also uses an umbrella term, "social responsibility" to include "civic learning, ethical learning, intercultural learning, and applied learning" (2012, p. ix). These terms are important and helpful in certain circumstances; however, the re-defining of these terms causes inconsistency amongst institutions and individual understanding. As initiatives are set forth from the federal, state, and institutional level, varying terms result in confusion and inconsistency.

As Cuthill notes, "a civic mission for the university is now, once again, being debated in policy fora across the world" (Lyons, et al., 2012, p. 82). This debate causes further convolution of terms and confusion around the applicability of ideas and activities associated with these terms. Bringle and Clayton add that civic learning is "multifaceted and fruitfully resists universal definition; it will be redefined according to discipline, the institution, and social community of the institution's area and the nation" (Lyons, et al., 
2012). The wide-spread acknowledgement of the resistance to universally used definitions is troublesome as well. While each organization or research paper sets forth a definition of terms being used in that particular instance, the variance should be minor as the field of interest grows and develops. Consistency should develop over time as progress is made.

For example, the service-learning movement, according to Brabant and Braid (2009), can be divided into four branches of education including "enhancement of disciplinary-based competencies, development of social and personal responsibility, fostering intercultural competencies, and civic engagement" (p. 64). This type of division of service-learning sections helps to define the area of civic engagement within the service mission of higher education and demonstrates how this specific goal differs from other service-learning initiatives. However, Brabant and Braid's divisions also shed additional light on the problem of these words being used and defined differently in each situation because they are used interchangeably so often.

As evidenced by the varying definitions, it is necessary to establish a set of commonly understood terms. In my analysis of civic engagement, definitions will be put forth as used by or referenced from an authority on the topic of civic engagement: Dr. Harry C. Boyte. Definitions are included in this paper both from his personal definitions of terms, as well as through terms identified by others and used in his writings. Dr. Boyte is the founder of a theory-based approach to civic engagement, Public Achievement, which focuses on public work for the common good (Humphrey, n.d.). Additionally, Dr. Boyte co-leads the Center for Democracy and Citizenship at Augsberg College, and he serves as a board member of Imaging America, collaborating with colleges and 
universities to strengthen the democratic purpose of a number of disciplines (Humphrey). Dr. Boyte works with the American Democracy Project, specifically as moderator on the Agents and Architects of Democracy Webcast Series (AASCU, n.d.).

Previously, Dr. Boyte served on the National Commission on Civic Renewal as a senior advisor on the topic of the future of democracy and as a national associate to the Kettering Foundation (Augsberg, n.d.). He has authored nine books and has presented works in over 100 publications (Augsberg). He identifies his areas of expertise as "civic engagement; theory and practice of democracy; citizen politics, citizen professionalism, international democracy promotion; national service initiatives" (Augsberg, n.d., para. 8).

Because Dr. Boyte has worked with a number of organizations over many years, and because of his quality and quantity of publications, his definitions and recommendations for defining civic engagement are used in this paper in an effort to promulgate a more consistent use of terms. As efforts continue to develop and institutionalize civic engagement activities, it is necessary to strive for commonly and widely understood terminology, specifically in regards to standardizing the terms in order to effectively apply legal concepts and policy application.

Terms specific to the theoretical frameworks used in this dissertation by Dewey and Gutmann are included in the definition of terms as well, in order to consistently reference the theoretical and conceptual ideas offered from these experts. Additional perspectives are included in the literature review in terms of the development and historical use of the terms associated with this study. The definition of terms used throughout this paper, as used by Dr. Boyte, are identified within the methodology in Chapter Two. 


\section{Research Problem}

Service, as a mission of higher education, specifically in public and private four year institutions, is in need of institutional attention and definition, despite the potential for increased liability for the institution, as additional engagement activities are pursued. Administrators need the knowledge and tools necessary to accurately make decisions regarding institutional direction. Policy analysis and policymaking decisions regarding civic education issues and the manner in which higher educational institutions serve students, the community, and the needs of the nation, require a thorough examination of historical, current and future initiatives.

Students will be called upon as American citizens to be knowledgeable, engaged, contributing citizens, and higher education plays a role in the development of these citizens. Engagement must surpass simple volunteerism and avoid bureaucratic roadblocks in order to more fully realize the potential benefit of democracy and democratic engagement activities. In turn, institutions must respond effectively and responsibly, making informed decisions about educating these students in the safest manner possible.

As the civic engagement movement continues to grow and is considered a wide-

spread phenomenon within higher education, specifically given the growth and success of initiatives such as The American Democracy Project, all aspects of the movement must be evaluated and strengthened in order to protect the momentum and successes of projects such as these. Again, the absence of legal liability consideration from the founding of these projects (G. Mehaffy, personal communication, April 28, 2015) creates 
a potential vulnerability for the future of the initiatives and for other similar programs if the issue is not assessed.

The American Democracy Project is now collaborating with over 250 higher education institutions and growing each year. The movement has expanded successfully into America's expansive community college network and is reaching more and more students and communities. National organizations, government task forces, community organizations and many others are collaborating to build momentum in the quest to educate engaged, active citizen leaders. Given the litigious culture in America and the bureaucratic nature of both private and public institutions, issues such as legal liability in regards to institutionalizing civic engagement initiatives must be examined.

\section{Policy Issue}

The policy issue for this dissertation is: "Is higher education the appropriate venue for instruction on democratic engagement and, if so, do the benefits and rewards of instruction on democratic engagement outweigh the possible risks of incurring additional legal liability?" Another way to state this problem is, "Are the benefits of providing instruction on civic engagement in higher education more important than the increase in legal liability?" The following fact-gathering questions help to identify the information necessary to support addressing the policy issue in this dissertation.

\section{Guiding Questions for Fact-Gathering}

1. What is civic engagement?

a. How is it defined?

b. What benefits are attributed to such education?

2. How is civic engagement currently being integrated into higher education? 
a. Is participation integrated into the curriculum?

b. Is participation voluntary or mandatory?

3. Is there currently a progression of civic education from K-12 into higher education?

4. Could an increase in civic engagement increase the legal liability for higher educational institutions?

\section{Significance of the Study}

Service, as one of the three primary missions of the university, has been largely undefined and not identified as a top priority. As such, there is disconnect between the goals of the nation, the need for educated, engaged citizens, and the engagement opportunities offered by many universities. The risks and hurdles, which prevent universities from fully developing and implementing civic engagement opportunities, prevent effective progress and change. This dissertation addresses policy formation and liability assessment in order to provide crucial information for policy-makers and administrators. It is important to acknowledge higher education's responsibilities and roles associated with educating future participants in our nation's democratic environment, as well as analyze, formalize, and define the service mission of the university.

My analysis of this policy issue will contribute to the literature on civic engagement, higher education administration, and education law, as well as contributions to informed policy creation and practice. Specifically, this analysis will contribute to the design and administration of civic engagement programs and activities by aiding administrators in the formation of democratic engagement activities through knowledge 
of liability issues and potential problems. College and university business officers, student affairs staff, and risk managers will also find this information vital. This study, therefore, will be beneficial to scholars and graduate students in higher education and student affairs programs and all faculty and administrators active in or concerned with civic engagement and education.

\section{Limitations of the Study}

This dissertation focuses on the issue of civic engagement in higher education, provides a policy analysis of this issue, and specifically centers on the legal concerns regarding the implementation of an effective civic engagement policy in higher education. There are many other factors, beyond law, that could affect the implementation of any recommended policies, and these issues are not addressed in this study.

Although a global perspective is discussed within the context of this issue, the problem and policy recommendations here are targeted towards the goals and benefits of American students. Higher education in America serves students who benefit from civic engagement activities, regardless of the institution's goal to educate civically engaged citizens. This study does not address ways to best serve international students or ways in which these tangential goals could be quantified or communicated.

Additionally, it must be noted that civic engagement activities oftentimes involve activist demonstrations such as protests, sit-ins, and public demonstrations. These types of activities, especially, invoke First Amendment discourse and consideration; however, that specific issue is outside the scope of this particular study. The depth and breadth of the Amendment issues would overshadow the primary focus of this study, and an 
examination of First Amendment issues in terms of civic engagement in higher education could be an individual line of inquiry in the future. For these reasons, legal issues involving the First Amendment are excluded from this dissertation.

While this paper is particularly focused on traditional, public or private four-year universities, many of the policy recommendations can be applied to community colleges and other post-secondary education models with additional consideration for student development goals and opportunities to become involved with the community. There are a number of organizations specifically focused on service and civic engagement at the community college, and while a necessary and outstanding endeavor, this study is particularly focused on the development and engagement of students at four year institutions.

Chapter Four of this dissertation provides information about current and past organizations, as well as regional and national initiatives, regarding civic education and engagement initiatives, opinions, and recommendations. The list is by no means exhaustive. Instead, the aim is to provide a sampling of the type of work being done at this point in time. 


\section{CHAPTER II}

\section{METHODOLOGY}

\section{Introduction}

Policy analysis transcends beyond simply producing new knowledge or facts by attempting to include information about values and an ideal path or strategy (Dunn, 1981). Dunn defines policy analysis as "an applied social science discipline which uses multiple methods of inquiry and argument to produce and transform policy-relevant information that may be utilized in political settings to resolve policy problems" (1981, p. 35). As Dunn explains, however, policy analysis cannot not be constrained by the boundaries of traditional social science disciplines, as the more complex policy issues transcend those boundaries.

This dissertation is a policy study with imbedded legal research. This study is neither a qualitative study nor a quantitative study. It will not follow the five chapter format of introduction containing research questions, literature review, methodology, data gathered, and conclusion, of a traditional educational administration dissertation. Two of the most obvious differences include the lack of specific research questions and the inclusion of value judgments. In all forms of policy analysis, the starting point is the identification of a policy problem or a policy issue rather than a list of research questions. This policy issue then guides the collection of information or data in order to provide 
evidence to support conclusions or recommendations for solution of the policy issue.

Once this evidence is collected, values must be attached in order to offer and prioritize possible solutions.

Dunn notes that a belief in the "separability of facts and values" (1981, p. 37) results in a misunderstanding of policy analysis goals, leading to a mistaken belief that values cannot be debated or studied because they are relative only to an individual person. Normative statements, such as the policy recommendations that will be included in this study, are wrongly interpreted as "prescriptions, commands, pronouncements, or emotional appeals" (Dunn, 1981, p. 37).

Instead, it is important to note that putting forth a recommendation is quite different from forcing them to act according to the recommendation (Dunn, 1981). The recommendations, grounded in normative decision theory, are sound, researched, potential solutions to the proposed problem (Dunn). Therefore, the incorporating of or basing decisions on values is not a methodological flaw in a policy analysis, but an integral part in providing policymakers with information to solve policy issues in front of them (Dunn).

\section{Forms of Policy Studies}

There are several forms that policy studies may take. First, studying policy issues prior to decision making or prospective policy research is used to gather information on a policy issue, providing said information to policymakers as the process of making a decision on a course of action is occurring. Such situation may have been initiated by a change in the law or a specific occurrence causing a need for a response. The important 
element of this type of policy research is that it is providing information, possible solutions, and foreseeable consequences prior to the passage of a policy.

Second, corollary policy research is performed after a decision has been made or retrospective policy research. In these cases, the policy has already been passed and enacted. Subsequently, research needs to be completed to see its effect; has the policy been effective in obtaining the goals or outcomes envisioned when the policy was passed? This type of research is also often referred to as an impact study of evaluation research.

A third type of policy research is an integrated policy study. This type of research is basically a combination of prospective and retrospective policy studies, in that it is a comprehensive form of analysis. It is concerned with the gathering and analyzing of information from both before and after any policy action has been taken. Its goal is not only to see if the policy if fulfilling the original intent of the policymakers, but to analyze the reasons why the policy was enacted originally in order to better develop possible recommendations.

Finally, there is the exploratory policy study. In this type of policy study, current trends are observed, researched, and analyzed in anticipation of the policy action that might be taken. By necessity, it includes an analysis of the values underlying these trends. Exploratory policy studies are especially applicable when the current trend being watched has a legal component, such as possible tort liability. It is similar to a prospective policy study in that both are anticipating future policy action and providing guidance as to courses of action. An exploratory study, however, tends to be more theoretical; a specific policy or policy topic has not already been proposed for adoption. 
Rather, the policymakers desiring the exploratory study are attempting to study the waters in certain areas, ascertaining the values surrounding those areas in an attempt to determine what future action they should take.

\section{Type of Study}

This dissertation is an exploratory policy study that will gather information and propose resolutions which can be used by higher education administrators in making curricular and co-curricular decisions for their institutions. Because this analysis will be comprehensive in nature, reviewing information both in the social science realm on the topic of democratic engagement and legal research surrounding the issue of tort liability, one could categorize this as an integrated study. In fact, originally the thought was to classify this research as an integrated policy study. As the methodology of the study was further refined, however, because the inclusion of democratic engagement is more appropriately considered a trend, and a trend laden with values, the study has an overwhelmingly theoretical orientation which is more in-line with an exploratory study.

\section{Policy Issue}

The policy issue for this dissertation is: "Is higher education the appropriate venue for instruction on democratic engagement and, if so, do the benefits and rewards of instruction on democratic engagement outweigh the possible risks of incurring additional legal liability?" Another way to state this problem is, "Are the benefits of providing instruction on civic engagement in higher education more important than the increase in legal liability?"

Yet another way to state the policy problem is: "Providing instruction on civic engagement creates too much excess legal liability." Regardless of how it is stated, this 
exploratory policy study will look at instruction in civic engagement and surrounding legal liability, then using a balancing test of the type used by courts in determining issues of compelling state interest, provide recommendations to be used by higher education administrators as they deliberate on the current trend of instruction on civic or democratic engagement.

\section{Structure of the Policy Analysis}

The policy recommendation and argument will follow Dunn's six part outline and the following components will be included: policy relevant information as evidence, a policy claim, warrants necessary to the claim, backing necessary for the warrants, rebuttals relevant to the policy claim, and any needed qualifiers (1981, p. 42). "Analysts seek, not only to produce different kinds of information, but also to transform this information as part of reasoned arguments about public policy" (1981, p. 40).

\section{Policy-Relevant Information}

Policy-relevant information can be produced through multiple methods including quantitative research producing statistical data, review of conclusions of experts, as well as expressed values or needs by stakeholders in the policy making arena. For this exploratory study, the two major types of information or evidence gathered will be a comprehensive review of the literature surround democratic engagement. A series of questions, have been developed to guide that gathering of information which are as follows:

1. What is civic engagement?

a. How is it defined?

b. What benefits are attributed to such education? 
2. How is civic engagement currently being integrated into higher education?
a. Is participation integrated into the curriculum?
b. Is participation voluntary or mandatory?

3. Is there currently a progression of civic engagement from $\mathrm{K}-12$ into higher education?

This information will be used for the first part of the policy issue stated above: "Is higher education the appropriate venue for instruction on democratic engagement?" Without understanding what civic engagement is (definition), how it is currently being included in higher education, and whether there is any connection or coordination with $\mathrm{K}-12$ education, recommendations as to the appropriate place for such education cannot be made.

For the second half of the stated policy issue, do the benefits and rewards of instruction on democratic engagement outweigh the possible risks of incurring additional legal liability, a thorough review of case law is conducted. Case law analysis is used in my analysis to identify and evaluate cases which are on point with the potential liability issues associated with civic engagement policy. According to Putnam, case law analysis is "the analytical process you engage in to determine if and how the decision in a court opinion governs or affects the outcome of a client's case" $(2008$, p. 163) or, in this case, a specific legal issue related to policy formation. Putnam outlines methods to use case law analysis as a means of identifying cases which are on point or "cases that illustrate how law applies to the client's facts" (2008, p. 163).

Using the doctrines of precedent and stare decisis allow for consistent, uniform application of case law and improve the predictability of the law (Putnam, 2008). 
Precedent is defined as "an earlier court decision on an issue that governs or guides a subsequent court in its determination of an identical or similar issue based on identical or similar key facts" (Putnam, 2008, p. 164). The doctrine of stare decisis "requires that similar cases be decided the same way - that cases that are precedent should be followed" (Putnam, 2008, p. 165).

\section{Policy Claim}

The policy claim is the conclusion drawn at the end of gathering the data; it implies "therefore" (Dunn, 1981). Individuals involved in the debate could disagree about this claim because, even though it is "the logical consequence of the policyrelevant information" (Dunn, p. 42), it incorporates value judgments. For example, after gathering all the policy-relevant information, a policy claim might be that inclusion of democratic engagement as a mandatory requirement for graduation creates too much legal liability for the institution, and should not be adopted.

\section{Warrant}

A warrant is nothing more than an assumption that allows the researcher to move from collection of information to a policy claim. It provides the reason for accepting the policy claim. Continuing with the example stated above, a simple warrant for the policy claim is that avoidance of legal liability is the top priority for institutions of higher education.

\section{Backing}

The backing is the evidence or the reasoning for accepting the warrant. This reasoning is where underlying assumptions may be stated and supported by the policy- 
relevant information as well as where ethical and moral (i.e. value) arguments can be stated.

\section{Rebuttal}

A rebuttal is a second conclusion or argument stating why the original policy claim is in error or why it should only be accepted with qualifications. Combining the policy claim and the rebuttal provides the substance to the policy issue. Again, continuing with the original example that instruction on democratic engagement as a mandatory requirement causes excessive legal liability and should not be adopted and that avoiding legal liability should be the top priority of institutions of higher education, the rebuttal might be that the development of civically engaged students is more important than avoiding excess liability because it creates a greater societal good.

\section{Qualifier}

Finally, a qualifier is the degree of certainty in the policy claim. Words such as usually, probably, most likely, and probable are qualifiers. If the analyst is $100 \%$ certain of his or her policy recommendation, then no qualifier is needed.

\section{Definition of Terms}

\section{Definitions}

Citizenship. Citizenship is classified by some as simply a legal status based upon birth location or the obtainment of knowledge and the demonstration of that knowledge in order to obtain the legal status. When citizenship is viewed as a concept of actions and intent and participation, looking to Dewey's work and writings provides a more useful definition and explanation of citizenship for the purpose of democratic engagement and education. Dewey focuses on inquiry as the "means by which citizens became informed, 
communicated interests, created public opinion and made decisions" (Giles \& Eyler, 1994, p. 81). In regards to the actions and methods involved in teaching citizenship in schools, Dewey stated, "When the school introduces and trains each child of society into membership within such a little community, saturating him with the spirit of service, and providing him with the instruments of effective self-direction, we shall have the deepest and best guarantee of a larger society which is worthy, lovely, and harmonious (Dewey, 1900, p. 44).

For the purpose of this study, citizenship is defined as action beyond simply a legal classification. Dewey's work informs this action and, for the purpose of this paper, citizenship is defined as the active inquiry of American citizens to become informed and educated about civic processes, to communicate ideas and interests involving the community and society which help form public opinion, and to make informed decisions.

Civic agency. Boyte offers the following definition regarding the concept of civic agency, a clarification which speaks to the skill building of students, as well as the importance of participatory learning: "The concept of civic agency highlights the broader set of capacities and skills required to take confident, skillful, imaginative, collective action in fluid and open environments where there is no script" (2012, p. 11). Civic agency has also been referenced in Boyte's work as being defined by Mustafa Emirbayer and Ann Mishe as "the ability to negotiate and transform a world that is understood to be fluid and open" (Boyte, 2008, p. 10). Boyte continues to express the idea and importance of civic agency building in students by highlighting the over-regulating society we live in, which limits the ability for students to develop civic agency and results in the feeling of powerlessness. Additionally, he clarifies that "Civic agency emphasizes not only 
individual action but also the collective capacity to act on common challenges across differences" (2012, p. 10).

Civic education. In terms of civic education, both at a K-12 and collegiate level, Boyte states, "Civic education today in the schools usually means knowledge about government (as in "civics courses"), while colleges and universities focus on values such as care and responsibility and, in service learning, on the connections between the content of academic courses and community problems" (2012, p. 10). Most important to note, Boyte specifies that civic education "neglects the dynamics of power and politics" (2012, p. 10).

Civic engagement. Boyte references the work of Thomas Ehrlich in his writings and, for the purpose of this dissertation, Ehrlich's definition from his book, Civic Responsibility and Higher Education is used as a basic definition of civic engagement. Ehrlich states, "Civic Engagement means working to make a difference in the civic life of our communities and developing the combination of knowledge, skills, values and motivation to make that difference. It means promoting the quality of life in a community, through both political and non-political processes" (2000, Preface, vi).

Boyte (2012) additionally describes civic engagement activities through a lens of "empowering pedagogies" and a case study from Northern Arizona University. The university has a program-based mission of "building the democratic capacities and skills amount NAU undergraduates" (as cited in Boyte, p. 25). In this sample civic engagement program, "Pedagogies stress student ownership of their education and cultivating the "knowledge, dispositions, values, skills and habits that promote civic agency and foster grassroots democracy"'” (p. 25). Students are exposed to education and empowerment 
gained from working with and in the public sphere, where student learning delves into both the community narrative and wider communities as well (2012).

Community service. A dictionary definition is used in this paper to reflect the commonly understood meaning of this term. Because it is used both in higher education and within the community at large, the broadest definition is used. According to Collins Dictionary (n.d.), community service is "voluntary work, intended to be for the common good, usually done as part of an organized scheme" (para. 1).

Democracy. In definition alone, democracy means both "government in which the people hold the ruling power either directly or through elected representatives" and "the principle of equality of rights, opportunity, and treatment, or the practice of this principle" (Collins, n.d.). Both of these definitions are used in this paper to describe the American government structure and to describe principles associated with this environment. Boyte works with the Kettering Foundation, a not-for-profit organization which focuses on how democracy should work. This foundation bases its research around three hypotheses which define the requirements of democracy (Kettering Foundation, n.d.). These include: "Responsible citizens who can make sound choices about their future; Communities of citizens acting together to address common problems; and Institutions with public legitimacy what contribute to strengthening society" (n.d., para. 2).

Additionally, the Kettering Foundation specifies that democratic practices, or actions, "are ways citizens can work together - even when they disagree - to solve shared problems (n.d., Democratic Practices, para. 1). Most importantly, the Foundation specifies that problems should be named, issues framed in order for informed and 
deliberative decision-making, civic assets should be identified and committed while civic actions must be organized, and finally, that learning must be collaborative in order to keep momentum (Kettering, n.d.).

Democratic engagement. For the purpose of this paper, the term democratic engagement is used to imply specific civic engagement activities which serve a democratic purpose. Matthews (2011) alludes to this connection in his preface of the book, To Serve a Larger Purpose, of which Boyte is a chapter author. There are not specific activities which require a change from the term civic engagement to democratic engagement. Rather, it is the intent of the activity or the purpose of the program or discussion which necessitates the change in term. The engagement activity or program or discourse is intended to serve a democratic purpose.

Democratic theory of education. According to Gutmann, whose theory, along with Dewey's, informs this book, "the aim of a democratic theory of education is not to offer solutions to all the problems plaguing or educational institutions, but to consider ways of resolving those problems that are compatible with a commitment to democratic values. A democratic theory of education provides principles that, in the face of our social disagreements, help us judge (a) who should have authority to make decisions about education, and (b) what the moral boundaries of that authority are" (Gutmann, 1987, p. 11).

Most importantly, a democratic theory of education creates a "democratic virtue out of our inevitable disagreement over educational problems (p. 11). 
Patriotism. Boyte (2012) wrote a piece called Challenging Patriotism which evaluated the idea of citizenship and the need for redefinition. In this piece, he addresses patriotism and uses Julie Ellison's description that patriotism, especially through the struggle to obtain civil rights and strive for change, involves "a constantly questioned, historically aware, emotionally complex identification with and responsibility for America" (as cited in Boyte, p. 23). The idea of patriotism is an end result and goal for civically educated, active, and engaged students as they exit higher education and enter society.

Service. Service will also be defined according to a dictionary's description of this word as it applies to higher education due to the widespread understanding and use of this work, as well as the widespread application of this word within society and higher education. Service is defined by Collins Dictionary as "the act giving assistance or advantage to another" (section 6a) or "providing services, rather than goods" (section $16 c)$.

Service learning. Service learning is a difficult term to define concretely. Giles and Eyler (1994) reviewed over twenty-five years of research and publications about service learning and found that one researcher found 147 unique terms and definitions related to this topic. Following this quantification about the difficulty in defining service and service learning, Giles and Eyler (1994) turned to Dewey and attempted to define the concepts within a framework of Dewey's writings. The authors pull from many of Dewey's work to create a theory of service learning, resulting in the conclusion that service learning involves purposeful interaction where students learn from through reflective thinking; there is "an emphasis on the principles of experience, inquiry, and 
reflection as the key elements of a theory of knowing in service-learning" (1994, p. 79). Additionally, focus is on "how learning takes place, what the learning is, and the relationship to action" (1994, p. 79).

\section{Conclusion}

In the words of Dunn:

Policy arguments enable us to go beyond the mere production of information and transform it in light of specific facts and values. By answering questions about the meaning of information, analysts may employ multiple methods in a way that is open to challenges, is self-critical, and is directed toward the resolution of problems, rather than the justification of favored policy alternative.” (1981, p. 43) Although this policy study looks different from the traditional quantitative or qualitative study, it is a recognized and accepted methodology to research problems facing higher education administrators. Such a study starts with the identification of a policy issue, the gathering of evidence (empirical), the assigning of value (evaluative), and the call for action (normative). This examination is done through a six-part methodology in which policy relevant information is gathered, policy claims are made, support is provided, arguments are given, and certainty is assessed. 


\section{CHAPTER III \\ EDUCATIONAL SCHOLARSHIP ON \\ CIVIC ENGAGEMENT}

\section{Introduction}

The national need for global, civically engaged, contributing, active citizens calls for an effective analysis of civic engagement through the examination of literature surrounding the issue, including information which leads to informed decision-making about institutional liability issues in regards to civic engagement activities. Although service, as a general or even an undefined concept, has long been acknowledged as one leg of the tripartite missions of higher education, it was during the 1990s that service learning and civic engagement became a clearly designated and defined part of the curriculum (Kozeracki, 2000). As a fairly recent, formal phenomenon surrounded by uncertainty, evaluating the founding intent, the current environment and presenting recommendations for improvement is important to the success of the students, the community and the nation, and is a topic worthy of discussion for historical, social, economic, and political reasons.

Educational scholarship surrounding the issue of civic engagement is studied from multiple perspectives and is designed to, rather than identify a gap in the literature as in traditional methods of research, answer three of the four presented fact-gathering 
questions as identified in the methodology. The perspectives include: the theoretical roots of this topic, the concepts of citizenship and of the university, how these concepts converge within higher education, an examination of civic engagement as it is integrated into higher education, and the progression from the K-12 system to higher education. The purpose of this chapter of my analysis is to examine these perspectives in order to evaluate the historical development of civic engagement, identify and define the major activities which comprise civic engagement, and provide discourse about the purpose and goal of civic engagement in higher education to determine if higher education is the appropriate place for civic engagement, offering policy recommendations.

\section{Theoretical Perspective}

\section{Democratic Theory of Education: Dewey \& Gutmann}

Democratic and civic education, service-learning and civic engagement activities can be viewed through the theoretical framework and the conceptual ideas offered by John Dewey and Amy Gutmann. An examination of the two theories supporting democratic education and civic engagement aid in the creation and understanding of a conceptual framework supporting the education of citizens, including the evidence, methods, and justification for such an education.

Dewey. For Dewey, the quality of learning depended upon the agreeableness with and the effect on later experiences (Giles \& Eyler, 1994). This concept applies to democratic engagement, as it is defined in this analysis, in that the goal is to determine the learning and experiences needed as students in order to affect future experience. The aim is to educate engaged citizens. Dewey advocated participatory democracy and was committed to making the classroom culture radically democratic (Robertson, 1992). 
Dewey sought two major social ends through education: "experimentalism and radical democracy" (Robertson, p. 3). Additionally, Dewey stated that "what the best and wisest parent wants for his own child, that must the community want for all of its children" (1900, p. 7). This specific dictate is foundational to Dewey's goals; however, as identified later, it conflicts with another view on democratic engagement offered by Amy Gutmann.

Dewey's philosophy of experience involves how the actual learning happens, what is learned, and how the learning relates to action (Giles \& Eyler, 1994). Dewey also developed a principle of interaction where learning results from the transaction between the individual and the environment, often referred to as situational learning (Giles \& Eyler). As institutions and faculty incorporate civic engagement activities into higher education, focus is on the experience and the interaction in order to maximize the impact on future experiences.

Dewey's theory is used by Amy Gutmann in the development of her democratic theory of education. She agrees with much of Dewey's concepts and theory, with a few divergent ideas and development which is helpful to the understanding of education for a democratic purpose.

Gutmann. Amy Gutmann (1987) builds upon Dewey's theories with her democratic theory of education. Her theory is inspired by Dewey; however, she veers from his ideas in that Dewey's moral claim of what the best parents should want for all children does not leave room for deliberation. She argues that moral differences are an integral part of democratic theory and point to the need for deliberation rooted in democracy as both a means for resolving differences and as a method of democratic 
education, identifying disagreement as a democratic virtue (Gutmann, 1987). According to Gutmann, a democratic virtue "is that we can publicly debate educational problems in a way much more likely to increase our understanding of education and each other than if we were to leave the management to schools" (1987, p. 11).

Two major principles guide this democratic theory of education. First, in the event of social disagreement, democratic theory guides determination over who should have authority to make educational decisions (Gutmann, 1987). Second, the theory provides a framework for determining the moral boundaries of the authority (Gutmann). While citizens should be empowered to make education policy decisions without constraint based upon a specific moral view, the citizens must also be constrained only in order to prevent discrimination or repression (Gutmann).

Gutmann (1987) writes specifically of higher education and the need to teach students about the moral demands of democratic living. She recognizes that most character building is achieved in primary school, yet it remains critical that moral education continue in higher education through building skills in careful thinking, critical consideration of political issues, and the articulation and defense of one's views (Gutmann). Higher education is ideally suited for skill building in deliberation and conflict resolution (Gutmann). Gutmann's clarification about deliberation speaks to the growth of students who can defend, articulate, and debate personal values, morals, and opinions.

Both Dewey and Gutmann provide foundational and theoretical perspective for the development of ideas and opinions, as well as grounds for the analysis of literature about civic engagement, in this paper. 


\section{What is Civic Engagement?}

In order to understand the roots and development of civic engagement in American higher education, it is important to examine the history of the mission of higher education, the development of civic education and the emergence of civic engagement activities as a method of instruction and student development. Many social forces have influenced the development of civic engagement, including political and economic influences. Additionally, the potential benefits and effect on student development opportunities are important to consider in the examination of civic engagement.

First, however, an understanding of two major concepts is critical in order to understand how civic engagement developed and to make informed decisions about the appropriateness of higher education as a home for civic engagement activities.

Understanding the idea of citizenship in America as it was intended, how it developed throughout the past centuries, and how citizenship is now communicated conceptually is paramount to the full examination of civic engagement. Likewise, the concept of the university itself, the intent at its founding, the major shifts over time in the purpose and priorities of post-secondary education, and the current climate, is knowledge necessary for the informed examination of civic engagement within the scope of the university mission.

Unfortunately, as in so many other historical developments, it's not as easy to understand the social, political, and economic influences of the constructs of citizenship or the university as simply recounting a historical timeline. There is not simply one university to account for over time. As Williams writes, "it is mistaken to think that the 
university ever had a discrete idea grounding it...; it is mistaken to think that it ever existed in a pure state from which it veered off course" (2012, p. 50).

Opposing political parties disagreed, and continue to disagree, on the priority and focus of both the university and citizenship. The struggle involved in the recounting and communication of these ideas speaks to the resulting conflict over the purpose and definition of civic engagement. As parties disagree on the intent and priorities of both citizenship responsibilities and higher education, those programs designed to address these issues result in uncertainty and confusion as well. In the following text, key historical developments, as well as discourse around the differing viewpoints of citizenship and the university concepts are presented to shed light on the development and intersection between the university and citizenship, which results in civic engagement activities.

\section{The Concept of Citizenship}

Foundations. John Adams, in 1776, penned “Thoughts on Government” where he reflected on many aspects of a republic. In this piece, he sheds light upon the intent of America as it was formed as a republic writing:

"A constitution founded on these principles introduces knowledge among the people, and inspires them with a conscious dignity becoming freemen; a general emulation takes place, which causes good humor, sociability, good manners, and good morals to be general. That elevation of sentiment inspired by such a government, makes the common people brave and enterprising. That ambition which is inspired by it makes them sober, industrious, and frugal. You will find among them some elegance, perhaps, but more solidity; a little pleasure, but a 
great deal of business; some politeness, but more civility. If you compare such a country with the regions of domination, whether monarchical or aristocratical, you will fancy yourself in Arcadia or Elysium" (Adams, 1776b).

In this piece, Adams is commenting on the characteristics or qualities of a free citizen versus a subject on a monarchy or other form of government. During the founding of America, it was quite intentional that the people of the country were referred to as citizens and not subjects. In fact, spectral imaging and scientific advances have allowed further examination into drafts of the Declaration of Independence, and it is shown that Thomas Jefferson first wrote the word 'subjects' then smudged this word out and wrote 'citizens' in its place (Kettering, n.d.). As the Kettering Foundation notes, "This finding reveals an important shift in the Founders' thinking: the people's allegiance was to one another, not to a king" (para. 7).

John Adams wrote another letter in 1776 on the topics of reason, honor, and the commitment to liberty. In this letter, Adams expresses additional necessary commitments from citizens of America which differ from subjects under a king and the subsequent results if Americans could not be inspired as citizens to commit to liberty. He stated: "Statesmen, my dear Sir, may plan and speculate for liberty, but it is religion and morality alone, which can establish the principles upon which freedom can securely stand. The only foundation of a free constitution is pure virtue; and if this cannot be inspired into our people in a greater measure than they have it now, they may change their rulers and the forms of government, but they will not obtain a lasting liberty. They will only exchange tyrants and tyrannies" (Adams, 1776a, para. 8). 
Adams' writings, which describe qualities and characteristics of the idea of the citizen when America was founded, along with founding documents such as the Declaration of Independence and the Constitution, provide support for the idea that Americans were held to a higher expectation to participate in society and the community than the subjects of England. They were to be involved and educated about government. They were expected to engage.

Political Influences \& Challenges. Beyond the founding documents expressing the idea of the citizen in America, as the country developed and political parties formed, the early ideas and expectations of the citizen began to diverge and morph through varying views and opinions. Susan Giroux (2012), in her contribution to the book, Education as Civic Engagement, examines the undertones to the formation of citizenship concepts in the formation and growth of America through three political ideologies: liberalism, civic republicanism, and ascriptive Americanism in her book chapter, "Races, Rhetoric, and the Contest over Civic Education".

Briefly explained, she finds that the republicanist version of citizenship involves "constant and direct involvement in governing as well as being governed, on duties and reciprocal responsibilities" (p. 37), with value placed on "the common good, community, and self-sacrifice" (S. Giroux, p. 15). Liberalism is the focus on citizenship as a legal status with priority for the individual over the collective; where "all one has to do is pledge allegiance to a political ideology centered on the abstract ideals of liberty, equality, and freedom" (S. Giroux, p. 11). Ascriptive Americanism involved a focus on commonalities - in cultures, practices, and customs, rather than a specific political ideology (S. Giroux). These varying political ideologies affect citizenship ideas and 
reflect the variance within America about how citizenship should be viewed and demonstrated.

Most importantly, S. Giroux (2012) points out that, because large groups of people were excluded from being considered or being eligible to obtain true American citizenship as ideas of citizenship were being formed, those racial and discriminatory undertones affected the idea of citizenship throughout its development and transformation, thereby affecting citizenship ideas currently. As analysis of citizenship ideas are examined in this paper, this political perspective issue is important and used as a frame for differing views on the development of citizenship ideals.

Jacobson claims that during the creation of the idea of the American citizen, because the shift from a monarchy to a democracy was so extreme, a great amount of self-possession was necessary, and that required parameter was denied to a number of groups of people as the idea of American citizenship developed, resulting in racialism in both republicanism and liberalism tradition (as cited in S. Giroux, 2012). Horsman even notes that it was "unusual by the 1840 s to profess a belief in innate human equality and to challenge the idea that a superior race was about to shape the fates of other races for the future good of the world (as cited in S. Giroux, p. 18).

Even as late as 1921, government administrators were promoting the idea of groups of people unfit or unable to become good citizens with Coolidge stating, "Biological laws tell us that certain divergent people will not mix or blend... Quality of mind and body suggests that observance of ethnic law is as great a necessity to a nation as immigration law" (as cited in S. Giroux, 2012, p. 28-29). These statements lead S. Giroux to find Coolidge's political agenda lacking in the complexities of citizenship in 
terms of a citizen's rights, duties, and role in the community, leaving the idea of citizenship to simply an issue of membership based upon heredity and race. These opinions supporting the exclusion of large groups of people affected the idea of citizenship and "membership" in America, yet another subset of politicians and leaders looked at citizenship through a different lens.

Thomas Jefferson's views on citizenship, as well as education, conflict substantially from Coolidge and, according to S. Giroux (2012), coincide with a major curriculum shift in higher education, as well; a shift which will be examined in the analysis of citizenship as it intersects with higher education. Jefferson supported a liberal republicanist view of citizenship involving duties and work for the commonwealth. He focused on the fostering of an active citizenry with an emphasis on the preservation of democracy (S. Giroux). Examining Jefferson and Coolidge provides an example of how differing concepts of civic engagement translate into pedagogy and curricular undertones and influence identity and community perceptions in regards to citizenship and social relationships (S. Giroux). S. Giroux summarizes the value of a comparison between the political ideas of Thomas Jefferson and Calvin Coolidge by stating that the comparison suggests:

"that different versions of citizenship - liberal democratic, civic republican, and ascriptive Americanist - find expression in curricular and pedagogical models that put into place subjectivities invested with specific notions of identity and community, knowledge and authority, values and social relations" (p. 31).

The founding concept of citizenship, as well as an understanding of the political influences on the development of this concept aid in the understanding of how citizenship 
expectations correspond with the concept of the university as it is examined in the following section.

\section{The Concept of the University}

The difficulty in clearly outlining a history and purpose of the concept of the university was noted previously; however, this difficulty is not to be confused with a lack of evidence or examples or historical record of events and even leader opinions. It is still informative and necessary to examine many of the founding college documents and opinions as they were held at a specific time and in a specific setting. These contributions helped form the current institutions in structure, priority, place and idea. There are key lines of historical thought in regards to education, and while differing in focus from other political and educational leaders, all hold value in the sense that these events and ideas contribute to our current understanding of education.

For example, as S. Giroux (2012) noted in her recount of political ideologies in regards to citizenship, the treatment of large groups of people as unworthy of education or a political voice during the time when universities were being founded affected the development of curriculum and the access for many of these groups to education. As political ideologies changed and developed over time, especially based upon the popularity of the political opinion at any point in time, the permission to be included as a contributing citizen with access to formal education also shifted (S. Giroux, 2012).

These societal shifts and developments affected the development of America as a democratic nation and of the educational system, and no single university experienced the same changes or growth as another. Leadership, institutional history, student backgrounds, and many other factors influence the changes and developments over time. 
As indicated, it is valuable to understand the purpose and intent of higher education as presented in historical documents and speeches with the understanding that one proclamation does not represent the whole of higher education direction at that point in time.

The founding purpose. Now, as with the concept of citizenship, there are many political and social opinions regarding the purpose and intent of education. Some of the founding educational authorities, such as John Dewey, Thomas Jefferson, and Horace Mann, expressed that education is the means to societal change and that free education will serve to create a culture around democracy (S. Giroux, 2012). Again, it is worthwhile and necessary to examine some of the opinions, declarations, and writings of major political influences, including their works regarding education of the citizenry.

George Washington, in 1795, wrote the following in a letter to the Commissioners of the District of Columbia regarding the formation of a university:

"It has always been a source of serious reflection and sincere regret with me, that the youth of the United States should be sent to foreign countries for the purpose of education...” (Washington, 1795, para. 2). “...For this reason, I have greatly wished to see a plan adopted by which the arts, Sciences and Belles lettres, could be taught in their fullest extent; thereby embracing all the advantages of European tuition with the means of acquiring the liberal knowledge which is necessary to qualify our citizens for the exigencies of public, as well as private life; and (which with me, is a consideration of great magnitude) by assembling the youth from the different parts of this rising republic, contributing from their intercourse, and 
interchange of information, to the removal of prejudices which might perhaps, sometimes arise, from local circumstances" (para. 3).

From the founding administration in America, educating the citizens of this country at a post-secondary level has been a priority.

Colleges in the nineteenth-century focused upon the needs of society rather than individual needs and success (Rudolph, 1962). The message was communicated distinctly that young men had an obligation to society, not that society had an obligation to the students (Rudolph). Rudolph points out that this service purpose will not disappear, but the importance of this mission will be thinned throughout the century.

Joseph McKeen, in 1802, stated the following passage (as cited by Rudolph, 1962, p. 58-59):

It ought always to be remembered, that literary institutions are founded and endowed for the common good, and not for the private advantage of those who resort to them for education. It is not that they may be able to pass through life in an easy or reputable manner, but that their mental powers may be cultivated and improved for the benefit of society. If it be true no man should live for himself alone, we may safely assert that every man who has been aided by a public institution to acquire an education and to qualify himself for usefulness, is under peculiar obligations to exert his talents for the public good.

Rudolph (1962) notes in regards to McKeen's statement, that Americans had replaced this obligation to society with a sense of individualism, resulting in a lessened obligation for colleges to produce future leaders. 
In one pivotal and foundational document, the Yale Report (1828), the faculty articulated a number of opinions about the purpose and curriculum of higher education. Among the most important, the faculty stated, "The ground work of a thorough education must be broad, and deep, and solid" (Yale, p. 192). This statement describes the faculty's position that general education, rather than the specific learning of trade skills, is important at the university level. Not every student should go to the university, but those who should attend, need a thorough experience. The faculty stressed the importance of a broad, general education as a foundation for students (Yale).

Additionally, in the Yale (1828) report, the faculty wrote of the importance of a balance of character and the calling upon the knowledge of one's own mind. The authors note that students who are educated in only one narrow area will then have a narrow viewpoint on new subjects and will be limited in their ability to influence society and be useful, resulting in a character which is not fully developed (Yale). The importance and stress of these skills for students speak still to the need for educated, well-rounded students who have the ability to consider a subject fully and influence society.

The next topic in the foundational purposes of the university to examine is the idea of education as a private or public good, specifically the creation of the land-grant university and the impact this new development had on the future of higher education.

Land-grant universities. Land-grant universities were funded through agreements with the federal government and often focused on science and agricultural education (Williams, 1991). Multiple acts of Congress produced the Morrell Land Grant Act of 1862, the second Morrell Act and the Hatch Act, each providing federal funding for changes in program offerings (Williams). Among many other aims, this bill helped 
define the mission of the public institution. It was expected that the land-grant universities would provide an affordable education, as well as provide resources to the surrounding community (Gunn \& Lucaites). While this was the founding intent of the land-grant university, Danika Brown (2012) notes that as higher education continued to develop, the concept of the land grand university is used more as a means of invoking a misguided interpretation of the Act and its intent rather than an accurate understanding of how this type of university came to fruition.

The Act provided federal mandate for the relationship between the public university and the state. Many claim that the passing of this Act demonstrates the country's commitment to democracy and the education of all people, which spurred a revolution for the post-secondary education and the university (Brown, 2012). Brown argues that this Act was not actually a democratically driven piece of legislation, rather it was economically driven during a time when the country was being torn in two directions. Agriculture of upmost importance, as was the use of American land; it was these economic and social issues which spurred the passing of the land-grant university, not simply the country's desire to provide all citizens with access to higher education (Brown). She also notes that much of the Act language revolves around economic issues, yet is it the small amount of text about promotion of education that receives most of the focus (Brown).

Despite the actual intent of the Act and the resulting affect on higher education throughout history, the actual passing of the land-grant university legislation helped form the public university. 
The collegiate way. The development of a collegiate way during the colonial period focused on the development of the student as a person through engagement with the community and extracurricular activities (Dean, 2012). The growth of the collegiate way both solved many problems and created many new challenges, both logistically and through problems within the community. The collegiate way emerged as more and more colleges were founded in rural areas; the students needed a richer residential experience, and the absence of large urban populations required a more active extracurricular experience (Rudolph, 1962). As colleges were founded in large urban settings, the tradition of the collegiate way was already established with strong roots in American higher education (Rudolph).

The Service Mission. Frederick Rudolph (1962), in his thorough report of the history of American higher education, documented many instances of the service mission of higher education as a priority. In fact, from the very first college established, higher education aimed to educate students to serve and participate as leaders in society in order to perpetuate learning and not leave an uneducated people to lead the country (First Fruits, 1693). Despite times of regression away from this mission, it is evident throughout a comprehensive review of past educational movements to demonstrate the importance and resurgence of service as a mission of higher education.

\section{Linking Citizenship \& the University}

Foundational links. In 1796, George Washington delivered a farewell address at the end of his term as the first President of the United States. In this address, he offers advice and his hopes for the continued administration of America. A number of these statements point to the intent of the country's leaders and provide foundational links 
between the citizens and the need to educate these people to become engaged citizens. For example, he offered the following advice: "Promote then as an object of primary importance, Institutions for the general diffusion of knowledge. In proportion as the structure of a government gives force to public opinion, it is essential that public opinion should be enlightened" (Washington, 1796, para. 28). As noted, one public address or one foundational decree does not relay the intent of all citizens and political leaders; however, it is still beneficial to examine some of these archival pieces.

It is helpful, as well, to review President Washington's statement in the same farewell address about his hope for the country and its citizens after he left them. His words can inform and frame the analysis of the current national climate and help put into perspective the direction of our nation and the link to the need for an informed and enlightened citizenry:

"In offering to you, my Countrymen these counsels of an old and affectionate friend, I dare not hope they will make the strong and lasting impression, I could wish; that they will controul the usual current of the passions, or prevent our Nation from running the course which has hitherto marked the Destiny of Nations: But if I may even flatter myself, that they may be productive of some partial benefit, some occasional good; that they may now and then recur to moderate the fury of party spirit, to warn against the mischiefs of foreign Intriegue, to guard against the Impostures of pretended patriotism; this hope will be a full recompense for the solicitude for your welfare, by which they have been dictated" (Washington, 1796, para. 42). 
Washington's foresight into the need to review his advice and reexamine the direction of the nation, particularly in regards to "fury of party spirit" and "Impostures of pretended patriotism" (para. 42), is an idea worthy of contemplation. In that vein, an examination of additional, foundational documents and lines of thought is helpful to understanding the links between citizenship and the university.

Thomas Jefferson, one of the most active proponents of a strong link between an active citizenry and the university both wrote and spoke extensively about the purpose of education and about how education is the "primary means for producing the kind of critically informed and active citizenry necessary to both nurture and sustain a democratic nation" (S. Giroux, 2012, p. 22). Jefferson also created many pivotal pieces of legislation regarding education and its social purpose. Through these pieces, S. Giroux extrapolates that Jefferson clearly and publicly associates education as a political concern and politics as an educational problem, thereby supporting the link between citizenship, civic education, and the university.

Furthermore, in one of the most directly penned pieces of legislative work from Thomas Jefferson linking the university to citizenship, he stated objectives for higher education in the Rockfish Gap Report of 1818. In the report, he identified many objectives for both education at the primary level and at the post-secondary level. Those most closely linked to using the educational system to educate American citizens at the primary level include:

- To understand his duties to his neighbors and country, and to discharge with competence the functions confided to him by either; (Jefferson, 1818, para. 6) 
- To know his rights; to exercise with order and justice those he retains; to choose with discretion the fiduciary to those he delegates; and to notice their conduct with diligence, with candor, and judgment; (Jefferson, para. 7)

- And, in general, to observe with intelligence and faithfulness all the social relations under which he shall be placed (Jefferson, para. 8).

- To instruct the mass of our citizens in these, their rights, interests and duties, as men and citizens, being then the objects of education in the primary schools, whether private or public... (Jefferson, para. 9).

For the university, Jefferson states the purpose of higher education, and those purposes most applicable to citizenship education and development include:

- To form the statesmen, legislators and judges, on whom public prosperity and individual happiness are so much to depend; (Jefferson, para. 10)

- To expound the principles and structure of government, the laws which regulate the intercourse of nations, those formed municipally for our own government, and a sound spirit of legislation, which, banishing all arbitrary and unnecessary restraint on individual action, shall leave us free to do whatever does not violate the equal rights of another; (Jefferson, para. 11)

- To develop the reasoning faculties of our youth, enlarge their minds, cultivate their morals, and instill into them the precepts of virtue and order; (Jefferson, para. 13). 
This Rockfish Gap Report is clear and concise regarding Jefferson's beliefs on the purpose of education and provides yet another example of the founding opinions of education by American leaders.

Jefferson's views on the purpose of education and its reach into citizenship and collaboration did not extend to some leaders in education. As with any issue, debate ensued and varying viewpoints and opinions continued to contribute to the landscape of higher education. Due to the exclusion of large groups of people from citizenship during this foundational time for education reform, politics and opinions from educational leaders greatly affected the education of students for citizenship. There was a transition of political thought regarding citizenship in the late $19^{\text {th }}$ century, one which occurred simultaneously with a curricular change in higher education from a focus on rhetoric then a shift to philosophy, and eventually to literary studies, absent "public discourse and the practice of citizenship as an educational imperative (S. Giroux, 2012, p. 20).

In fact, in 1908, during the same year that Charles Eliot of Harvard was promoting the classification of citizens into four major, unchanging social groups designed to encourage American youth to adapt to a current environment rather than attempt reform, Alfred Schultz stated the following about the educational system, a comment which sheds light on the exclusion of large groups of people from the benefits of democratic education:

"The opinion is advanced that the public schools change the children of all races into Americans. Put a Scandinavian, a German, and a Magyar boy in at one end, and they will come out Americans at the other end. Which is like saying, let a 
pointer, a setter, and a pug enter one end of a tunnel and they will come out three greyhounds at the other end" (as cited in S. Giroux, 2012, p. 28).

Steffen (1909), another educational leader with yet another perspective on the purpose of education, uses his article, Sending a State to College, to describe the "Wisconsin Idea," articulating his take on the two purposes of college: service to the state and service to the public. This document is an example of one state's foundational link between citizenship and the university. The Wisconsin Idea was created under the president of the University of Wisconsin, Charles Van Hise, and articulated a unique mission for a state university focused upon service (Steffen). The college focused on bringing education and correspondence to all people, regardless of economic status or profession; families participated in the programming together, and a new culture developed around extension services (Steffen). Steffen notes that the university became "the instinctive resource for instruction, light and guidance" (p. 590). Faculty members were expected to hold public office or offer expert services to the community and Wisconsin led the way towards a public, cooperative way of thinking where universities, cities, and communities worked together to make progress, developing a public mind (Steffen).

As another example of differing models and missions, while the University of Wisconsin operates as a state-funded, public institution, Princeton used religion to frame its method of service (Wilson, 1896). Princeton also attributes much of its culture and the type of graduate produced to religion (Wilson). Princeton was seen as a political center with a focus on participation in the war and on policy, rather than on extension services and education to the public (Wilson). Princeton was instrumental in providing well- 
qualified political servants during this crucial time after the Revolutionary War; it is noted clearly by Wilson that Princeton provided more politicians than any other college at the time (Wilson).

The University of Wisconsin educated any interested person, on any subject (Steffen, 1909). The goal was to educate through service to the community. Princeton's goal was to produce graduates who could lead the nation as a method of service (Wilson, 1896). The impact of the Wisconsin Idea was direct while Princeton's method of service was one step removed from the public. Princeton men served the community after graduating, while the University of Wisconsin served the public as potential students.

These examples provide support for the longstanding link between citizenship and the university, despite different approaches and political thought. As noted in the introduction, service has long been a component of the tripartite mission of higher education, yet it has also been the component most often set aside as colleges focus on academics and research (Kozeracki, 2000). Service is defined individually by each institution and integrated into the college's mission in unique ways. As colleges continue to grow and develop, the service component of the mission continues to alter over time as well. Because of the varying political and economic influences and because of the lack of definition or focus, contemporary links between citizenship and the university must be viewed through a number of examples and from a number of perspectives in order to examine how concepts of citizenship and the university are now linked.

Contemporary links. Again, varying opinions and political influences continue to affect contemporary links between citizenship and the university. Williams notes that "one thing that has defined the history of the university has been the continual struggle 
among the competing interests of the groups comprising it, from students and parents, administrators to legislators, and over the general public vista that the each purport to represent" (2012, pp. 52-53). The current civic engagement movement is not immune to this political and often contradictory influence, though examination of contemporary links and trends is helpful to understanding the current links between citizenship and the university.

From the founding links between citizenship and the university comes a more contemporary, yet brief history of the movement away from a civic purpose. According to Rudolph (1962), the commitment to the public became an obligation soon after the American Revolution. As land-grant institutions were formed, this dedication to the public good continued to be reinforced. After this movement came a shift towards a German research model with a focus on research and a corresponding de-emphasis on the civic mission of higher education (Hartley, 2011). This research model persisted through a number of decades. The 1980s followed with a consumer and market -driven purpose, further shifting the institutional mission away from civic engagement (Hartley).

Beginning in the 1990s and continuing now, a renewed interest in civic initiatives began with focus first on volunteerism then on service-learning (Hartley, 2011). Tension has built around the idea of incorporating service-learning into the curriculum, yet model institutions have emerged that provide expert examples of how institutions have begun successfully incorporating service-learning (Hartley). While service-learning initiatives are typically positive university activities, a larger, democratic goal is often set aside and debate continues over the appropriateness of addressing social justice issues in servicelearning activities (Hartley). 
In 1999, the President's Declaration on the Civic Responsibilities of Higher Education was released which lent credibility and authority to the civic mission of higher education. A shift began and service-learning which had taken place as a transformational, student-based activity transformed into service to academic discipline and again, democratic and social responsibility issues were excluded (Hartley, 2002).

According to Saltmarsh and Hartley (2011), we are still in the beginning phases of the current movement which began in the 1990s. Higher education institutions are environments ripe for the development of civic engagement and education activities, especially related to social justice movements. Although methods of facilitating discussions and action regarding civic issues have evolved and changed, the need for educated citizens who can participate in finding solutions to problems and issues in a democratic society has not changed (Imel, 2012). According to Youniss, "Encouragement of service as public work is one strategy higher education can use in fulfilling its civic mission to socialize society's future leaders" (2011, p. 6).

McIllrath writes that universities should be examined as part of a wider community and not the elite, distant, exclusive institution of the past (Lyons, et al., 2012). Additionally, Gouley claims that education is the unifying factor among all the forces of change in our society and universities have an ethical obligation to contribute to the common good of society (Lyons, et al.). Bringing these two claims closer to one another, Munck ascertains that universities must be socially embedded in order to avoid being the ivory tower of the past (Lyons, et al.). These suggestions lead to the realization that, while discourse around civic engagement and service-learning exists, there is a lack of cohesive and generally understood objectives and goals. Institutions are still often 
defining terms independently from other institutions of higher education and implementing programs haphazardly without regard for the larger academic community. Of course, initiatives to bring together cohorts of institutions to work together towards common goals have emerged, such as the American Democracy Project. The initiatives are gaining recognition and participation from a number of institutions.

Many occasions exist for the inclusion of service-learning and civic engagement activities in higher education. Institutions have the opportunity to education students to become contributing members of society, to engage in addressing social justice issues, and to become a contributing force to the local community as well. With opportunity, comes challenge, and it is necessary to examine the need for this link between citizenship and the university in relation to the challenges institutions face in regards to this topic.

Challenges. Citizens have cause to be concerned over the education of engaged and active citizens. A growing concern regarding the lack of engagement of young Americans encourages attention on and analysis of recent trends in American youth behaviors, values, and opinions. Boyte (2003) summarizes that during a period spanning the 1970s through the 1990s, voting participation amongst citizens aged 18 to 29 dropped by more than 20 percent, totaling less than one third of that group casting votes.

Additionally, UCLA issues an annual survey to gauge political attitudes and engagement amongst college students; "By 2000, only $26 \%$ of freshmen voiced the belief that keeping up with politics is important, compared with $58 \%$ in 1966 . Only $14 \%$ say they regularly discuss politics - down from 30\%" (as cited in Boyte, p. 86). And possibly even more telling, NACE reports that "four in ten believed that it does not matter who is president, twice as many as in 1992" (as cited in Boyte, p. 86). 
Boyte asks, "What does it mean to educate students to be patriots with a sense of agency who hold the nation to its highest ideals?" (2012, p. 25) and calls for discussion and debate in order to allow higher education to respond to the needs of the nation. As well, he claims, "in an era of globalization, there is new urgency for citizens to learn the skills and identity of empowered citizenship in their own societies, linked to the democratic aspirations and struggles of others around the world" (Boyte, p. 26). These questions and concerns from Boyte guide further analysis into the challenges facing the education of engaged citizens and the political and economic influences affecting the progress of this education.

Beyond the traditional challenges involved in creating and executing effective civic engagement programming, there are those who support a narrow interpretation of the mission of the university, focusing solely on academic preparation rather than the development of students as citizens. For example, Stanley Fish's (2008) book, Save the World On Your Own Time, offers advice to faculty members and outlines what, exactly, he finds to be the mission or the scope of the university. Fish offers,

"Colleges and university teachers can (legitimately) do two things: (1) introduce students to bodies of knowledge and traditions of inquiry that had not previously been part of their experience; and (2) equip those same students with the analytical skills - of argument, statistical modeling, laboratory procedure - that will enable them to move confidently within those traditions and to engage in independent research after a course is over" (pp. 12-13).

For faculty, he advises, “do your job, don't try to do someone else's job, and don't let anyone else to your job" (Fish, 2008, p. 16). Beyond these parameters, Fish 
explains why he finds the university to be overstepping and clearly articulates that the goal of fostering student development and shaping morals and values is absolutely outside of the responsibility or the ability of universities (Fish). The perspective of Fish as either an administrator or a faculty member, or even just a fellow American, challengse the success and progress of contemporary civic engagement programming.

Political \& economic influence. As higher education continues to undergo reform and is faced with limitless challenges and opportunities, it is beneficial to also explore political and economic forces of influence. The neo-liberal economy, as discussed by Henry Giroux (1999) in his writings on corporate culture, has critical ties to the future of civic engagement and democratic citizenry. He writes "Within the language and images of corporate culture, citizenship is portrayed as an utterly privatized affair whose aim is to produce competitive self-interested individuals vying for their own material and ideological gain” (H. Giroux, p. 148). In his analysis, H. Giroux delves into the issues and associated challenges, politically and economically, regarding this individualistic approach to corporate culture in America. This approach can be tied especially to the experience and education of the participants in corporate culture, America's higher education graduates.

National, state, and institutional leaders navigate a complicated web of policy and funding decisions which ultimately affect civic engagement policy at higher education institutions. Charles Kolb, in A Crucible Moment, states, "The heart of a vibrant democracy is educated, engaged citizens who are able to make choices for themselves, their families, their communities, and their country. In this respect, the success of American postsecondary education is critical to the success of American democracy" 
(AACU, 2012, p. 16). Active and engaged participation in a democracy is inherently political and the political reach is extensive.

Economically, focus on the service mission of higher education is often viewed as a burden to college budget allocations. It is difficult to prioritize civic engagement curriculum and program development when many institutions are struggling to fund basic academic programming and research needs. While difficult, it is also necessary to examine the long-term and tangential effects of failing to educate students to be active and engaged future leaders.

Important as well, is the need for colleges to consider the growth and reach of civic engagement initiatives into a number of institutions through the American Democracy Project. If 250 institutions have committed to the need for attention towards the education of active and engaged citizens within higher education, outcomes will begin to speak to some of the best and brightest students looking for the most rich and rewarding preparatory program. Funding civic engagement may be burdensome, but for a number of compelling reasons, it should be taken seriously and prioritized.

Government agencies have issued declarations and charges in the past, and institutions have published service and community engagement statements, yet a cohesive, effective program for engagement still commands attention and improvement. Student values and goals endlessly shift over time and these transformations continue to shape political and economic policymaking for higher education.

In regards to the shifting values and goals, Hartley (2002) claims that 80 percent of youth students stated a goal of developing meaningful philosophy in college in 1969, and in 1996, that number dropped to 42 percent. Astin (1998) discovered that 74 percent 
of college students attended because they wanted to make more money when only 49 percent identified money as a priority in 1971. These shifts in student attitude and decision-making skills speak to larger policy problems, both politically and economically.

After examining the concepts of citizenship, both from a founding and contemporary perspective, and the concepts of the university from a founding and contemporary perspective, as well as the links between the citizen and the university, it is now prudent to examine literature focused on civic engagement as a mission integrated into higher education in order to address the second fact-gathering question and to inform future policy analysis.

\section{How is Civic Engagement Integrated into Higher Education?}

The link between citizenship, civic agency, and civic engagement with higher education can and should be examined, fostered, and promoted in order to fully educate and prepare students to become engaged and contributing citizens. As the saying goes, 'there's more than one way to skin a cat," and in the same line of thought, there are many ways for higher education institutions to provide civic education to students.

On one hand, these varying approaches are undesirable because it contributes to issues involving consistency, definition, and effective results. On the other hand, varying approaches are necessary in order to make new discoveries, alter teaching methods towards a new type of students, especially in regards to technology and the manner in which students are engaging in personal and public relationships. Current opinions and interpretations of 'the citizen' will also affect approaches to civic engagement. 
In the previous section, the founding and current concept of the universities and of citizenship were examined, and it is clear to see that the university was first intended to prepare students for society and to act as engaged citizenships. As differing politics affected the idea of citizenship and the direction of the university and its priorities, civic education for students changes as well. As Boyte notes regarding the multiple approaches to civic education, "The differing paradigms of 'the citizen' in each hold implications for widely different politics" (2003, p. 88). Paradigm shifts are inevitable; however, shifting to more effectively educating students to be engaged citizens in change worth pursuing.

The relationship between the public sphere and the university must be revitalized because true democracy requires opposing views and powers, and educational institutions must provide an environment conducive to public debate, building social relationships, and political discourse in order to aid students in developing personal identities, values, and actions (S. Giroux, 2012). S. Giroux points out that

"what recent progressive work makes clear is that the alleged crisis over the "politicization" of university curricula is chimerical, for it is impossible to engage the university's historic commitment to civic education apart from the political life of the nation, to think citizenship and community without politics" (pp. 4041).

A notable distinction in regards to civic engagement terms is the difference between community service as a voluntary activity or as a vague requirement for a club or component of reflection and is often a task which must be completed in order to fulfill a requirement. The action of community service becomes a meaningful component of civic engagement when learning and reflection accompany the activity. Kinsley states, 
"In our own century, John Dewey, and more recently, Ralph Tyler and Hilda Taba have reminded us that students who actually do things, who engage in activities related to school subjects, learn more efficiently, more effectively, and remember what they have learned much longer than students who don't" (1994, p. 41). While community service, both within the curriculum and for co-curricular reasons is worthwhile, it is just one component of civic engagement.

Service learning is often the "next step" towards civic engagement beyond simple community service hours, and this activity usually involves some type of reflection on the activity and learning objectives are often in place. Service learning typically addresses two types of activities: community service as an extracurricular activity and experiential education, most often through practicums or internships (Kozeracki, 2000). The difference between service learning and experiential learning is vague and unclear with many using the terms interchangeably. Some consider service learning to merely be a type of experiential learning while others do not agree that service learning includes coop educational programs or internships (Kozeracki). Brown, Collins, and Duguid (1989), write of conceptual knowledge being similar to the use of tools; the tools can only be understood through active use and using them changes the user's worldview and system of beliefs. Additionally, anyone can acquire a tool but the successful use of that tool is different; acquiring knowledge is different than putting that knowledge to use actively (Brown, Collins \& Duguid).

It is this area beyond community service activities and simple service learning objectives where terminology, objectives, integration, and purpose begin "muddying the water". In 2008, the Kettering Foundation hosted a meeting with academic leaders to 
evaluate the civic engagement movement in higher education. Though the meeting was viewed through a filter of Research 1 institutions and small, private universities, rather than inclusively for all institutions, a number of key ideas came from the meeting which help inform the analysis of civic engagement in American higher education. In this meeting, two major ideas were confirmed: first, "this nation faces significant societal challenges, and higher education must play a role in responding to them," and second, "the civic engagement movement has not realized its full potential" (Saltmarsh \& Hartley, 2011, p. 5). These ideas speak to the need for clarification and collaboration, as well as the identification of challenges and opportunities to develop the civic engagement movement effectively and beyond community service and service learning activities.

Civic engagement, as defined in this dissertation, is present in higher education; however, a number of distinct challenges exist within this integration, especially if the goal is effective engagement with a democratic purpose, resulting in educated, engaged citizens. Saltmarsh and Hartley (2011) include in the introduction to the book, To Serve a Larger Purpose, five themes which emerged from the above noted Kettering Foundation meeting. First, "An obligation for higher education to develop the civic agency of its students is not high on the public's agenda," next, "Our inadequate conception of what effective democratic education might look like is reflected in the imprecise and even conflicting language by members of the movement," third, "The movement is highly fragmented and compartmentalized," fourth, "The movement has largely sidestepped the political dimension of civic engagement," and finally, "The dominant epistemology of the academy runs counter to the civic engagement agenda" (Saltmarsh \& Hartley, 2011, pp. 5-6). Again, these five themes are specific to the environment at Research 1-level 
universities and small, private universities; however, the intent of the themes and the application to nation-wide civic engagement in higher education continues to be helpful to consider.

In the next sections, civic engagement as a component of the curriculum is assessed, as well as student benefits associated with civic engagement. First, however, the idea of a hypothetical administrator is presented, along with a number of scenarios that may face an administrator in regards to activities which could have a civic engagement component. Keeping these potential scenarios and examples in mind assists in the evaluation of civic engagement activities.

\section{The Hypothetical Administrator}

It is helpful when examining civic engagement activities to imagine a number of scenarios that could occur in a university setting and imagine how these specific situations could result in decision-making challenges or case-by-case consideration. As literature is examined further in my analysis of civic engagement, the scenarios can be considered examples of civic engagement activities. These same examples will be utilized in terms of the policy recommendations and considerations later in the study.

Below, a number of hypothetical situations are presented; imagine a university administrator fielding these requests in an institution, $\mathrm{ABC}$ University, without a clear definition of service-learning, civic engagement, or democratic engagement. Service is, in theory and in documentation, listed as a mission of ABC University. As in many institutions, the mission identifies academics, research, and service as the primary missions of the university; however, service is not an area with clear objectives, nor is it measured or benchmarked over time. 
The administrator, the Vice President of Student Affairs, fields the engagement activities requests and must decide how ABC University will respond.

Animal shelter adoption. A group of students at the graduate school wants to support the local animal shelter by bringing adoptable dogs on campus to raise funds and place dogs in homes. The dogs are chosen by the shelter employees, and will accompany students throughout the day. The shelter will host an information booth on campus.

Temporary warming shelter. During a severe storm resulting in massive power outage, student leadership groups band together to open and manage a warming shelter for community members without power. The outage is expected to last a number of days, and temperatures remain dangerously low.

Homelessness experiment. A faculty member wants to conduct a homeless experience activity with students sleeping on the city streets for one night and panhandling. The goal is for students to experience homelessness in order to conceptualize the difference between treating the symptom by donating clothing and food and treating the cause by addressing potential root issues of homelessness.

Community request. Members of the community have requested use of the local health facilities during a city health initiative project. Community members would be issued gym memberships for a two month period during the school year. The facilities have the capacity to serve more members, but membership would be granted based on residence and proximity to the university.

Voting rally. Student leaders, in conjunction with a national voting promotion and activist organization, plan a voting rally with an overnight lock-in, concerts, catering, 
and multiple guest speakers. Students will be able to register to vote and will learn about the candidate platforms.

Donations \& fund management. Students in the College of Business want to raise and independently manage funds for community projects, asking for donations from community businesses and alumni.

Energy demonstration. Students want to conduct an environmental demonstration and education project by turning electricity and water off in a number of buildings to demonstrate the inconvenience of learning without modern facilities. The goal is to educate students about education challenges in developing countries.

\section{Civic Engagement in the Curriculum.}

A number of the above examples and scenarios would be considered curricular activities, while some are co-curricular or student-led activities. Examination into the differences between curricular and co-curricular activities will have implications for university risk and liability, as well as curricular concerns over meeting the learning objectives of individual courses and programs. There are a number of levels of examination required to effectively include civic engagement activities into the curriculum. For example, is the activity directly related to the course objectives? Does the activity server a larger purpose by tying into general civic education or does it promote democratic and civic engagement and reflection for students?

Gourley and Bolund both strongly promote the inclusion of civic engagement in the curriculum through service-learning and as an orientation rather than simply add-on activities (Lyons, et al., 2012). Bolund continues his argument by defining academic citizenship as "a way of knowing, acting and being in higher education" (Lyons, et al., p. 
54). Many additional authors, including Scheutze and Cuthill, call for social responsibility in scholarship despite the fact that it is difficult to measure (Lyons, et al.). Additionally, many contributors promote using the community as a classroom and redesigning the curriculum in order to incorporate service activities which can be directly linked to civic learning.

Bringle and Clayton write extensively about "The Civic-Minded Graduate" (Lyons, et al., 2012, p. 113) and identify a number of approaches and definitions of a graduate who has experienced civic engagement in the curriculum. They also note Astin's study findings that the participation in service-learning activities plays a significant role in the student's political community involvement after graduation (Lyons, et al.). Cuthill, as well, notes the need for responsible corporate citizens and the need to engage students in these service activities (Lyons, et al.).

Many questions still remain regarding the appropriate design and delivery of civic engagement curriculum, though McIlrath identifies a number of common characteristics which provide a structure (Lyons, et al., 2012). Students should have a meaningful experience, receive academic credit, the activities should address societal issues, enhance academic knowledge, and develop critical thinking (Lyons, et al.). Additionally, students should develop critical thinking, engage in reflective practice and learn how to integrate theory with practice (Lyons, et al.).

Challenges. As expected, there are a number of challenges to the incorporation of civic engagement activities into the curriculum. The culture in higher education, one which is "consumerist, hypercompetitive, and privatized" allows a small, elite group to govern institutions, training students to focus on individual success over societal gain, 
training them to believe they cannot affect change in the world, that societal problems should be discussed at a distance, not acted upon (Boyte \& Fretz, 2010, p. 77). Students are trained to believe that college is about attaining ever-higher individual income levels; they discuss homelessness and hunger and even animal control issues from a distance without believing their work can result in improvement or that action should be taken beyond classroom discussion.

This technocratic culture also speaks to the bureaucratic roadblocks put into place regarding civic engagement activities and liability issues. It's much easier to claim an increased level of institutional risk as a reason to deny faculty and students access to true active, participatory learning than to change higher education culture into one of inclusivity and change.

Boyte and Fretz (2010) call for changes to civic engagement in higher education in order to update an unsustainable and rigid model steeped in "individualism, privatization, and isolation" (p. 68), thereby realizing the civic engagement movement's potential. They also note the regular, everyday activities of higher education which are negating the collaborative intent of civic engagement, including the faculty award and compensations system which encourages isolated work rather than engagement activities embedded in the curriculum (Boyte \& Fretz). Boyte and Fretz (2010) call for a shift away from the technocratic model used currently in higher education in order to allow faculty members to truly incorporate meaningful civic engagement activities into the curriculum, activities focused on the self-interest of faculty members in order to gain buy in for the projects. The faculty member interested in the homelessness experiment should be 
encouraged and supported through administration for incorporating a hands-on activity with corresponding reflection and student action.

Despite the challenges embedded in higher education culture, it is critical that progress towards civic engagement and civic agency building activities continue in order to affect student experiences and provide them with the benefits they deserve.

Student benefits. Undergraduate education is currently not satisfying the moral and civic purposes of the college (Beaumont, 2002) and the limited civic intelligence of students provides abundant concern for the future of our democracy (Coley \& Sum, 2012). A concerted effort is necessary to preserve democracy including the improvement of civic knowledge, a more educated and literate population, a higher level of civic commitment, economic and personal voting incentives, and voter registration reform (Coley \& Sum). Developing civic agency, as defined and explained by Boyte, is of utmost importance as well for the development of students into engaged citizens. He states, "The concept of civic agency highlights the broader set of capacities and skills required to take confident, skillful, imaginative, collective action in fluid and open environments where there is no script" (Boyte, 2008, p. 11).

Higher education is uniquely situated to address the education of these participatory citizens. Psychologist Erik Erikson $(1946,1956)$ presented the concept of identity and he claimed that late adolescence and early adulthood offer the unique opportunity for one to develop a personal and social identity (as cited in Gurin, et al., 2010). Additionally, he found that identity develops best when a young person has a safe environment to experiment with social roles before making life-long decisions (as cited in 
Gurin et al.). Colleges and universities offer a safe, experiential environment for the development of citizens in early adulthood.

A number of recommendations have been put forth from authors in national reports, books, articles and other writings. Many of these recommendations relate to student benefits and the opportunities available to educate students with a civic or democratic purpose in mind. For example, Coley and Sum (2012) suggest that colleges and universities take a more active role in student voting participation, civic participation, and community service, resulting in a population more politically active and assimilated into society where service learning and political advocacy help to build leadership skills. Because the student population has become significantly more diverse in recent decades, substantial opportunity is available to promote civic learning and student development, potentially shifting attitudes towards civic engagement, thereby increasing participation in service and political activities (Bowman, 2010).

Additionally, Mickelson and Nkomo (2012) write of the benefit to students when making connections between issues regarding diversity, democracy, and social cohesion and assume a social justice dimension to this topic, one which moves beyond simply community service and volunteerism. Diversity significantly affects learning and democracy outcomes and is believed to be "especially important during the college years because students are at a critical developmental stage, which takes place in institutions explicitly constituted to promote late adolescent development" (Gurin et al., 2002, p. $334)$.

The idea of the good citizen is explored in regards to qualifications or factors that comprise this "good citizen". Westheimer and Kahne (2004) identify three factors that 
identify a good citizen, all of which are benefits and goals for students participating in democratic engagement. The factors include personal responsibility, participation and justice-orientation (Westheimer \& Kahne). The student who is personally responsible basically does good deeds and does volunteer activities; the participatory citizen is more involved in the community and this person may organize a volunteer activity and recruit others (Westheimer \& Kahne). The justice-oriented citizen focuses on the connections between society, economy, and politics and brings attention to socially unjust issues with an emphasis on collective work (Westheimer \& Kahne). These citizens often are involved in activist and social movement activities rather than charity and community service work (Westheimer \& Kahne).

When students are not exposed to political concerns and community building skills, they are missing a large component in developing the necessary skills for engaged citizenship. Colby, Beaumont, Ehrlich, and Corngold, in "Educating for Democracy", found that over 50 percent of 600 service-learning programs in their study included direct service while one percent provided "a focus on specifically political concerns and solutions such as working with groups to represent the interests of a community" (as cited in Boyte, 2012, p. 10). The focus should be on encouraging participation in democracy by being political participants rather than simply performing tasks that help the needy (Youniss, 2011). The difference comes with the intention and the design of the engagement program in regards to citizenship development; one direction fosters a charitable attitude while another fosters a social justice attitude (Wang, et al., 2005).

Westheimer and Kahne (2004) provide an excellent example of the differences involved with these three categories: the personally responsible citizen donates canned 
goods to a community food drive while the participatory citizen decides to organize the food drive and the justice-oriented citizen inquires to why the community has a hunger issue in the first place. It is this justice-oriented citizen who will make long-lasting change for society. Higher education should strive to cultivate these justice-oriented students in order to affect society in a positive manner.

In addition to benefits surrounding diversity education and levels of participation, globalization education is important to civic engagement. Efforts to connect campuses across the world are the essence of globalization in higher education. As Ernest Boyer wrote in Scholarship Reconsidered: Priorities of the Professoriate, "Now is the time to build bridges across disciplines, and connect the campus to the larger world... If the nation's colleges and universities cannot help students see beyond themselves and better understand the interdependent nature of our world, each new generation's capacity to live responsibly will be dangerously diminished (Boyer, 1990, p. 77). Data gathered by Hendersot and Sperandio (2009) find that students see global citizenship to involve engagement in activism, open-mindedness, accepting and respectful behavior, tolerance, pursuit of knowledge, and a sense of awareness. Fostering these insights in students is the responsibility of higher educational institutions world-wide.

Taking the American perspective of democratic engagement to a global perspective is also imperative as higher education continues to become more and more interconnected and the civic mission of higher education must remain relevant. Giddens (1990) wrote, "the intensification of worldwide social relations which link distant localities in such a way that local happenings are shaped by events occurring many miles away and vice versa" (p. 64). As students study and investigate options in higher 
education, it is important that institutions understand and embrace, not just a local perspective, but a global perspective of civic engagement.

Finally, Nie, et. al (1996) found that each additional year of formal education increased participation in all of the seven areas of democratic engagement activities that were measured through the 1990 Citizen Participation Survey, the General Social Survey and the National Election Survey. These seven areas included participation in political activities, voting regularly, demonstrating tolerance, showing political attentiveness, and exhibiting knowledge of democratic principles, political leaders, and current political facts (Nie, et. al). Additionally, the authors found that more education develops cognitive proficiency and sophistication.

As evidenced through a number of authors, student development through civic engagement activities is possible and critical to the growth of future citizens. It is necessary to not just state a service mission for the institution, but to incorporate meaningful, purposeful programming designed to foster these young adults in a safe and experiential environment with the goal of educating active, engaged citizens. Many components contribute to the development of an effective civic engagement program and a discussion follows regarding the inclusion of civic engagement in higher education from the perspective of administration.

\section{Civic Engagement within the Context of Administration}

The topics of higher education administration and civic engagement are both multi-faceted and complex. Many areas within these two, broad subjects cross paths or dove-tail, and an examination of these convergent areas leads to a rich understanding of 
both higher education administration and democratic engagement, including components of this topic as an educational and legal issue.

Critical analysis and practical application play a central part in the understanding of higher education trends and issues and a multi-perspective analysis is necessary in order to understand and address these organizational concerns. Within the over-arching topic of higher education are a number of sub-topics which are relevant to civic engagement administration and policy formation, and these topics fall into three major areas: administration, faculty and students. These three identified major areas will be further examined within each major subject area including: leadership, planning, organization and shared governance, student development, and global perspectives. By examining each of these areas through the lens of civic engagement, a more comprehensive picture of civic engagement within higher education is constructed through an examination of the literature.

Additionally, by examining civic engagement through the lens of administration, one can better understand the call for higher education to change, as defined by Benson, Harkavy, and Puckett:

"for universities and colleges to fulfill their great potential and really contribute to a democratic...revolution, the will have to do things very differently than they do now....To become part of the solution, higher eds must give full-hearted, fullminded devotion to the painfully difficult task of transforming themselves into socially responsible civic universities and colleges. To do so, they will have to radically change their institutional cultures and structures, democratically realign 
and integrate themselves, and develop comprehensive, realistic strategy" (as cited in Saltmarsh \& Hartley, 2011, pp. 3-4).

This change cannot be made independent of a full understanding of the current culture and structure of higher education, including leadership, faculty, students, planning, and governance. My study now turns to leadership and examines the need for both leadership from the administrative perspective and leadership capacity building for students.

Leadership. Leadership is applicable to the civic engagement movement in higher education from a number of perspectives. Administration, faculty and student roles should be examined from a lens of leadership in general and in terms of the application of democratic engagement initiatives. It is important to first examine leadership and provide perspective from this area before examining other higher education topics. Major topics within higher education will be affected by the institution's prioritization of leadership development, the leadership abilities of administrators and faculty, the determination of the administration and faculty to develop students into future leaders, and, most specifically, the effectiveness of a democratic engagement program in providing leadership opportunities for students.

An example is provided here to support the consideration of leadership theory, organizational structure, shared governance and implementation. This example, the Political Engagement Project initiative by the American Democracy Project, is one of many that could be used to justify a leadership perspective in the development of civic engagement initiatives. For example, the University of Minnesota example as outlined in the chapter, "Institutionalizing Civic Engagement at the University of Minnesota" in the book, Democracy's Education: Public Work, Citizenship, \& the Future of Colleges and 
Universities (Bruininks, Furco, Jones, Sommers \& Konkle, 2015) could be used as well. Both pieces shed light on the need for a leadership perspective in intentional civic engagement development in higher education, one from an institutional perspective and the other from an organizational perspective with reach into many institutions. For the purpose of an example for this dissertation, the Political Engagement Project initiative through the American Democracy Project is used to illustrate the benefit of a leadership perspective.

The Political Engagement Project provides a relevant, applicable example for the need to understand and apply leadership theory to the study of civic engagement and for the need to examine leadership topics prior to the formation of civic engagement policy. The book, Educating Students for Political Engagement: A Guide to Implementation and Assessment for Colleges and Universities, is the resulting guidebook for institutions interested in the political engagement, specifically, of students.

Political engagement was one of the initiatives tackled by the American Democracy Project through the Civic Engagement in Action Series in an effort to address the way civic engagement efforts of the program, while well-received, were found to be "marginal, celebratory, and episodic" (Mehaffy, 2010, p. 6). The plan to implement this Political Engagement Project was thorough and complex. Eight institutions were asked to participate with the ultimate goal for the American Democracy Project (ADP) to "drive the work of civic engagement deep into the core of the academy" (p. 6). This program was brought to ADP by a number colleagues at the Carnegie Foundation for the Advancement of Teaching, and ADP was interested due to the "belief that the preparation 
of undergraduates to be informed engaged citizens must be an all-university responsibility" (p. 7).

Now, the remainder of the Political Engagement Project book provides case study information and advice from the eight participating universities. The program was, and continues to be, quite successful due to the coordination, collaboration, and cooperation of ADP with the eight participating universities and the Carnegie Foundation team. Throughout the guidebook, multiple authors provide insight and advice for interested institutions, and all of this information can be related to the need for two concepts which tie in with leadership.

First, administrators looking to make institutional progress towards effective civic engagement must act as leaders and evaluate potential opportunities and challenges through a lens of leadership and effective planning. Second, the goal is to support, develop, and foster engaged, active leaders through engagement activities. The programming and goals must be created with the knowledge of leadership theory and goals in order to effectively foster this collaborative type of behavior.

Kouzes and Posner (1993) identify the top four leadership characteristics as honesty, forward-looking, inspiring, and competent. They also note that the single-most important quality for a leader to possess is personal credibility (Kouzes \& Posner). Without credibility, followers will not believe in the leader and will, therefore, not believe the leader's message. Developing leadership skills in students and prioritizing leadership skills for administrators and faculty is critical in the success of fostering civically-minded, active leaders for our community, both inside and outside the academy. 
These characteristics and qualities are equally important for administrators who are attempting to implement civic engagement programming.

The behaviors of leaders are important and being forward-looking is what differentiates leaders from other credible people. Leaders take every opportunity to show others by their own example (Kouzes, 2003). Leaders can revitalize shared beliefs and help keep values fresh. They conceive and articulate goals that move people from their own interests to unite for higher ends (Bass, 2006). The vision and mission of an organization can affect all constituents of the university, and the link between the actual statement and the traits and behaviors of the leader as they communicate the vision and mission is critical to success and development. These skills are some of the very outcomes desired for student development from democratic education and engagement; however, imagine the seemingly insurmountable challenge for administrators seeking to build civic engagement activities within the institution if not forward-looking or without the ability to create momentum around shared beliefs or values. An administrator is not leading well if unable to conceive and articulate civic engagement goals which move the group towards a higher end.

Nanus writes, "Amidst all the chaos and conflicting pressures, the vision compels an organization to remember what's really important and where it intends to go" (from Hickman, 1998, p.232). Though the vision articulates the picture, strong leaders are necessary to translate the vision into a conceivable goal and the characteristics and behaviors of the leader influence this process. Showing students, by example, how vision can lead to action and goal achievement is necessary for civic agency building, as well. The goals of civic agency are closely tied to leadership development as well. Boyte 
describes civic agency as emphasizing "not only individual action but also the collective capacity to act on common challenges across differences" (2012, p. 10).

Leaders, both administrators and students, can be trained and can grow in their practice, an important idea to note in regards to the responsibility of the university to train future leaders. Kouzes writes that "Leadership is an observable set of skills and abilities... a learned set of practices" (2003, p. xvii). Through cultivation and exposure to purposeful experiences, leaders can learn to use the characteristics, skills and abilities they possess to expand and grow leadership behaviors.

Kirkpatrick and Locke (1991) show evidence that successful leaders are not like other people. There are certain core traits that contribute to a leader's success. They note that these traits are only a pre-condition and the leaders must also take certain actions in order to realize the potential to be successful. According to this research, six specific traits have evidence showing that they contribute to successful leadership. They include: drive, honesty, integrity, self-confidence, cognitive ability, and knowledge of the business. Building leadership traits and providing opportunities to foster these traits are a responsibility of the university as well in the development of students as well-rounded, active citizens.

Integrity and knowledge of the business are two of the traits most applicable to higher education. Honesty and integrity ensure a leader is open with followers while still maintaining a level of discretion and confidentiality. Effective leaders are credible, maintain high levels of integrity, and uphold an outstanding reputation (Kirkpatrick and Locke, 1991). All skills desired from active citizens, as well. These two traits, specifically, are exemplified through the success of the ADP Political Engagement 
Program. It is clear through the guidebook content that the leaders and institutions involved with this project held the integrity of the program and the administration of the content as key.

Knowledge of the business is an important trait for a leader. Having the skills necessary to gather extensive amounts of information and make informed decisions allows the leader the ability to understand the implications of those decisions and focus on the best choices for the organization (Kirkpatrick and Locke, 1991). As for the ADP program example, the right people were brought into the project to contribute knowledge of the 'business' as well as to uphold an outstanding reputation. The recommendations found within Chapter Two of the guide speak to the importance of knowledge of the business when Keenan and Carr (2010) recommend the recruitment of the appropriate people to implement a successful political engagement program.

Most important in the evaluation of leadership in the university through a lens of democratic engagement goals is Kouzes' (2003) claim that ordinary men and women can get extraordinary things done in organizations when given opportunity and support. This mentality applies to administration, faculty, and students and should provide another incentive for institutions to create an efficient program aimed to develop students into future leaders. Beyond leadership within higher education, administrators must also excel in planning, organization, and shared governance in order to effectively lead institutions towards successful civic engagement programming in order to develop students into engaged, active leaders. If the base structures and processes for effective planning, organization and governance are not in place, the potential success of a civic engagement program is compromised. 
Planning, organization \& governance. Transformational leadership, as defined by Burns (1978), occurs when "one or more persons engage with others in such a way that leaders and followers raise one another to higher levels of motivation and morality" (p. 133). Planning in higher education identifies an overarching goal to engage multiple constituencies and mobilize their interests and a well-designed planning and governing system distributes resources and rights equitably, resulting in the constituents perceiving the system fairly determined and providing for valuable outcomes (Leslie, 2003). As democratic engagement is prioritized as a worthy mission of higher education, attention and resources will be necessary in order for constituents to feel the process has been fairly governed and optimized for valuable outcomes.

Again referencing an example project, the ADP Political Engagement Project utilized planning and organization in the conception and implementation of the program, as well as effective shared governance techniques when coordinating the activities and cooperation of administration, faculty, and students. One cannot simply determine and develop a program intended to "drive the work of civic engagement deep into the academy, particularly work with faculty in courses and majors" (Mehaffy, 2010, p. 6) without understanding the purpose and intricacies involved with shared governance.

This concept of shared commitment and collaboration transfers to the skills needed for student participants in civic engagement as well. As social issues are addressed and community collaboration activities are designed, engaged leaders must take into account the views of all stakeholders. Shared governance and planning implies that each constituent group has input and influence over the determination of the resource allocation and the values-based outcomes. The goal of shared planning, therefore, goes 
hand in hand with the leadership goal of Burns' to engage with others (1978). In the academic setting, it's crucial for administration and faculty to understand the needs and roles of each group in order to effectively move forward with college initiatives, including democratic engagement.

As previously noted, Ernest Boyer, in a thorough study of American higher education, concluded that undergraduate education fails to meet the civic and moral goals of higher education (as cited in Beaumont, 2002). Civic engagement and hands-on, active learning opportunities are critical to student development, yet this short-sighted, narrow view of the importance of civic engagement will not serve the goals of humanity at large. Examination of institutional organization is addressed through an examination of shared governance and planning approaches to follow.

Shared governance. Governing in higher education identifies an overarching goal to engage multiple constituencies and mobilize their interests (Leslie, 2003). Good governing systems distribute resources and rights equitably, resulting in the constituents perceiving the system as being determined fairly and providing for valuable outcomes (Leslie). Shared governance, or governing, implies that each constituent group has input and influence over the determination of the resource allocation and the values-based outcomes. The goal of shared governance, therefore, goes hand in hand with the leadership goal of Burns' (1978) to engage with others.

Shared governance is an especially important topic in regards to democratic engagement as administration, faculty, and students can all benefit from the coordination of shared governance efforts with democratic engagement opportunities. Often, shared governance changes and improvements focus on structure and bureaucratic changes 
rather than meaningful, collaborative leadership improvement and compromise. Creating an environment where students can learn to navigate the political and economic policy system when administrators and faculty can also provide a learning opportunity and guidance will serve students well.

Kezar (2004) suggests abandoning the conventional idea that changing structure will improve the effectiveness of governance and instead focus on governing through leadership and relationships. After all, she writes, "structures and processes are not the heart of organizations - people and relationships are" (p. 39). Leslie (2003) also notes that structures are necessary, but not sufficient to handle the conflicts that arise in higher education. The recommendations offered in Chapter Two of the ADP Political Engagement Project guidebook suggests spending effort and time to "solidify collaborations across campus" (p. 25). These collaborative relationships are key to the successful implementation of civic engagement activities.

Academic capitalism offers many challenges to traditional shared governance and rather than address change and improvement to each separately, Rhoades (2003) offers an alternative model focusing on democratic accountability. The entrepreneurial shift of universities has resulted in increasingly powerful administrative roles in governance and a diminished role for faculty (Rhoades). Focusing on academic capitalism also results in a shift away from the focus on community health and service. Rhoades (2003) calls for a new structure of governance valuing not revenue generation but the improvement of society, socially, culturally, politically, and educationally. Again, a governance structure with these goals is an excellent match with the goals of democratic engagement and learning. 
Rhoades calls for the expansion of constituents in the governing process. The community, the students and the faculty could all have a seat at the table. The focus could be on "democratic governance oriented to the public good" (2003, p. 38). As Leslie (2003) writes, conflict is inevitable, but it must be managed, not suppressed. What better way to introduce students to the political forces at play in decision-making, even within organizations outside of the traditional public, political arena?

Rhoades (2003) suggests, by reemphasizing the College's role in creating public good, governing bodies can connect to the philanthropic sector and impact the social infrastructure of the community. Colleges have the opportunity to strive for institutionalization and focus on "culture-building around core values, key people, and symbolic representation of what the organization means and stands for" (Leslie, 2003, p. 18).

Both Rhoades (2003) and Leslie (2003) offer attractive ideas about new models of governing in higher education and both speak to the revitalization and promotion of an institution's values. Balance is a common theme in the literature about emerging ideas of governance. Effectiveness and legitimacy, transparency without over-analyzing, the taskrelationship theory of leadership, and formal and functional authority all involve balance. An effective system of shared governance involves the shift away from a traditional focus on structure, authority, power, and academic capitalism and shift towards achieving balance and democratic sharing of governance.

Evaluation \& the culture of the academy. Many steps are involved in the strategic planning process, especially at the level involved with shared governance and the collaboration between administration, faculty, and students. Strategic planning is 
relevant to the study of civic engagement activities and policymaking in a number of ways. Again, the guidebook for the ADP Political Engagement Project provides an example of the level of planning and strategy involved in the successful implementation of a program designed to change an institution to the core. This program implementation is not a one step process; it is not simple nor easy; it is not quick nor isolated. The collaboration of multiple constituent groups is necessary to the success of civic engagement program building.

These constituent groups working to improve an institution are, ideally, working to form the best system possible for all involved in the institution of higher education. One of the most important pieces of the planning process is the evaluation of the culture of the institution and how a program such as civic engagement prioritization will fit into the culture of the institution. Bergquist and Pawlak (2008) provide a structure for evaluation of democratic engagement programming within an organization.

Bergquist and Pawlak (2008) offer six cultures of the academy which provide an opportunity to view issues and trends via multiple perspectives, a critical process in strategic planning. The following cultures are all present in an institution at any given time and each situation can be viewed from multiple lenses. Bergquist and Pawlak's goal is to offer a framework for leaders to be guided towards new courses of action which result in improved function.

By analyzing the mission of civic engagement through each of these cultures, we can effectively evaluate how planning strategically to address the mission of civic engagement can be leveraged to result in positive change rather than simply trying to ignore a core mission of the institution because it is challenging and expensive (Bergquist 
\& Pawlak, 2008). Culture provides continuity and helps hold groups of people together to work collectively towards a specific purpose, all of which help reduce anxiety within an organization (Bergquist \& Pawlak). Again, in order to make positive progress with an issue facing higher education, it's important to understand how the issue is perceived through multiple cultures.

Collegial culture. The collegial culture is often represented by faculty members who value scholarship, research, and rationality along with faculty governance, autonomy and academic freedom (Bergquist \& Pawlak, 2008). While this culture may seem unrelated to civic engagement missions, it will be important to consider how faculty will react to initiatives that may affect curriculum and methods of instruction. Many servicelearning projects are hands-on initiatives and often time-consuming for both students and faculty. As faculty members focus efforts on preserving academic freedoms and scholarly research interests, administration and other constituent groups should recognize that perspective in order to understand how best to reach collective goals. Keenan and Carr (2010) suggest in the Political Engagement Project guidebook that, in order to successfully implement a program similar to the one initiated by ADP, both curricular and co-curricular changes must be considered. Changes to faculty expectations must be viewed through the collegiate culture in order to effectively and successfully gain faculty buy in for the project.

Managerial culture. The managerial culture values specific goals and purposes, effective supervision and fiscal responsibility; student learning is more important to the managerial culture than scholarship or research, specifically teaching that is also fiscally cost-effective (Bergquist \& Pawlak, 2008). Critics often note that the managerial culture 
fails to take into account the impact of the collegial culture and treats the college as a corporation. Those in the managerial culture also value hierarchical structures, articulate communication, and clearly assigned responsibilities (Bergquist \& Pawlak). Often, this culture is highly bureaucratic. The managerial culture may require additional information about the purpose of incorporating civic engagement more fully in the college plan. Typically, these initiatives are costly and not revenue-generating for the college. It will be important to view these initiatives through a values-based lens.

In reference to the ADP Political Engagement Project, Keenan and Carr note that "intentionality in higher education tends to be more structure and process oriented, rather than outcomes oriented" (2010, p. 23). This example is the type of culture which must be considered as projects addressing civic engagement programming are undertaken.

Developmental culture. The development culture focuses on personal and professional growth where values include service to others, attaining personal maturation while helping others, and rationality (Bergquist \& Pawlak, 2008). Faculty members are asked to make decisions based on the institution's needs rather than purely on collegial concerns of autonomy and scholarly research. This culture can be idealistic and naïve about the political processes in higher education (Bergquist \& Pawlak). The developmental culture also values the institution's mission.

Civic engagement, service-learning, philanthropy and relationship-building efforts are best examined through the development culture. Valuing the institution's mission is of utmost importance, as well as the maturation of students, faculty, staff, and the community through opportunities to develop within service experience. The Political Engagement Project recruited key participants, established a network of support, focused 
on campus-wide collaboration, and promoted the development of a rewards and recognition system, all activities tied to this developmental culture (Keenan \& Carr, 2010).

Advocacy culture. The advocacy culture values equitable policies and procedures which ensure the fair distribution of institutional benefits and resources (Bergquist \& Pawlak, 2008). Faculty members feel that confrontation is necessary to produce change, resources can be leveraged to ensure this change and collective bargaining is an activity that demonstrates the advocacy culture (Bergquist \& Pawlak).

Those who would prefer to engage in political behavior (collegial culture) and those who are concerned with collaboration (development culture) will often be focused on different values than those who are concerned with unjust or inequitable practices (advocacy culture) during the shared planning process (Bergquist \& Pawlak, 2008). In program development such as the Political Engagement Project, understanding the values and focus of varying stakeholders is critical to the success of the program and the view that a fair distribution of benefits and resources has been achieved.

Virtual culture. The virtual culture values "open, shared, responsive education systems" (Bergquist and Pawlak, 2008, p. 147). This culture also focuses on technological resources in order to broaden the network of learning in higher education institutions. The term virtual does not refer to technology directly; it describes the nature of collaborative relationships that do not have a physical presence (Bergquist \& Pawlak). This culture has grown recently due to the increased use of computers and the internet, as well as a dramatic shift in the economy affecting higher education and the changing 
organizational boundaries within an institution (Bergquist \& Pawlak). Colleges no longer strictly control information and teaching methods within a specific framework.

The network established through the collaboration amongst groups and institutions for the Political Engagement Project exemplifies the academy's virtual culture. The institutions are wide-spread with varying backgrounds and specific missions, yet the members used technological resources effectively and focused on collaborative relationships without a physical presence to share important information. Had this use of the virtual culture not been the case, the relationship building and communication taking place prior to national conventions and meetings may not have allowed for such rich and successful conversation and progress.

Tangible culture. In contrast to the virtual culture, the tangible culture values face-to-face education in a physical location (Bergquist \& Pawlak, 2008). This culture also finds meaning in a community and historical roots where traditional university characteristics are stressed: the campus, the endowment, prestigious faculty, difficult admissions requirements, and outstanding reputations (Bergquist \& Pawlak). The focus on traditional education by the institution is often in conflict with the needs and wants of the students.

Although much of the Political Engagement Project involved virtual relationships, the in-person meetings and the regional and national conferences offered by the American Democracy Project allowed participating institutions and those participants who favor tangible relationships an opportunity to converse in person.

Appreciative inquiry. Appreciative inquiry is a perspective Bergquist and Pawlak (2008) suggest to bridge the gap between the six cultures. Appreciative inquiry at the 
collegial level will promote a change in attitude with a focus on the successes of the institution in order to build a better future (Bergquist \& Pawlak). Again, the notion of the democratic sharing of planning and governance supports the notion of appreciative inquiry and the acknowledgement and appreciation of each of the six cultures of the academy. The use of the Political Engagement Project as an example of a collaborative effort amongst a diverse group of institutions and individuals aids in the understanding of appreciative inquiry and the manner in which multiple cultures within the academy can come together to create a successful, effective, and progressive benefit for the civic engagement movement in American higher education.

After examining the culture of the academy and the importance of viewing civic engagement issues through the lens of higher education administration, it is now important to view student development through the lens of administration and the evaluation of student development challenges.

\section{A Focus on Student Development}

Challenges in student learning and social views of the value of higher education surface consistently and will continue to do so. Occasionally the challenges are documented and addressed in a systematic manner. Sometimes the media presents information to society prior to the availability of supporting evidence. In other instances, educational or political leaders publicize an opinion and offer strong claims about the problems in higher education. As these claims and challenges are brought to light, it will remain important to evaluate and examine the challenge and how it connects with the future of the civic engagement movement. One method of evaluating new challenges is to 
consider higher education and the issue through the academy's role as creator, curator, and critic, as outlined by Scott (2008).

For example, in the Association of American Colleges \& Universities (AAC\&U) journal, Liberal Education, an issue was released entitled "Special Issue: Civic Engagement and Psychosocial Well-Being" in 2010. In this special issue, many authors come together including Barry Checkoway, Peter Levine, Constance Flanagan, Matthew Bundick, and James Youniss, amongst others, to provide information about the connection between the challenges of the psychosocial well-being of students and the potential benefits of civic engagement (AAC\&U, 2011).

This over-arching issue is approached from many angles, and James Youniss (2011) clearly identifies one issue in his examination of the benefits of service and public work by stating, "Although public work comprises only some portion of all youth service, it is relevant to contemporary political-economic conditions and important for the civic and mental health of young people... The future calls for strong leadership, yet recent generations of youth have sent mixed signals about their commitment to sustain our democracy" (p. 28).

Youniss continues by linking Harry Boyte's call for service as public work to the responsibility of higher education institutions to connect with the development of students, "The translation of this charge to college campuses would encourage young people to move beyond offering help by emboldening them to participate in democratic life as political actors" (p. 28). Youniss and the other authors offer a number of connections between the need for civic engagement in higher education and the over-all well-being of students in the university (AAC\&U, 2011). 
It is this type of issue or charge to the university that, when viewed from the policy-maker perspective and from a perspective of civic engagement, can be examined through consideration of the College as creator, curator and critic (Scott, 2008). The development and prioritization of student well-being is paramount to the success of higher education, yet as these claims are promoted widely both within and outside the academy, leaders in the civic engagement movement must be prepared to continue supporting and providing evidence for the benefit of civic engagement programming and the development of students. In the following sections, examples are provided regarding the evaluation of a challenge in higher education, student development and well-being, and how civic engagement can be examined through consideration of the academy as creator, curator, and critic (Scott, 2008). This method of systematic examination and application of the idea of the university to individual challenges and issues provides structure and consistency for the evaluation of challenges and can be applied to emerging issues.

Creator. The university as a creator is focused upon the formation of new knowledge and applications of that knowledge to create new paths to problem-solving. Policy-makers look to the university to create new solutions to address not only issues in higher education, but also issues in other areas where higher education can offer solutions through means such as workforce training, medical research, community development, and citizen engagement.

As policymakers look to problems with students, specifically the problem of student development and well-being, they will look to the university to create new solutions. Given President Obama's goal to "lead the world in college attainment by the 
end of this decade" (Department of Education, 2013, p. 1), it will be crucial to create new strategies to address student success.

These issues relating to student development and well-being can be directly linked to democratic engagement and civic learning as well. The university should be responsible for creating new solutions and policies supporting the development and success of democratic learning programs. President Obama's goal cannot be fully separated from the need to not just have graduate numbers but be graduating future leaders who are well prepared to enter society and contribute meaningfully.

Curator. As curator, the university is responsible for documenting the past events and cultural heritage which contribute to changes and formation of higher education today. This history is important to the understanding of the future. For example, understanding the changes that have occurred throughout the past generations in student behavior and methods of learning has bearing on the creation of new solutions today. Recognizing the longstanding history and tradition of service in the academy is important to the development and prioritization of democratic engagement today.

Studying the habits of baby boomers and gen-x students in order to understand millennial students will aid policymakers and administrators in the creation of new curriculum and teaching methods. For example, it may be surprising to learn that generation X students were typically pessimistic, self-absorbed and frequent rulebreakers while millennial students are often rule-followers and optimistic, high-achieving students who prefer high levels of structure (Bowen, et. al, 2011). Additionally, Youniss (2011) addresses the transition to the use of social media and digital means of communication over time in his contribution about public work and the opportunities and 
challenged involved in bringing civic engagement efforts in the academy to the digital world. Consideration for past methods and the transition to new, digital means is critical to the successful development of civic engagement.

Understanding past and present attitude towards service and involvement will aid universities in the development of effective programming. Universities cannot be viewed collectively to address every issue. It is important for universities to preserve the history of the individual institution in order for college policymakers to create unique solutions which take into account the institution's own past. If a university has a strong history of engagement in a specific area, that momentum and tradition should be harnessed and included in the growth and improvement of future programming.

Critic. As a critic of the issue of students not being engaged and thus negatively affecting well-being, it is important for the university to be an environment where these issues and related issues can be discussed and openly evaluated. As policymakers look to meet President Obama's completion initiative, it will be important to view student motivation, the culture of student development and well-being, and actual student engagement to evaluate if completion numbers are reflective of students graduating with the necessary skills to contribute to the national goal. As Denham and Gadbow (2002) note, each generation has created a philosophy which has helped shape the attitudes, values and work styles of the generation and, while not transferable to each individual, it will be helpful for policymakers to keep this perspective in mind while critiquing the effort and learning outcomes for students.

Beyond this evaluation of challenges facing student development, administrators must also take into consideration the need for a global perspective of civic engagement. 


\section{Global Perspective}

Taking the American perspective of civic engagement and service-learning to a global perspective is imperative as higher education continues to become more and more interconnected and the civic mission of higher education must remain relevant. Giddens (1990) wrote, "the intensification of worldwide social relations which link distant localities in such a way that local happenings are shaped by events occurring many miles away and vice versa" (p. 64). As students study and investigate options in higher education, it is important that institutions, both administration and faculty, understand and embrace not just a local perspective, but a global perspective of civic engagement.

As Battistoni, et. al (2009) note, Campus Compact and the Council of Europe have both declared the importance of civic responsibility and issued a call for a global orientation to education. Battistoni, et. al, also examine openings for organizations to use local engagement opportunities to teach students about global problems. They claim that students needn't necessarily travel abroad to learn about global engagement if institutions are innovative and collaborative in programmatic efforts.

It may seem that local engagement and global engagement are at odds or competing for activity; however, Battistoni, et. al, (2009) demonstrate that "servicelearning offers an avenue not only to understand these competing forces, but also to help revitalize local culture with an understanding and respect for the global (p. 95).

Efforts to connect campuses across the world are the essence of globalization in higher education. As Ernest Boyer wrote in Scholarship Reconsidered: Priorities of the Professoriate, "Now is the time to build bridges across disciplines, and connect the campus to the larger world... If the nation's colleges and universities cannot help students 
see beyond themselves and better understand the interdependent nature of our world, each new generation's capacity to live responsibly will be dangerously diminished (Boyer, 1990, p. 77).

Data gathered by Hendersot and Sperandio (2009) find that students see global citizenship to involve engagement in activism, open-mindedness, accepting and respectful behavior, tolerance, pursuit of knowledge, and a sense of awareness. Fostering these insights in students is the responsibility of higher educational institutions worldwide.

Additionally, many authors acknowledge three major missions of the university: teaching, research and service. Of these "three pillars" of higher education, civic engagement is neglected most (Lyons et. al, 2012). Gourley writes that universities which lean on the first two pillars, teaching and research, result in the third mission being neglected, specifically service to the community (Lyons et. al, 2012).

While civic engagement has long been a mission of higher education, Schuetze claims that it is a renewed area of interest due to a new world and new student body with emerging trends which influence the focus of the college mission (Lyons et. al, 2012). These trends include technological advances, an international focus, increased competition and advertising, a focus on college rankings, the "commercialization of knowledge" (Lyons et. al, p. 63), and new governance structures.

While these competing trends are vying for university attention and resources, there are many reasons why a service mission is unattractive to administrators and faculty. The current programs may not be meeting expectations, faculty may favor 
traditional methods of content delivery, there may be a lack of funding, or administrators may consider this mission to be academic drift (Lyons et. al, 2012).

Gouley writes of universities, "As they struggle to be politically correct or avoid the risk of offending any group or persuasion, they end up rather doing nothing at all" (Lyons et. al, 2012, p. 33). The mere recognition of this third mission in principle does not translate into active and serious engagement (Lyons et. al).

\section{Is there a Progression from K-12 to Higher Education?}

In order to address the third fact-gathering question as identified in the study methodology, the K-12 system and the progression from this system into higher education is analyzed. The examination of previous experiences with civic education of higher education students is important to the understanding and development of a civic engagement program for a number of reasons. First, the program should be examined to identify gaps or issues better suited for older, more mature students. Second, the content should be examined to avoid repetition and to expand upon previous knowledge, rather than repeat content. Finally, the K-12 system can be evaluated from a policy and legal perspective. Because mandatory civic education programs have been implemented in the K-12 system, much can be learned before pursuing a change to policy and requirements for higher education.

\section{Approaches to K-12 Civics Education}

The Education Commission of the States [ECS] (2010) produced an issue of The Progress of Education Reform that examines a number of research pieces on the K-12 system in regards to citizenship education and $21^{\text {st }}$ century skills. Within this piece, the commission clarifies the goals of civic education in the K-12 system and identifies a 
number of achievement and access gaps which should be considered in the formation and evaluation of higher education democratic engagement (ECS).

The goal, according to this commission, of civic education is to cultivate "active, involved community members, citizens and future leaders" with the purpose being "to create an informed citizenry, with the knowledge, skills and will to participate in our government and community affairs" (ECS, 2010, p. 1). Obviously, the goals are similar to the purpose of civic engagement in higher education. It is most important to note that, while both programs have similar objectives, the problems identified throughout the remainder of the article lead to problems within the higher education system, as well.

In 2012, The Center for Information \& Research on Civic Learning \& Engagement (CIRCLE) published a paper summarizing civic education parameters across states (Godsay, et al.). The data is extensive and unwieldy, though a number of key points emerge. Courses are typically labeled civics or government or U.S. government and the topics include "citizenship, government, law, current events, and related topics" or content within social studies sources (Godsay, et al., 2012, p. 1). The Center finds that all states set social studies standards with identified themes of "power, authority, and government" with all but one state including civic ideals (Godsay, et al., p. 1).

Forty states included at least one course in government or civics within the required courses and only nine states require students to pass a social studies examination in order to graduate (Godsay, et al., 2012). It is important to note that these standards were evaluated under the influence of No Child Left Behind Act of 2001 and the Race to the Top federal policy. Common Core state standards are becoming available with details, but it is difficult to find data summarizing trends across states. 
According to a recent, interactive map of 2014 standard requirements by state, approximately half of the states require a service-learning component while almost all states require at least one year of social studies courses and civics education of some sort (CIRCLE Interactive Map, 2014). About half of all states include a state assessment in social studies while only a select few include state assessment of civics education (CIRCLE Interactive Map, 2014).

Beyond the summary and grouping state requirements into specific categories, the specific state standards are varying and include nuances that make it very difficult to summarize exact requirements. Obviously, as states, not the federal government, are responsible for education, there will not be just one, easy answer to the K-12 system of higher education. It is important to note, however, that many states require some sort of community service in order to fulfill a civics or social studies state requirement for graduation.

\section{Challenges in K-12 Civics Education}

Pipeline concerns abound in the public education system and much literature exists evaluating readiness and preparation issues for students entering higher education. Civic education, however, is not a subject receiving attention when students arrive to college without the same experiences and learning opportunities as their peers. According to the commission's review of research, in 2003, the Carnegie Corporation of New York and the Center for Information and Research on Civic Engagement and Learning (CIRCLE) identified six approaches to civic engagement learning which will help the K12 system find success preparing students (as cited in ECS, 2010). These approaches include the following: 
Provide instruction in government, history, law and democracy

$>$ Incorporate discussion of current, local, national and international issues and events into the classroom

$>$ Design and implement programs that provide students with the opportunity to apply what they learn through performing community service that is linked to the formal curriculum and classroom instruction Offer extracurricular activities that provide opportunities for young people to get involved in their schools or communities

$>$ Encourage student participation in school governance

Encourage students' participation in simulations of democratic processes and procedures (as cited in ECS, 2010, p. 2).

These approaches are important to note for a number of reasons. First, these are well-designed goals for a K-12 citizenship program and many of the same principles should be applied, at a level more appropriate for older students with more experience, to higher education. Most importantly, however, is to note that these are suggested approaches and the researchers do not indicate that the K-12 system has implemented nor been successful in this endeavor. The points are identified as "promising approaches" (as cited in ECS, 2010, p. 2). These points were created based on research finding that the activities would help the schools reach the goal of competent, responsible citizens (ECS). Again, a noble plan grounded in research, but these activities are not yet a reality and K12 students are entering higher education without this experience.

In addition to the general notion that K-12 students are not being successfully prepared through the civic education program, another significant issue affects the 
preparation of K-12 students in basic civic education. In the 2008 working paper, Democracy for Some: The Civic Opportunity Gap in High School, Kahne and Middaugh find that race and ethnicity influence the access to civic engagement activities in high schools. Additionally, socio-economic variables influence the depth of education opportunities surrounding issues of civic education (Kahne \& Middaugh).

Large groups of students are being excluded from opportunities of engagement. This exclusion of minority and low socio-economic status students provides evidence that all students are not arriving to colleges and universities with the same basic knowledge. Even without considering the issues involving access to higher education for these same groups, it's important to consider the K-12 experiences of students in these groups as they transition to higher education and have mediocre or poor knowledge and experience in civic engagement.

In a related study, Levinson (2007) found that civic participation, including the knowledge of basic civic and political processes, the skills and favorable attitudes towards political activity, and basic participation in political activities, are all significantly lower for poor, immigrant, and non-white citizens. These groups perform poorly on the National Assessment of Educational Progress (NAEP) and, as adults, lowincome families have low voting rates and are rarely politically active (Levinson, 2007). Possibly of most importance is Levinson's finding that people falling into these groups have a low sense of efficacy, the confidence that individual people can affect positive change within the government. Again, it is important to understand the far-reaching effects of poor civic preparedness in the K-12 system which can cause additional pipeline issues in the future. 


\section{Conclusion}

This review of education scholarship serves to provide research and evidence to support the first three fact-gathering questions in this exploratory policy analysis:

1. What is civic engagement?

a. How is it defined?

b. What benefits are attributed to such engagement?

2. How is civic engagement currently being integrated into higher education?

a. Is participation integrated into the curriculum?

b. Is participation voluntary or mandatory?

3. Is there currently a progression of civic engagement from $\mathrm{K}-12$ into higher education?

After an examination of current trends and policies, a review of case law follows in answer to the fourth fact-gathering question. Many of these same issues are addressed, as well, in the evaluation of civic engagement for a democratic purpose, the legal implications, and the resulting policy implications. The information in this dissertation chapter will help to frame and answer the policy issue for this study: "Is higher education the appropriate venue for instruction on democratic engagement and, if so, do the benefits and rewards of instruction on democratic engagement outweigh the possible risks of incurring additional legal liability?” or, “Are the benefits of providing instruction on civic engagement in higher education more important than the increase in legal liability?"

Additionally, the literature about civic engagement provided in my analysis and the compounding idea of civic engagement for a democratic purpose, prompt the transition to a focus on democratic engagement, rather than specifically on civic 
engagement, in the remainder of this study, specifically in the use of democratic engagement as the preferred term used in policy recommendation in order to consistently put forth the idea of educating students for a democratic purpose. It is beneficial to examine the history and development and purpose of civic engagement activities using terms that were in place during this development. For the purpose of future initiatives and policy development, the term democratic engagement will be used. 


\section{CHAPTER IV \\ CURRENT INITIATIVES AND ORGANIZATIONS \\ IN CIVIC ENGAGEMENT \\ Introduction}

The information in this chapter offers a sampling of the international, national, regional, and institutional civic engagement related activities currently being administered. This list is not comprehensive; however, it does provide context for the analysis of strengths, weaknesses, opportunities, and threats associated with this movement. As one continues reading the final two chapters of this dissertation, the information provided regarding the organizations and initiatives currently in place help the reader comprehend the policy issue more fully, including the legal liability issues surrounding the execution of effective engagement efforts. Civic engagement is a complex issue, and, therefore, many institutions with a variety of missions are related to education, preparation, and activities of engaged Americans. 


\section{Key Organizations, Trends, or Initiatives}

The following organizations have ties to the civic engagement movement, and the accompanying links were valid as of the date of publication for this dissertation:

\section{The American Democracy Project (ADP) [AASCU]}

http://www.aascu.org/programs/ADP/

The American Democracy Project is an initiative organized through the American Association of State Colleges and Universities (AASCU). Founded in 2003, the ADP focuses on "preparing the next generation of informed, engaged citizens for our democracy" (AASCU, n.d., para. 1). 250 higher education institutions collaborate to "produce graduates who are committed to being knowledgeable, involved citizens in their communities" (AASCU, para. 2). The project organizes the Civic Engagement in Action Series and delves into nine specific, critical issues which affect the nation including health, voting issues, political involvement, and many others (AASCU). Additionally, the project works in conjunction with the Carnegie Foundation for projects such as Stewards of Place II (AASCU).

ADP has demonstrated wide-reaching success through the centers developed on the campuses of participating institutions. For example, The Docking Institute for Public Affairs at Fort Hays State, The William J. Hughes Institute for Public Policy at Richard Stockton College of New Jersey, and the Illinois Institute for Rural Affairs at Western Illinois University. 


\section{The American Democracy Project - South (ADP-South)}

http://www.utm.edu/staff/mabneyj/adps/

The ADP-South is the Southern Consortium of the American Democracy Project and coordinates the efforts in 12 southeastern states (ADP-South, para 1). The organization aims to "provide support for campus ADP leaders and to recognize the efforts of campuses, organizations, faculty, administrators and students whose work contributes to the goals of ADP National" (para 1).

\section{American Sociology Association: Sociological Practice and Public Sociology} https://sspps.wordpress.com/

The goal of this organization is to "advance sociologically-informed research and public action, to further public discussion of sociological issues at local, national, and global levels, and to promote the use of sociology to inform public policy" (para 1).

\section{Association of American Colleges \& Universities (AAC\&U)}

https://www.aacu.org/about

The AAC\&U has a mission to "make liberal education and inclusive excellence the foundation for institutional purpose and educational practice in higher education" (AAC\&U, n.d., para. 1). One of the four major, strategic goals for the organization is to advance social responsibility and "foster civic learning, ethical reasoning, and engagement with US and global diversity" (AAC\&U, para 7). AAC\&U publishes widely distributed reports, such as the five volume Civic Series and A Crucible Moment: College Learning \& Democracy's Future. 


\section{The Corella and Bertram F. Bonner Foundation (Bonner)}

http://www.bonner.org/mission/

This foundation works with both colleges and congregations to provide food and educational opportunities (Bonner, n.d.). The foundation is dedicated to community service and the connections or opportunities available through the collaboration with colleges (Bonner).

\section{The Democracy Commitment (TDC) [AASCU-TDC]}

http://www.aascu.org/programs/adp/democracycommitment/

Modeled after the American Democracy Project, TDC is also sponsored by AASCU and focuses on community college civic engagement. Specifically, the organization "aims to engage community college students in civic learning and democratic practice. The goal of the project is for every graduate of an American community college to have an education in democracy" (AASCU-TDC, n.d., para. 1). Over 50 presidents of American community colleges have signed the Commitment and are working to align institutional goals with the Commitment (AASCU-TDC).

\section{Education Commission of the States (ECS)}

http://www.ecs.org/html/aboutECS/home_aboutECS.htm ECS seeks to "track state policy trends, translate academic research, provide unbiased advice and create opportunities to learn from one another" (ECS, n.d., Para 1). This non-partisan organization offers weekly policy updates for states and covers P-20 education policy (ECS). One can track policy changes, compare states to one another, and research policy summaries and explanations. 


\section{Campus Vote Project}

http://campusvoteproject.org/about/

In order to encourage college student voters to participate in elections, Campus Vote Project (n.d.) aims to inform students about registration information, help students prepare identification documents, clarify voting location information and transportation options, and communicate effectively with election officials.

\section{Campaign for the Civic Mission of Schools (CCMS)}

http://www.civicmissionofschools.org/the-campaign/educating-for-democracy The campaign was formed to increase effective civic learning in both K-12 and higher education (CCMS, n.d.). With an aim to "bring about changes in state, local, and national policy that promote civic learning and implement the recommendations in "Guardian of Democracy: the Civic Mission of Schools" report published by the campaign in 2011" (CCMS, para. 2), the organization operates at both a national and state level.

\section{Campus Compact}

http://www.compact.org/about/history-mission-vision/

Over 1,100 presidents of colleges and universities work through Campus

Compact to fulfill the public purpose of higher education (n.d.). The organization states, "As the only national higher education association dedicated solely to campus-based civic engagement, Campus Compact promotes public and community service that develops students' citizenship skills, helps campuses forge effective community partnerships, and provides resources and training for 
faculty seeking to integrate civic and community-based learning into the curriculum" (Campus Compact, n.d.).

\section{The Carnegie Foundation for the Advancement of Teaching (Carnegie) http://www.carnegiefoundation.org/who-we-are/} The Carnegie Foundation works with "scholars, practitioners, and designers in new ways to solve problems of educational practice" (Carnegie, n.d., para. 1). Overall the Foundation aims to "integrate the discipline of improvement science into education with the goal of building the field's capacity to improve" (Carnegie, para 1). The Foundation works in conjunction with AASCU on projects like Stewards of Place II (AASCU, n.d.).

\section{The Center for Engaged Democracy at Merrimack College (CEDMC)} http://www.engageddemocracy.org/

Housed at Merrimack College in Andover, MA, the Center "acts as a central hub for developing, coordinating, and supporting academic programs - certificates, minors, and majors - around the country focused on civic and community engagement, broadly defined" (n.d., para. 1).

\section{The Center for Information \& Research on Civic Learning and Engagement (CIRCLE)}

http://www.civicyouth.org/about-circle/

This organization produces research with the aim to inform both policy formation and practice which promotes youth development towards improved democracy (CIRCLE, n.d.). The focus in on research and publications covering young Americans as citizens (CIRCLE). 


\section{Corporation for National and Community Service (CNCS)}

http://www.nationalservice.gov/about

CNCS is a federal agency that facilitates programs that aid citizens through service. Programs include SeniorCorps, AmeriCorps, Social Innovation Fund, and United We Serve (CNCS n.d.).

\section{The Engagement Academy for University Leaders (Engagement Academy)} http://www.cpe.vt.edu/engagementacademy/eaul/

The Engagement Academy aims to provide executive development "designed for higher education leaders committed to developing institutional capacity for community engagement (n.d., para 1.). Campus leaders attend the annual academy in teams to design civic engagement institutional plans (Engagement Academy).

\section{Innovations in Civic Participation (ICP)}

http://www.icicp.org/about-us/

ICP is a global organization involved in youth civic engagement initiatives. The organization finds that "well-structured youth service programs can provide innovative solutions to social and environmental issues, while helping young people develop skills for future employment and active citizenship" (ICP, n.d., para. 1). ICP helped to develop the Tallaires Network, a network specific to global higher education engagement. 


\section{The Kettering Foundation (Kettering)}

https://www.kettering.org/about

This non-profit organization uses research to address the question: "what does it take to make democracy work as it should?" (Kettering, n.d., para. 1). The research is "conducted from the perspective of citizens and focuses on what people can do collectively to address problems affecting their lives, their communities, and their nation" (Kettering, para. 1).

\section{NASPA - Lead Initiative on Civic Learning and Democratic Engagement} (NASPA)

https://www.naspa.org/rpi/lead-initiative

NASPA, Student Affairs Administrators in Higher Education, developed an initiative to address civic learning and democratic engagement to promote the "work of student affairs in making civic learning and democratic engagement a part of every student's college education" (n.d., para. 1). Lead institutions are choses through the initiative to meet a number of civic learning goals (NASPA).

\section{National Center for Learning and Civic Engagement: (NCLCE)}

http://www.ecs.org/html/ProjectsPartners/nclc/nclc_main.htm

Housed within the Education Commission of the States (ECS), NCLCE "seeks to support state policymakers in establishing civic learning and engagement programs for pre-K through postsecondary students" (n.d., para. 1). Research and data is used to support the preparation of youth to participate in civic engagement activities (NCLCE). 


\section{National Coalition for Academic Service Learning (NCASL)}

http://ncasl.org/about-ncasl/

With an emphasis on K-12 education and state education, this group focuses on supporting effecting academic service-learning (NCASL, n.d.).

\section{National Conference on Citizenship (NCC)}

\section{http://ncoc.net/about}

This organization is congressionally chartered and tasked with building and improving civic life (NCC, n.d.). The organization states, "At the core of our joint efforts is the belief that every person has the ability to help their community and country thrive" (NCC, para. 1). The organization began addressing national service in 2013 with a focus on the Service Year exchange (NCC). "This exchange will be a dynamic, online marketplace designed to significantly increase service opportunities for Americans between 18-28 years old” (NCC, para. 4).

\section{National Issues Forum (NIF)}

\section{https://www.nifi.org/en/about-nif-forums}

This organization specifically provides the forums needed for people to address tough, critical problems. The organization provides guides and the platform to bring people together to have meaningful conversation (NIF, n.d.) The organization believes, "democracy requires an ongoing deliberative public dialogue" (NIF, para. 2). The organization utilizes forums, moderators, conveners, and issue guides to inform and facilitate conversation, and one of the topics is education (NIF). 


\section{Partnership for $21^{\text {st }}$ Century Learning (P21)}

http://www.p21.org/about-us/our-mission

P21 works to collaborate and build relationships between "education, business, community and government leaders so that all learners acquire the knowledge and skills they need to thrive in a world where change is constant and learning never stops" (P21, n.d., para. 1). One focus for the organization is to provide the $21^{\text {st }}$ century skills needed to function effectively as a citizen (P21).

\section{Partnership for Public Service (PPS)}

http://ourpublicservice.org/about-us/index.php

PPS is a non-profit organization with an aim to assist the government by focusing on the improvement of civil service and the accompanying programs which support civic service (PPS, n.d.). Specifically, PPS works with institutions of higher education to connect students with federal agencies through career services (PPS). PPS also finds value in "Advocating for needed legislative and regulatory reforms to strengthen the civil service" (para. 2).

\section{The Pew Charitable Trusts}

http://www.pewtrusts.org/en/about

As an independent, non-profit organization, The Pew Charitable Trusts performs global research and addresses public policy issues through data, analysis, and a focus on democratic participation (Pew Charitable Trusts, n.d.). 


\section{Public Agenda}

http://www.publicagenda.org/pages/who-we-are

Public agenda works directly with citizens through research and engagement to address critical issues including: K-12 and higher education, energy, health care, and national debt (Public Agenda, n.d.).

\section{Robert R. McCormick Foundation}

http://www.mccormickfoundation.org/about-us

Based in Chicago, IL, this foundation also focuses on the development of engaged citizens (McCormick Foundation, n.d.). Programs focus on civics, communities, education, journalism, and veterans (McCormick). The Foundation holds over $\$ 1$ billion in assets and also facilitates the Illinois Democracy Schools program with the Illinois Civic Mission Coalition (McCormick).

\section{Sabo Center for Democracy \& Citizenship}

http://www.augsburg.edu/sabo/about/mission-purpose/ Housed at Augsberg College in Minnesota, the Sabo Center for Democracy \& Citizenship strives to foster civic agency and engagement for all constituents of the College and Center, connect with the Twin Cities community, and focus on the democratic purpose of higher education (Augsberg, n.d.). The Center facilitates programs and offers training (Augsburg).

\section{Conclusion}

The organizations and initiatives listed above help describe the current landscape in civic engagement across America. A number of organizations recognize the importance to preserving democracy and democratic education within the higher 
education system, and many of these organizations are working collaboratively to make real change. The list, while not comprehensive, offers a sample of the current initiatives and a resource for further information. 


\section{CHAPTER V \\ LEGAL REVIEW OF POTENTIAL}

LIABILITY

\section{Introduction}

The nation is in need of educated, engaged citizens and, due to the potentially negative results of not cultivating these engaged leaders, it is important to mitigate and limit risk for higher education institutions through responsible, well-documented legal research. Institutions, as they are charged with making intentional improvements to the democratic engagement and education of students, should also make better-informed decisions, thus necessitating an examination of potential legal liability. The clear, linear, and responsible presentation of the legal ramifications of democratic engagement activities will aid administrators in the development of effective democratic engagement programs. Uncertainty around this type of program development may prevent institutions from developing democratic engagement programming for students. As current initiatives such as the American Democracy Project continue to grow and reach more institutions, it is important to shield these efforts from threats through proactive consideration and analysis of the potential liability.

In order to fully examine this topic of the legal liability associated with democratic engagement and determine the level of liability and risk for institutions, an examination of legal theory and relevant court cases is presented in this dissertation. 
Federal and state law, court opinions, and secondary sources, such as periodicals, legal encyclopedias, treatises, digests, and restatements of law, are used to inform this legal analysis of democratic engagement activities in higher education. While very few published cases are directly related to civic engagement liability issues, the courts use seminal cases with similar grounds to inform decision-making in new cases. This same approach is taken in the examination of liability issues as a means to anticipate how the courts would approach a new legal issue by referencing seminal cases to support new findings.

\section{Higher Education \& the Law}

Higher education institutions are subject to local and state laws, as well as federal law. The difference is determined by authority, and it is important to understand the differences between these legal authorities in order to understand how institutions are subject to compliance from multiple sources of authority.

Local law tends to involve issues such as zoning, voting, and community access to the campus. In regards to democratic engagement activities, higher education institutions will most often encounter local law and regulations when students are demonstrating or, potentially, during an election and voting period.

States are assigned the duty to govern higher education in most cases. This statelevel governance includes constitutions, statutes, rules and regulations, as well as common law. State law is most applicable to higher education in that it provides parameters for operating, funding, regulating, planning, and financial aid. Education is mandated by state law, in general. 
Other state agencies become involved with higher education institutions, despite being non-educational agencies. These agencies can involve labor law, civil rights protection, and environmental protection issues. Both public and private institutions are subject to state law, though private institutions are not subject to the same extensive rules and regulations which apply to public organizations. State law and regulation may be relevant in issues of democratic engagement activities, dependent upon the nature of the case.

Federal law is applicable to higher education, despite the fact that states have been granted authority to mandate education. Examples of federal authority over higher education include discrimination, equity in employment, copyright, patent and trademark law, bankruptcy, immigration, and voter registration, among others. The Americans with Disabilities Act is also a federal act, and many facets of this act are applicable to higher education.

Authority is the most important issue regarding the delineation between local, state, and federal law. Express authority is defined within the regulation itself and the accompanying documentation; implied authority is important to the execution and following of the express authority and can also be linked to the founding documentation (Lugg, 2012). Apparent authority is not official; it causes one to believe the institution has authority when it does not (Lugg). This apparent authority is important to all higher education issues because courts take into account the reasonable belief and expectation of the injured party.

After considering the varying levels of legal authority and the manner in which higher education institutions must comply with a number of local, state, and federal laws 
and agencies, this analysis now turns to the most relevant and timely issue in regards to civic engagement programming, legal liability.

\section{Liability}

Liability, as defined by Mirriam-Webster's Dictionary, is “the state of being legally responsible for something" (2014). In relationship to liability, a tort is "a civil wrong which can be redressed by awarding damages" (Legal Information Institute, Cornell University Law School [LII], 2014). This civil wrong implies liability for a party and results in the awarding of damages to the victim. According to tort law, colleges must protect from injury any student to whom the college owes a duty (Lugg, 2012).

Tort claims are civil infractions that claim an institution did not perform the duty according to a defined standard of care (Lugg, 2012). It is necessary to show that breaching the standard of care is the cause of the injury sustained by the plaintiff. Tort claims often involve negligence after the establishment of foreseeability or a duty of care. Tort claims can also involve defamation; however, negligence claims are the most relevant for democratic engagement activities.

While institutions do not have an established special relationship that requires a duty of supervision, as described below in the section on in loco parentis, institutions do have a duty to protect students from foreseeable harm (Lugg, 2012). In order to

constitute a valid and defensible tort claim, the following four criteria must be met:

1. The institution must owe a duty

2. A standard of care must be established

3. The established duty must have been violated

4. The violation caused injury (Lugg). 
These four criteria are important in the determination of liability for institutions of higher education.

A number of major legal issues are involved with liability and tort cases, and these issues require the examination of legal theory and court cases. The legal theory and case law examined in the following sections of this analysis include the following: in loco parentis, special relationships, duty of care, the reasonable person, foreseeability, negligence, assumption of risk, voluntary assumption of duty, voluntary participation and actions to mitigate or minimize risk and liability. The examination first of the concept of in loco parentis aids in the understanding of the role of the university over time and the changes which occurred in regards to the institution's responsibilities for the safety of students.

\section{In loco parentis}

The concept of in loco parentis originated in $18^{\text {th }}$ century England, and the concept held in the early American higher education system as well. As Edwards (1994) defines, in loco parentis places the institution in control in the absence of the parents; he states, "Colleges assumed the rights inherent in the parental status as well as the associated duties of parental responsibility" (Edwards, p. 4). The 1837 case out of North Carolina, State v. Pendergrass (19 N.C. 365 (1837)), is often cited in regards to in loco parentis because of the ruling that teachers act as substitutes for parents. This ruling was later confirmed with the case of People v. Wheaton College in 1866, giving power to college authorities to regulate discipline (Edwards).

In State v. Pendergrass (19 N.C. 365 (1837)), a young child was punished by a teacher with a switch and another instrument, and the courts determined it was acceptable 
to use corporal punishment if it was not used too excessively. At that time, the judge warned of the repercussions of claiming the manner of punishment to be too excessive and found that the right to punish the child was equivalent to the right of the parent to punish the child (19 N.C. 365 (1837)). In People v. Wheaton College (40 Ill. 186 (1866)), the courts described the rights of the college to discipline and restrict activity as it found fit for students.

According to Edwards, "Administrators had a duty to protect the safety, morals, and welfare of their students because parents transferred their authority and obligation to the institution" (1994, p. 4). Institutions operated under the principle of in loco parentis, although the justice system did not become involved officially until 1913 in the case of Gott v. Berea College (156 K.Y. 376, 161 S.W. 204 (1913)). This 1913 case became the grounds for judicial distance from administrative decision making and discipline until the middle of the $20^{\text {th }}$ century (Edwards, 1994).

In Gott v. Berea College (156 K.Y. 376, 161 S.W. 204 (1913)), students were prohibited by the College to enter an eating establishment near the campus. It was determined that the College had the right and responsibility to look after the students' well-being and make decisions for the students regarding the spending of time and money on appropriate activities and in appropriate venues (156 K.Y. 376, 161 S.W. 204 (1913)).

Through the decision on this case, it was clear that the judicial system would defer to the decision-making and rule-making of the university in regards to student activity. The statement and justification for the decision references in loco parentis and the authority of the College to enforce rules meant to protect the physical and mental health of the student (156 K.Y. 376, 161 S.W. 204 (1913)). 
The concept of in loco parentis began to lose favor in the 1960s. Edwards (1994) cites a number of reasons for the decline of in loco parentis during that decade, including general student rebellion and the protests around civil rights and Vietnam. Students demanded more responsibility and to be treated as independent adults (Edwards). Many scholars contribute that the changes during that time aided in the change in public opinion that higher education should not be a privilege, it should be a right for all citizens (Walton, 1992 and Millington, 1972, as cited in Edwards).

Institutions also largely supported the shift away from in loco parentis doctrine as the German model of the research institution grew, necessitating a more autonomous student body (Edwards, 1994). The 1961 case of Dixon v. Alabama State Board of Education (294 F. 2d. 150 ( $5^{\text {th }}$ Cir. 1961)) became the leading case in the demise of in loco parentis (Edwards). In summary, "The state, operating as a public institution of higher learning, was prohibited from violating students' rights simply because they were students" (Edwards, p. 7).

Scholars differ in opinion about in loco parentis and the true status of this doctrine now. Some argue that in loco parentis was solely related to student discipline, while others claim that student physical well-being was also a component of in loco parentis as a responsibility of institutions when standing in as parent (Edwards, 1994). Some authors link the rise in modern liability cases to a "judicial return to in loco parentis" (Edwards, p. 8) and support this claim by pointing out that student litigants rarely win cases against institutions.

Understanding the history and roots of the in loco parentis concept is important to understanding the context behind the special relationship concept, which some claim is 
close to the original doctrine of in loco parentis (Edwards, 1994). Szablewicz and Gibbs predict that the influx of negligence and liability claims against higher education institutions is a step towards a full return of in loco parentis with little rights for institutions to control morals or character but a duty to protect students' physical wellbeing (as cited in Edwards).

Additionally, Edwards (1994) offers a number of potential alternatives to in loco parentis due to the expectation of the university to help develop students as whole, wellrounded individuals. This concept of a new, revised version of in loco parentis, where the focus is one of personal development rather than discipline, may be especially relevant to democratic engagement activities in the future.

\section{Special Relationship}

The end of an official doctrine of in loco parentis resulted in the determination that colleges and universities did not owe a duty of care to students unless a special relationship was established (Jamerson, 2013). Duty is determined based upon the relationship between the parties. Most courts viewed the institution as a bystander, thereby establishing that no special relationship exists, though flexibility is afforded in this determination (Jamerson, 2013 \& Lugg, 2012). It is this difficult, institution-student interaction which necessitates further investigation into the intricacies of this relationship and how democratic engagement activities fit into each scenario. Three cases are particularly useful in regards to special relationship determination between higher education institutions and students.

Beach v. University of Utah. In Beach v. Univ. of Utah (726 P.2d 413 (Utah 1986)), the court found that adult students are responsible for their own choices, 
independent of the university because a university is an education institution, not a custodial party. This case is named as the most cited case in the determination of the existence of a special relationship.

In this case, Beach voluntarily consumed alcohol on a school trip and, subsequently, injured herself after wandering away from the campsite (726 P.2d 413 (Utah 1986)). The case established that the duty of the institution to protect the student only exists in the case of a special relationship where the responsibility of the student was assumed by the faculty member, and the student was deprived of her normal ability to protect herself (726 P.2d 413 (Utah 1986)). The case of Beach v. Univ. of Utah determined clearly that this special relationship did not exist; therefore, no duty of care existed, and liability could not be established (726 P.2d 413 (Utah 1986)).

Webb v. Univ. of Utah. In a more recent interpretation of the special relationship between institutions and students, the case of Webb v. Univ. of Utah finds that institutions may have a special relationship to students, dependent upon a professor's actions (Jamerson, 2013). On a required class field trip, students were instructed to visit a site which had dangerous, ice-covered sidewalks. The instructor told students to traverse the sidewalks carefully and avoid specific areas. One student slipped and grabbed another student, causing him to fall. This second student sued the institution.

The case of Webb v. Univ. of Utah clarifies that "the distinction between acts and omissions is central in assessing whether a duty is owed a plaintiff' (125 P.3d 906 (Utah 2005)). Additionally, it is important to note that this case demonstrates that two meanings are used in regards to special relationships. The first is applied to the analysis of duty in general tort cases while the second defines "the necessary predicate to the creation of 
duty in a governmental actor" (Webb v. Univ. of Utah, 125 P.3d 906 (Utah 2005), paragraph 13).

The key here is the presence of a governmental or non-governmental worker and the establishment of a special relationship and duty. Additionally, it is important to understand that a special relationship, where no such relationship existed previously, can be created when an instructor alters the academic environment (Webb v. Univ. of Utah, 125 P.3d 906 (Utah 2005)). Students in higher education, although of adult age, will typically defer to an instructor and surrender behavioral decision-making due to the knowledge and experience of the instructor; thereby resulting in the importance of the educational environment and the alteration of this academic environment (Webb v. Univ. of Utah, 125 P.3d 906 (Utah 2005)).

Davidson v. Univ. Of N. Carolina at Chapel Hill. In the case of Davidson v. Univ. of N. Carolina at Chapel Hill (142 N.C. App. 544, 543 S.E.2d 920 (2001)), the University did form a special relationship with a student cheerleader due to the nature of the relationship between the institution and the student in her role as cheerleader. The courts found that the University depended upon the entire cheerleading program for a number of university benefits; conversely, the cheerleaders also relied upon the university for benefits beyond just those of a typical cheerleader (142 N.C. App. 544, 543 S.E.2d 920 (2001)). Due to the nature of the relationship and the exchange of benefits, the university monitored and controlled many of the activities of the cheerleaders, thus creating a special relationship (142 N.C. App. 544, 543 S.E.2d 920 (2001)).

The determination of the presence or creation of a special relationship will be critical in the establishment of duty when students are asked to participate in democratic 
engagement activities on campus. This case will also help determine if a difference exists between voluntary engagement activities and activities which are required within classroom curriculum.

\section{Duty of Care}

After the demise of in loco parentis, universities entered a bystander era where institutions are simply acting as witnesses or onlookers to student behavior (Bickel \& Lake, 1997). Certain circumstances, specifically when a special relationship exists, create a duty on the part of the institution to maintain a safe environment for students and to warn students in the case of foreseeability (Lugg, 2012).

When a duty exists, a number of additional areas of liability become relevant in regards to democratic engagement activities on campus. In summary, if a duty exists, a standard of care is determined and institutions must uphold that standard of care in order to avoid negligence claims. In recent years, foreseeability has aided in the determination of an owed duty and the creation of a special relationship (Lugg, 2012). According to Davidson v. University of North Carolina at Chapel Hill, "a university should not generally be an insurer of its students' safety, and, therefore, the student-university relationship, standing alone, does not constitute a special relationship giving rise to a duty of care" (142 N.C.App. 544, 2001)).

While a duty of care does exist for the university to provide a reasonable level of care for students, it has been expressly shown in many cases that the duty does not include the need to warn students of obvious and known dangers. It is at this point that the concept of the reasonable person begins to really affect case outcomes. The reasonable person will be examined in a subsequent section of this chapter; however, a 
number of cases first provide insight into the intricacies involved in determining a duty of care including:

Wellhausen v. Univ. of Kansas. In the case of Wellhausen v. Univ. of Kansas, the parents of a student claimed that the University was responsible for the wrongful death of their son because he fell to his death after climbing out a small opening in a casement window on the seventh floor of a campus dormitory (40 Kan. App. 2d 102, 189 P.3d 1181 (2008)). The courts determined in this case that the University did not owe a duty of care to the student to warn of the dangers of this act, as the nature of the act is known to be dangerous (40 Kan. App. 2d 102, 189 P.3d 1181 (2008)). Again, the doctrine of in loco parentis does not apply to collegiate life any longer, and universities do not have a duty to protect students from their own negligent and careless acts.

Furek v. Univ. of Delaware. In this case, a fraternity student was a victim of fraternity hazing when he was burned by a lye-based cleaner as it was poured over his body (594 A.2d 506 (Del. 1991)). It was determined by the court that the university did owe a duty of supervision and protection for the student under these circumstances, despite taking place outside of official university business (594 A.2d 506 (Del. 1991)).

The University has the responsibility to use reasonable care to protect its students from known, dangerous acts of third parties, specifically in this case because the University was aware of hazing activity on campus (594 A.2d 506 (Del. 1991)). As the landowner, the University held even more duty of care because the actions were foreseeable, and the University had the ability to control the environment (594 A.2d 506 (Del. 1991)). In terms of democratic engagement, it will be key to determine cases where the university is aware of a potentially dangerous situation or activity. 


\section{The Reasonable Person}

The reasonable person, according to Glannon's description, is “a model of propriety and common sense, a person of sound judgment who acts at all times with "ordinary prudence, $\ldots$ reasonable prudence, or some other blend of reason and caution"”' (as cited in Glannon, p. 118). The author goes on to note that, despite the reasonable person being fictitious, impossibly perfect, and altruistic, it is possible to apply this concept to "describe in a general way the factors that the reasonable person considers before acting, and how he weighs those factors" (Glannon, p. 119). The reasonable person considers the foreseeability of the risk for injury, the extent of said risk, the likelihood of a risk, alternate, safer choices, and the cost associated with an action (Glannon).

There are a number of reasons why the concept of the reasonable person should be examined. First, due to the nature of negligence claims and the sheer number of ways a person can be injured or damaged, it is impossible for courts to proactively create specific rules outlining appropriate conduct (Glannon, 2010). Anticipating every way in which a student could become injured during democractic engagement activities is not realistic. Of course, it will be evident that certain activities will carry a high risk and others very low risk, similar to that of a normal classroom environment.

Additionally, while physical disabilities are considered in a defense of action or circumstance, a 'disability' in terms of a lack of common sense or good decision-making abilities are not found to be acceptable (Glannon, 2010). College students will not be allowed special consideration for lack of poor decision-making due to poor judgment. 
Lastly, while personal circumstances are occasionally taken into consideration beyond simply having poor character, external circumstances are considered fully (Glannon, 2010). As Glannon further clarifies, “The reasonableness of the defendant's decision is always judged in relation to the unique context or "circumstances" in which she made it" (p. 125). The following items are considered in terms of external circumstances: emergencies or timeliness of the unique situation, customs in regards to similar situations, statutes governing action in similar situations, changes in circumstances due to acting in the role of an expert, resources available at the time of the action, and countless other facts that could provide critical information as to the exact circumstances of the action (Glannon).

The concept of the reasonable person will be a factor in the examination of various claims of liability against a university. The circumstances surrounding a democratic engagement activity will be examined to determine if and when a party has acted negligently.

\section{Foreseeability}

The concept of foreseeability comes into consideration in the determination of liability. Foreseeability and the determination of prior knowledge of risk will be especially pertinent in the determination of liability and negligence for democratic engagement activities. When risk and danger are foreseeable, the institute of higher education will have a greater standard of care and a higher risk of liability for student safety. Two cases, in particular, offer insight into the repercussions of heightened foreseeability in terms of the liability of an institution and the duty of care owed. 
Bd. of Trustees of Univ. of D.C. v. DiSalvo. In the case of Bd. of Trustees of Univ. of D.C. v. DiSalvo (974 A.2d 868 (D.C. 2009)), a student at the University of the District of Columbia entered a campus parking garage and was attacked by armed assailants (974 A.2d 868 (D.C. 2009)). It was decided that the University was not liable because there was no heightened foreseeability that the parking garage posed a danger to students. According to the discussion about the case, "heightened foreseeability is... premised on the assumption that the court must limit the extent to which defendants become the insurers of others' safety from criminal acts" (974 A.2d 868 (D.C. 2009), para. 5).

It is clear that DiSalvo's injury was the fault of a third-party criminal, but the question which was the determining factor was whether or not the University owed a greater duty of protection because of the foreseeability of the danger (974 A.2d 868 (D.C. 2009)). As the University did not have prior knowledge that the parking garage was a common place for criminal activity, nor did the University have an increased awareness of criminal activity, there was no heightened foreseeability, and the University did not owe a higher duty of care to the student and was, therefore, not liable for the injuries nor negligent in its actions.

Tarasoff v. Regents of the University of California. The highly cited case, Tarasoff v. Regents of the University of California offers insight into institutions owing students a duty of care, finding that "a reasonable [duty] to protect the foreseeable victim of that danger" is the responsibility of the institution (551 P.2d 334 (Cal. 1976)). In this case, two students at the University of California-Berkeley were friends, and when the 
male, Prosenjit Poddar, was refused by Tatiana Tarasoff when he pursued a relationship, he became emotionally disturbed (17 Cal. 3d 425, 551 P.2d 334 (1976)).

Mr. Poddar sought counseling from a University psychologist and revealed his intention to kill Ms. Tarasoff, spurring the psychologist to contact police (17 Cal. 3d 425, 551 P.2d 334 (1976)). Mr. Poddar was released, the psychologist did not pursue treatment, nor was Ms. Tarasoff warned of any danger before Mr. Poddar followed through with his threat later in the year, killing Ms. Tarasoff (17 Cal. 3d 425, 551 P.2d 334 (1976)). The danger to Ms. Tarasoff was foreseeable, the verbal intent did equate to immediate danger, and the University was responsible for warning Ms. Tarasoff of the threat (17 Cal. 3d 425, 551 P.2d 334 (1976)).

The concepts in the prior two cases provide transferable examples of both a foreseeable and an unforeseeable danger and can be applied in theory to future situations and democratic engagement activities.

\section{Negligence}

As negligence is one of the highest occurring claims against universities by students, it is important to examine a number of cases which may apply to potential situations arising in the execution of a democratic engagement programs. The prior examination of legal concepts and cases surrounding the topics of liability, special relationships, duty of care, the reasonable person, and foreseeability all contribute to the court's determination of negligence.

The existence of these suppositions are often compounding. Negligence cannot be proven without first establishing the relationship and subsequent duty: "Actionable negligence presupposes the existence of a legal relationship between parties by which the 
injured party is owed a duty by the other, and such duty must be imposed by law" (142 N.C. App. 544, 543 S.E.2d 920 (2001).

Glannon specifies by stating, "A torts claim is only as strong as its weakest link; you have to examine the whole chain to give a realistic assessment of the chances of recovery" $(2010$, p. 448). There are no simple, always applicable rules to which a negligence or liability determination can always be attributed. Each case will be unique, and courts must look at the entire chain of events in order to first assess if a duty of care or special relationship existed and then determine if negligence is an issue and if the defendant assumed at least partial risk.

\section{Assumption of Risk}

According to Glannon, the premise of the doctrine of assumption of the risk involves "a person who is aware of a risk, and knowingly decides to encounter it, accepts responsibility for the consequences of that decision, and may not hold a defendant who created the risk liable for resulting injury “ $(2010$, p. 535). In order to fully understand the intricacies involved with assumption of risk, it is important to first understand that the courts are not consistent in the interpretation nor the application of assumption of risk decisions (Glannon).

Shifts over time have occurred due to the redefinition of statutes as well as political and administrative changes in our government and in society (Glannon, 2010). For example, as it became more popular to stress the freedom of choice in the nineteenth century, express assumption of risk, or the clear acknowledgement that a party will not hold a defendant liable for and injury, became more popular as well. (Glannon). Individuals tend to want to live a life of choice, including exciting or risky behavior. 
There are a number of qualifications, however, that determine the validity of express assumption, some of which will have connections to the democratic engagement activities of students.

Express Assumption of Risk. The consent for express assumption of risk must be freely given and not be classified as a situation where no meaningful alternatives existed; most notably, Glannon clarifies, "it is now generally held that the inequality of bargaining power inherent in the employment relationship bars express assumption of the risk by employees" (as cited in Glannon, 2010, p. 24). This interpretation is applicable to higher education and the authority relationship between university administrators or faculty and students. As established previously in the examination of the faculty-student relationship, students tend to defer to faculty authority as an employee would defer to employer authority due to the inequality of the relationship.

Next, under express assumption, "the plaintiff must clearly consent to accept the particular risk that led to the injury. For example, some courts have held that a provision releasing the defendant from "all claims for personal injury" does not waive recover for injury due to negligence of the defendant, since it does not sufficiently bring home to the plaintiff the extent of the risks she is accepting" (Glannon, 2010, p. 538).

In other words, waivers of liability cannot simply state that any and all injury is assumed by the participant. The waiver or exculpatory clause must be quite specific in the exact risks possible for the participant (Glannon).

Finally, express assumptions of risk "are also limited by general contractual principles concerning the understanding of the parties, thus, an agreement to assume the 
risk of injuries will not extend to the collateral risks beyond their contemplation" (Glannon, 2010, p. 538). The participant must only consider the usual risks involved with a specific activity, not any unforeseen risks or risks one would not normally consider.

Inherent Assumption of Risk. Under the concept of inherent assumption of risk, the participant freely chooses to join in an activity offered by the defendant and chooses to accept the risks associated inherently with the activity (Glannon, 2010). No one forced the plaintiff to participate, nor have the inherent risks been masked or misrepresented; this assumption of risk is also referred to in some cases as primary assumption of risk (Glannon). Glannon specifies, "the plaintiff considers the trade-off worthwhile, and accepts the possibility of injury because she enjoys the activity" (p. 539). The conduct in these cases on the part of both parties is considered reasonable. The case of Patterson v. Sacramento City Unified School District further explains the application of the primary assumption of risk concept.

In Patterson v. Sacramento City Unified School District, the court found that "the doctrine of primary assumption of risk applies where, by virtue of the nature of the activity and the parties' relationship to the activity, the defendant owes no legal duty to protect the plaintiff from the particular risk of harm that caused the injury" (155 Cal.App.4th 82, 2007)).

In this specific case, where unsupervised students in an adult truck driving class were required to load bleachers onto a tractor trailer bed, negligence was assigned to the institution because the risk was foreseeable, and there was no primary assumption of risk as the activity should have been supervised by a representative of the institution because the activity was designed to teach a specific portion of the curriculum (155 Cal.App.4th 
$82,2007))$. There was, therefore, foreseeable risk in the activity, and the District did not act to provide a standard duty of care to the student.

The primary assumption of risk will be applicable in many cases of democratic engagement activities, and higher education administrators will need to understand this assumption of risk and assess the activities to determine who has the risk and if the college is risking a claim of negligence. Additionally, a full understanding of the nuances involved in assumption of risk situations is necessary for administrators because the fine details in comparative and contributory negligence, as well as secondary assumption of risk, hold potential consequences of damage recovery in complex cases. As noted, assumption of risk cases are inconsistently decided in courts due to the uniqueness and complexities of each case.

\section{Voluntary Assumption of Duty}

Voluntary assumption of duty occurs when a university voluntarily engages in an activity which creates an established duty of care for a student. Examples of this potential assumption of duty include threat assessment training, initiatives to prevent hazing, and the increased desire for universities to foster the development of students in a holistic manner.

When programs are put into place to develop students as engaged members of society, it is possible that the university, by developing and publicizing specific programming, is undertaking a voluntary duty of care in relation to these areas. Courts are increasingly showing flexibility in the determination of duty, a phenomena which should be closely examined and watched in relationship to democratic engagement and 
the potential for liability. The following two cases and explanations shed additional light on this topic.

Davidson v. Univ. of N. Carolina at Chapel Hill. In the case of Davidson v. Univ. of N. Carolina at Chapel Hill (142 N.C. App. 544, 543 S.E.2d 920 (2001)), as established previously in this review of cases, a special relationship was found to exist between the University and a cheerleader. The courts found that the University of North Carolina at Chapel Hill also voluntarily undertook a duty of care when it provided education and advice to cheerleaders about safety during performances and practices; thereby, the university voluntarily undertook the duty to care for the cheerleaders while performing or practicing a cheer 142 N.C. App. 544, 543 S.E.2d 920 (2001).

Furek v. Univ. of Delaware. Similar to the case above, the Furek case also determined that the University had voluntarily assumed a risk. In this case, where the student was injured during a hazing incident in an on-campus fraternity house, the College voluntarily assumed risk when it created policies prohibiting hazing activities and when it provided training to students about the danger and consequences of participating in hazing activities (594 A.2d 506 (Del. 1991)). The College was aware and actively addressing the problem, thereby voluntarily assuming some risk of injuries due to the foreseeability and prior knowledge of this danger (594 A.2d 506 (Del. 1991)).

\section{Voluntary Participation}

Voluntary participation contributes to the establishment of liability and negligence in a number of ways, many of which may be applicable to the establishment of negligence when students are participating in community service activities or required engagement activities as part of a curriculum. Again, the case of Patterson v. Sacramento 
City Unified School District (155 Cal.App.4th 82, 2007)) involves community college students participating in a community service activity.

A student was injured when participating in a community service project where he was loading bleachers onto a trailer. This issue involves "the test for whether an offcampus activity is a "school sponsored activity," such that a duty of care exists and the school or community college district is subject to a student's negligence claim, is not really whether the student's participation is voluntary or not, but whether the off-premises activity is part of the school curriculum" (155 Cal.App.4th 82, 2007)).

The activity was determined to be part of the curriculum because students were to learn how to properly load the trailer in this truck driver training program. The student was not under the direct supervision of an instructor. The college claimed that it was not responsible under the doctrine of assumption of risk which eliminates the duty of care. As demonstrated previously, the assumption of risk did not apply in this case and, although this activity was classified as community service, it was not merely voluntary participation because the objective of the activity fit into the curriculum and the need to teach students to load flat-bed trailers (155 Cal.App.4th 82, 2007)).

\section{Conclusion}

As evidenced throughout this examination of tort law, liability, negligence and accompanying legal theory and case studies, it is evident that the relationship between universities and students is complex and multi-faceted. As students are asked or required to engage in politics, policymaking, community service, and other engagement activities, colleges and universities must evaluate the potential liability. Additionally, it is necessary for administrators to examine the benefits of a democratic engagement program, the ways 
in which the program will meet the nation's and society's needs, the responsibility of the college to prepare and train engaged citizens, and the overall desired outcomes in order to determine if the potential liability is worth the risk of the program.

If the program is deemed necessary and worthwhile, administrators must then move towards mitigation of the risk in order to minimize potential danger to students. As evidenced through the case studies, it will be necessary to identify times where special relationships exist or could be created, to determine when activities are curricular or extra-curricular, to ascertain the existence of heightened foreseeability, and finally, to determine if the institution could be held liable. Administrators have the option, if pursuing the engagement activities, to employ other means of risk mitigation including risk avoidance, risk control, risk transfer and risk retention (Lugg, 2012).

The development of a preventative law system may aid the university in the retention of engagement programming while mitigating as much risk as possible (Lugg, 2012). This type of system proactively coordinates with administrators, counsel, faculty, and students to minimize legal disputes and encourage training and effective relationship building amongst key constituents (Lugg). This type of preventative system also encourages the campus community to work together to retain important programming, such as democratic engagement, despite potential liability.

In the following section, this legal analysis of liability issues is combined with the fact-gathering information in prior chapters of this dissertation in order to effectively analyze future items for consideration in terms of democratic engagement programs in higher education. The fact-gathering questions are readdressed and these key considerations are evaluated in terms of policy claims and creations. 


\section{CHAPTER VI \\ POLICY RECOMMENDATION \& CONCLUSIONS}

\section{The Policy Issue}

It's now time to turn towards the policy issue and the analysis needed in order to evaluate the civic engagement movement in higher education and determine if the movement needs protection against potential threats to success. In the presentation of information throughout this dissertation, a number of key items emerge for consideration of the policy issue at hand. These areas of discussion are presented in my analysis prior to the application of Dunn's six-part analysis.

The policy issue, as identified in Chapter One for this study is: "Is higher education the appropriate venue for instruction on democratic engagement and, if so, do the benefits and rewards of instruction on democratic engagement outweigh the possible risks of incurring additional legal liability?" or, "Are the benefits of providing instruction on civic engagement in higher education more important than the increase in legal liability?" The key areas which emerged through fact-gathering and case study include, first, the case for civic engagement or the need to prioritize the education of engaged citizens, and second, the responsibility of higher education institutions in the preparation of these citizens. 
First, it must be acknowledged that supporting and fostering our nation's democratic environment is a priority; if we are to uphold and, according to some, repair democracy in this country, we must make educating engaged, informed, active citizens a priority as well.

Second, my analysis identifies the connection between democracy and higher education, making a case for democratic engagement in the university. There are, essentially, two critical reasons why higher education and democracy intersect and should be examined together. The first reason being, an informed, educated citizenry is necessary to democracy, and higher education reaches citizens at a critical life stage, one where they are better prepared to apply civic knowledge than simply understand the concepts as in earlier life stages. Higher education also has the opportunity to create engagement opportunities for students to prepare them to contribute effectively to the community, make informed voting decisions, and more fully understand and participate in solutions to pressing issues, worldwide.

The second reason being, higher education has a mission of service. This inclusion of service was a founding mission. It is documented and clear that institutions of higher education are intended to serve in a number of ways. This mission of service and the need for engaged, informed, and active citizens substantiates the need for a relationship between higher education, democratic education, civic engagement, and citizens.

Finally, after determining and substantiating the preceding claims, the policy issues become, "how is higher education the right place for democratic engagement?" and "Are the benefits of providing instruction on civic engagement in higher education 
more important than the increase in legal liability?" As these issues are addressed, policy decisions are necessary in order to leverage the needed change. The subsequent portion of this dissertation addresses the first key issue: why do we need civic engagement?

\section{The Case for Civic Engagement}

W.E.B. DuBois, in The Talented Tenth, wrote, "A system of education is not one thing, nor does it have a single definite object, nor is it a mere matter of schools. Education is that whole system of human training within and without the school house walls, which molds and develops men" (1903, p. 40). In the evaluation of democratic engagement in higher education, it must be taken into consideration that service, as a mission of higher education, has been identified, time after time, as an important component to the success of the higher education system. Yes, service as a term is highly contested, but, based upon the context surrounding the multiple examples of foundational documents supporting the concept of service performed by the university, it is important to apply the term to the intended outcome of improvement to society through the education and development of students in a number of manners. This mission is integral to the foundation of the educational system in this country, and reference to this service mission is evident throughout the founding publications.

As policymakers and government leaders aim to make political change, higher education institutions provide a platform and environment for this discourse to directly reach the educated, democratic population. Charles Kolb of the Committee on Economic Development states, "The heart of a vibrant democracy is educated, engaged citizens who are able to make choices for themselves, their families, their communities, and their 
country. In this respect, the success of American postsecondary education is critical to the success of American democracy" (as cited in AAC\&U, 2011, p. 9).

It is logical to place the responsibility for educating adult citizens, citizens who are expected to fully engage in political, economic and social issues, within the higher education system. Many of the issues adults must consider in regards to community life, including issues involving morals and values, do not become authentic, significant concerns until the citizen is above the age of eighteen. If, as a nation, we rely solely on the civic education program in the K-12 system, we overestimate the maturity level and readiness of our population as a whole. We are only educating these citizens about potential issues that will eventually require consideration because students in the K-12 system are, largely, too young to even vote. The issues are not yet real to these young students, so the information is not applicable nor concrete.

Students in higher education, while still somewhat isolated from the full responsibilities of adulthood, are exposed to an environment of critical inquiry and educated discussion. They continue to build the skills necessary to examine political, economic and social issues and make educated decisions which align with personal morals and values.

Again, it is widely noted in the literature on civic engagement that it is a goal of higher education to produce educated citizens who can contribute to the American system of democracy in a productive manner. Higher education is prepared and aligned to build civic engagement programming to effectively meet this goal. As attention towards service grew in the 1990s, Kozeracki (2000) writes of the increased attention towards service learning which was spurred by President Bush implementing the National and 
Community Service Act of 1990 and President Clinton's signing the National and Community Service Trust Act of 1993. Both of these acts address the nation's focus on an ethic of service and a focus on integrating students in community service and volunteer activities, as well as the incorporation of service learning into the curriculum.

In an attempt to distinguish civic learning from other types of service-learning or civic engagement, Musil (2003) identifies three national reform movements which have contributed to the need for, specifically, civic learning including "the diversity movement; the civic engagement movement; and the movement to create more studentcentered institutions" (p. 5). She continues by clearly stating the purpose of this civic learning by identifying the common traits of these movements and the intended outcome for students:

All three argue that students need to be prepared to assume full and responsible lives in an interdependent world marked by uncertainty, rapid change, and destabilizing inequities. Each recognizes the societal and cognitive development that results when students step out of their comfort zones into contact zones. All emphasize student-centered pedagogies that foster engaged, participatory learning dependent on dialogue and collaboration (Musil, 2003, p. 5).

Coley and Sum (2012) suggest that colleges and universities take a more active role in student voting participation, civic participation, and community service. Our population should be more politically active and assimilated into society and knowledge must be bolstered (Coley \& Sum). It is this active role and deep level of assimilation that is of particular concern. Again, the life stages of citizens must be taken into account, as well as intention. Engagement activities designed with the intention of assimilating 
citizens into active, engaged decision-making will be quite different based on the age of the citizen. The outcome of these activities may not meet the nation's goal if engagement activities are haphazard and without structure, efficient design, and implementation.

In addition to the report by Coley and Sum (2012), a number of national reports have been issued by the Department of Education, the Association of American Colleges \& Universities, the American Association of Community Colleges, Campus Connect and many more as noted in Chapter Four of this study. The frequent number of reports calling for attention to democratic education, civic engagement and service learning demonstrate the national goal for civic engagement.

Beaumont (2002) writes that higher education cannot separate intellectual, moral, and civic values. They are closely intertwined, and higher education should cultivate civic education that does not shy away from morality (Beaumont). As Rhoades (2003) suggests, institutions have an opportunity to reemphasize higher education's role in creating public good and serving humanity; they can connect to the philanthropic sector and affect the social infrastructure of the community. Institutions of higher education also have the opportunity to strive for institutionalization and focus on "culture-building around core values, key people, and symbolic representation of what the organization means and stands for" (Leslie, 2003, p. 18). Rhoades (2003) even calls for new structure in higher education valuing not revenue generation, but the improvement of society, socially, culturally, politically, and educationally. These scholars provide support rooted in literature for the inclusion of morals and values in civic engagement activities; discussion about this inclusion follows below. 
After examining the topics of civic education, civic engagement, and democratic education, I find that higher education is, indeed, responsible for educating engaged, knowledgeable citizens and well-situated to do so. Civic engagement, according to Brabant and Braid (2009), is, at its roots, political. Despite the broad issues surrounding civic engagement, such as widely accepted and used definitions, civic engagement must be evaluated from an institutional standpoint in order to overcome obstacles such as cost and reluctance to support large-scale engagement programming (Brabant \& Braid). After confirming in my analysis that higher education is responsible for educating civically engaged students, I now turn to the concept of democratic engagement within higher education and details surrounding this inclusion.

\section{Democratic Engagement in Higher Education}

A number of areas of consideration are critical in the further development and refinement of democratic engagement programming in higher education. In this analysis, consideration for terminology, program goals, the purpose of the program, the roles and responsibilities of the institution, the inclusion of morals and values, and discussion about the program within society follows.

\section{Terminology}

In order to accomplish the goal of educating engaged citizens, engagement must be prioritized, specifically as a combination of civic education, civic engagement, civic agency and education about participating actively in a democracy. It is this unique combination of priorities which necessitate a term beyond those commonly used in the past, terms with pre-defined connotations and implications. I support using the term democratic engagement, as do a number of scholars in this field, to convey the 
importance of engaging, as Westheimer and Kahne (2004) defined, the justice-oriented student. This term implies a focus on democratic education, civic engagement, and political change.

It is necessary to place an emphasis not just on community service and volunteerism, but on the importance of engagement and education about democracy and social issues if society is to be served and improved. Prioritization must be endorsed from national, state, and institutional levels. National and state political agents, as well as higher education administrators and faculty, must be involved in the execution of a democratic engagement program.

Terminology can often be even more important than simply ensuring common application of a term. Often, the words used to describe a movement are also responsible for inspiring participation. In his chapter, "Idealism and Compromise and the Civic Engagement Movement," Hartley writes, "The question before the movement now is whether an often ill-defined and rather unconventional - even bland - conception of engagement will be adequate to the task of inspiring people to undertake the difficult transformational change our democracy needs" (2011, p. 44).

The refinement of terminology to inspire a clear outcome is critical to the success of true democratic engagement. Hartley also specifies that this intended outcome necessitates "building strategic initiatives that confront injustice and relentlessly seek change through every democratic means possible" and "it is what is required to inspire the active support of a new and ever-widening circle of people eager to join this important work" (p. 45). The need to inspire participation and collaboration with 
increasing more people and institutions speaks to the need for terminology that reflects the wide spectrum of goals for the democratic education of active, engaged citizens.

\section{The Goal}

To be clear, the goal I identify here for democratic education is not a program to simply administer community service opportunities or even add service learning projects into freshmen orientation or a capstone course. Community service and service-learning are important, valuable activities and may often be included in democratic engagement programming; however, a democratic engagement mission aims to educate, train, and engage future citizens who will be well-prepared to make thoughtful, responsible contributions and decisions. For example, social justice issues, while excluded from service learning in the past, should be discussed and approached for future solutions, and politics should be explored in order for students to begin forming personal political opinions. The depth and breadth of a democratic engagement program far exceeds the silo approach utilized in the past where community service is a broad, undefined expectation, and service learning is haphazardly included throughout the student experience.

This proposed democratic engagement policy and program is designed with the theories of John Dewey and Amy Gutmann in mind in order to provide a framework for decision-making and goal-setting. The aim is consistently to build a stronger democracy and to prepare students to participate fully as educated citizens. Additionally, democratic engagement programming aims to embed policies and action that promote the democratic principles of equitable learning opportunities, access, and success for all students. 


\section{The Purpose: Why Democratic Engagement in Higher Education}

Democracy has been given a mission to the world, and it is of no uncertain character. I wish to show that the university is the prophet of this democracy, as well as its priest and its philosopher; that in other words, the university is the messiah of the democracy, its to-be-expected deliverer. (Harper, 1899)

William Rainey Harper is one of many scholars, politicians, and citizens who have linked democracy with higher education throughout history, and he did so in a manner that is still relevant in the $21^{\text {st }}$ century.

Again, young Americans are less involved, both civically and politically, than ever, showing low levels of social trust and sense of civic duty, as well as little knowledge of current affairs (Beaumont, 2002). The national need for global, civically engaged, contributing, active citizens calls for an effective analysis of information sharing, priority-setting, and comparative perspectives which help foster democratic engagement in students, resulting in graduates who continue to participate in a meaningful way as adults.

Higher education is also uniquely situated to be more effective than the K-12 system for educating and preparing engaged citizens. College students are continuing to mature and beginning to address adult decision-making processes which children under the age of 18 can only imagine. Additionally, Nie, et al. (1996) provide empirical evidence that additional years of formal schooling results in significant, positive and consistent increases in democratic citizenship activities. 


\section{Roles \& Responsibilities of the Institution}

It is the role of higher education institutions to create consistent, cohesive terminology which will gain traction and inspire all involved to become fully engaged, educated citizens. Democratic engagement should focus on the transformational development of students rather than on transactions between students and the institution. As Nie, et al. claim, "In order for democracy to function, individual citizens must first be able to identify and understand their preferences and political interests" (1996, p. 15). This process should not be transactional, but should focus on reflection and the transformation of students into citizen leaders. Students should be taught skills necessary to make educated decisions about personal preferences and politics; learning outcomes should focus on the justice-oriented student at the deepest level of engagement and participations (Westheimer \& Kahne, 2004).

\section{Morals \& Values}

In line with Amy Gutmann's (1987) theory on democratic engagement, morals and values should not be excluded from education. Students will graduate and soon after be responsible for making moral and political decisions, and these decisions should be well informed. College graduates should be able to articulate and defend their personal opinions and preferences; diluting the higher education experience by refusing to discuss politics or difficult subjects directly is a disservice to students. Many times, honest and challenging discussion about socially unjust topics is not included in course curriculum until graduate school.

Despite viewpoints and opinions of critics such as Stanley Fish, undergraduate students should be exposed and included in these discussions, despite the chance that 
faculty members may bring personal opinions and biases to the classroom. There may even be value in faculty members expressing personal opinions about social and political issues as the students will be exposed to many viewpoints and opinions throughout adulthood. It is important to understand your personal opinion, understand the viewpoints of others in order to be prepared to defend your opinion if necessary, as well as have the ability to weed through messages from electoral candidates and others presenting contestable information.

The students are old enough to vote, many are working, some are starting families, and all of these students should have the means and opportunity to make educated, informed decisions as citizens with personal morals and values. It is not the responsibility of the institution to prescribe morals and values; it is the institution's responsibility to provide students with the information and education necessary to make responsible, personal, well-informed choices. An environment designed to foster the critical examination and discussion of topics is critical to the true development of educated, engaged citizens.

It is impossible to fully separate civic education from morals and values. Why would we want to do this? The student experience would be diminished, the content of the education would be undermined by trying to separate the two concepts, and students would leave the institution even less inclined to participate when morals and values are excluded from decision-making.

Simply telling a student to later apply personal morals and values to civic issues and experiences, without fully examining and reflecting upon the application of these morals to the student experience, will not be effective, participatory learning. Brabant and 
Braid address the link between civic education and morals by stating, "civic mindedness involves a developed awareness of others that engages our moral imaginations and enhances our sense of efficacy and empathy as human beings who dwell in civil societies" (2009, p. 73). Students are human beings who dwell in this civic society, and as expectations are defined for institutions to develop civically engaged citizens, civic mindedness, morals, and values must be interconnected and addressed directly.

\section{Democratic Engagement in a Democratic Society}

Many individual institutions are attempting to include civic engagement and service learning into the student experience; however, a democratic engagement program moves beyond these activities. There are, obviously through examples of the success of the American Democracy Project, institutions that are involving students in democratic education and doing it very well; however, I believe that every student should be able to attend any college and leave with the skills necessary to be a fully engaged citizen. This type of wide-spread program implies national and state organization. Saltmarsh (2005) states that "Civic learning outcomes need to be thoughtfully constructed and carefully assessed if there is a serious interest in knowing that students are learning the knowledge, skills and values for active, engaged civic participation" (2005, p. 53).

There are both strengths and limitations to a national program of democratic engagement supported by policy. It will take coordination and communication efforts that keep student transformation in mind rather than being bogged down in bureaucracy. Successfully implementing meaningful democratic engagement will require an official shift of focus to the service mission of higher education, as well as the inclusion of civic education within the academic mission. 
Students should come to expect consequential, personal decision-making, meaningful conversations and education about politics, and conversations about the rootcauses and possible solutions for social justice issues. In fact, students should certainly hold institutions responsible for providing this type of environment, culture, and information. Linking civic engagement opportunities to politics is a contentious area for many stakeholders. Brabant and Braid discuss the issues surrounding the connection between civic engagement and politics and acknowledge the discomfort linking the two areas by stating: "We contend that it is precisely because civic is a political term that people, whether intentionally or unintentionally, muddle its usage and its purpose because they do not want to admit that civic engagement really is about being politically engaged" (2009, p. 66). The Political Engagement Project and the accompanying guidebook (2010) for implementation offers excellent support for the inclusion of political activity into universities. Additionally, the project offers successful case studies from the participating institutions, all of which support the ability to effectively include political engagement in the university.

\section{K-12 System: Policy \& Legal Implications}

The K-12 system of higher education has successfully, in many cases, implemented a system of mandatory community service activities. The decisions and thought process behind the defense of these policies and activities may be applicable to the design and discussion of legal and policy issues regarding democratic engagement activities in higher education. It is important, not just for pipeline and previous experience reasons, to understand fully the K-12 system. Challenges that have already 
been explored and/or solved may provide much information to the higher education system in regards to civic engagement and education.

In the 2011 report, Guardian of Democracy, Justice Sandra Day O'Connor and Congressman Lee Hamilton write the following about American education which can be applied to both the K-12 system and higher education:

Bringing a high-quality civic education to every American student requires more than individual programs and curricula, however. It requires a systematic approach that is only possible through public policy. Since American federalism means that local, state, and federal governments share custody of education policy, restoring the civic mission of schools must be the responsibility of policymakers at every level (CIRCLE, 2011, p. 5).

The discussion presented about the need for civic engagement, democratic engagement in higher education, and the importance of keeping current with K-12 trends and changes all help inform the following policy analysis according to Dunn's six-tep process.

\section{Democratic Engagement Policy}

The resurgence of the service mission of the university in the 1990s is often attributed to two seminal works by Earnest Boyer: Scholarship Reconsidered, written in 1990 through the Carnegie Foundation for the Advancement of Teaching, and The Scholarship of Engagement from The Journal of Public Service and Outreach in 1996. In his 1996 publication, Boyer called for those in the academy to look beyond the typical responsibilities of teaching and scholarship and consider the larger mission to the public outside the academy. He concluded with this message: 
At one level, the scholarship of engagement means connecting the rich resources of the university to our most pressing social, civic, and ethical problems.... But, at a deeper level, I have this growing conviction that what's also needed is not just more programs, but a larger purpose, a larger sense of mission, a larger clarity of direction in the nation's life (Boyer, 1996, p. 19-20).

Boyer refers to the need to bring democratic engagement to a higher level of priority. In order to effectively achieve this priority status, policy creation is necessary. Not only policy supporting the inclusion of democratic engagement in higher education, but policy that examines the benefits and rewards of democratic engagement activities against the potential liabilities. Boyte and Fretz also claim that "civically engaged work at the university thus functions more as a reclamation project than a trendy and ephemeral movement within higher education" (p. 81), indicating that we need "bold, theoretically grounded, and deeply public conceptions of our work in the world" (p. 81).

I add that public policy supporting the need and the elimination of as many additional challenges as possible is necessary to allow for culture change in higher education which supports democratic engagement, including policy stating that there is a compelling state interest to pursue democratic engagement activities, despite a potential increase in liability. The result from a balance test of risk versus compelling interest speaks to the need for policy formation, clearing potential obstacles for universities to feel comfortable funding and enacting democratic engagement activities for students. If the nation needs educated, engaged citizens, and it's determined that higher education is an optimum environment for fostering or developing these skills and behaviors, democratic engagement policy formation is necessary. 


\section{The Hypothetical Administrator}

I return now to the hypothetical administrator first presented in Chapter Three. Again, as one considers the overarching issue of public policy reform for democratic engagement in higher education, it is helpful to imagine hypothetical situations that may arise in a higher education institution as democratic engagement activities are being evaluated by administration and considered in terms of risk and liability. In many cases, activities are brought to administrators by students for approval as student-led activities or by faculty for approval to be included in the curriculum. These activities can belong to a number of different categories and still serve as a democratic engagement opportunity: direct service, community capacity-building, advocacy, and philanthropy are examples.

Following are a number of hypothetical situations; imagine a university administrator fielding these requests in an institution without a clear definition of servicelearning, civic engagement, or democratic engagement. Service is, in theory and in documentation, listed as a mission of this university. As in many institutions, the mission identifies academics, research, and service as the primary missions of the university; however, service is not an area with clear objectives, nor is it measured or benchmarked over time.

The administrator, the Vice President of Student Affairs, fields the engagement activities requests and, when necessary, consults with the university attorney, asking the questions: "will this activity increase liability for the institution?" and "should we allow this activity based upon the liability assessment?"

Animal shelter adoption. A group of students at a graduate school wants to support the local animal shelter by bringing adoptable dogs on campus to raise funds and 
place dogs in homes. The dogs are chosen by the shelter employees, and will accompany students throughout the day. The shelter will host an information booth on campus.

Temporary warming shelter. During a severe storm resulting in massive power outage, student leadership groups band together to open and manage a warming shelter for community members without power. The outage is expected to last a number of days, and temperatures remain dangerously low.

Homelessness experiment. A faculty member wants to conduct a homelessness experience activity with students sleeping on the city streets for one night and panhandling. The goal is for students to experience homelessness in order to conceptualize the difference between treating the symptom by donating clothing and food and treating the cause by addressing potential root issues of homelessness.

Community request. Members of the community have requested use of the local health facilities during a city health initiative project. Community members would be issued gym memberships for a two month period during the school year. The facilities have the capacity to serve more members, but membership would be granted based on residence and proximity to the university.

Voting rally. Student leaders, in conjunction with a national voting promotion and activist organization, plan a voting rally with an overnight lock-in, concerts, catering, and multiple guest speakers. Students will be able to register to vote and will learn about the candidate platforms.

Donations \& fund management. Students in the College of Business want to raise and independently manage funds for community projects, asking for donations from community businesses and alumni. 
Energy demonstration. Students want to conduct an environmental

demonstration and education project by turning electricity and water off in a number of buildings to demonstrate the inconvenience of learning without modern facilities. The goal is to educate students about education challenges in developing countries.

\section{Policymaking}

With the wide-range of hypothetical scenarios for democratic engagement activities in mind, policymaking specific to democratic engagement in higher education is evaluated. Policy can be defined as "the manifestation of the choices society has made about the behavior that it wants to encourage or discourage; broad; over-arching; lasting" (Lugg, 2014, p.1). Additionally, the Illinois State Board of Education uses this working definition: "policy making involves decisions intended to have wide, rather than narrow, influences on people and operations and which are intended to have more than a shortrange impact" (as cited in Lugg, p. 1). Higher education policy, specifically, speaks to the intended or desired behavior of colleges and universities, or issues affecting education at the post-secondary level. Because of federal initiatives and state control over education, policy statements can be associated at the federal, state, or institutional level.

The American Association of State Colleges \& Universities (AASCU) identifies the top 15 policy issues for higher education as:

1. Tuition Policy

2. State Appropriations for Higher Education

3. Campus Sexual Assault

4. Veterans Education Benefits

5. Undocumented Students 


\section{Guns on Campus}

7. Secondary-Postsecondary Standards Alignment

8. State Student Aid Programs

9. Performance-Based Funding

10. Free Community College (AASCU, 2015, p. 1-5)

The policy summary, issued by AASCU (2015), additionally cautions that re-elected and newly elected lawmakers are taking office with budget-cutting agendas that affect state institutions negatively.

AACSU, in discourse about political influence on education policy cautions, "States' role in determining the policy framework for public colleges and universities is only expected to intensify this year, as political polarization and paralysis in Congress have left a backlog of federal education bills for congressional committees to consider next session" (AASCU, p. 1).

It is important to consider the current political environment during policy exploration and development. Additionally, current policy trends and political instability, such as the overdue reauthorization of the Higher Education Act, speak to the everimportant need to educate citizens on political issues and on the selection of wellqualified politicians. Congress has the opportunity to make true change in education policy. According to AASCU,

"among all the higher education policies and programs ripe for reform, there exists a tremendous need and opportunity for Congress to use the HEA reauthorization to align state and federal higher education financing and incentivize states to re-invest in public higher education" (AASCU, 2015, p. 1). 
Policymaking is an ever-flowing and ever-changing process. Political parties, politicians, reform groups, lobbyists, institutions, and many other stakeholders affect policymaking and influence changes consistently.

Although many authors and many scholarly works identify challenges to effective civic engagement programming and policy formation, Sandmann (2006) identifies initiatives to advance efforts successfully through attention to "key issues [of] assessment and documentation, policy and advocacy, faculty engaged scholarship, [and] professional development" (p. 44-47). Policymaking at the state and institutional level to guide the development of effective and meaningful democratic engagement activities, influenced by national direction, provides a starting point for student-centered, transformational initiatives. A shift of focus will take time and patience and necessitates clear goals and constant communication.

Coordination with outside organizations that focuses on specific portions of democratic engagement will be key to successful collaborations with experts in civic education, service-learning, volunteerism, and social-justice work. Even slow and steady progress towards better civic education and vocalizing the goal of civically educated, participatory citizens will be positive progress towards democratic engagement policy. As Sandmann (2006) notes, "cohesive public policy agenda around engagement" (p. 45) requires resources, budget dollars, and faculty time in significant quantities.

Boyer concluded that undergraduate education fails to meet the civic and moral goals of higher education (as cited in Beaumont, 2002), and this situation is an injurious failure for America's students. Policymaking and progress towards more civically engaged students is crucial for the future of our democracy. As Braibant and Braid claim, 
"privilege and wealth do not guarantee a democracy's survival, but a well-educated body of political actors, of engaged citizens, increases the likelihood that a democracy will endure over time" (2009, p. 67).

\section{The Balance Test}

The policy issue examined throughout this dissertation is: "Are the benefits of providing instruction on civic engagement in higher education more important than the increase in legal liability?" Information is presented in this study as guided by the factgathering questions:

1. What is civic engagement?

a. How is it defined?

b. What benefits are attributed to such education?

2. How is civic engagement currently being integrated into higher education?

a. Is participation integrated into the curriculum?

b. Is participation voluntary or mandatory?

3. Is there currently a progression of civic education from K-12 into higher education?

4. Could an increase in civic engagement increase the legal liability for higher educational institutions?

It is now appropriate to address policy formation based upon information gathering during fact-finding; specifically, the balance test must be used to weigh the potential rewards and benefits against the possibility of increased risk and liability, as examined in Chapter Five. Is there a compelling state interest to develop democratic engagement policy, despite potential increase in liability and risk for the institution? 
I conclude that the balance test, based upon the information provided in my analysis of these issues, clearly provides for the formation of public policy supporting democratic engagement in higher education due to the limited probability of an established special relationship between the institution and the student during democratic engagement activities, whether within or outside of the curriculum. If an increase in liability does occur in specific situations, the risk likely does not outweigh the potential benefit to the nation, the state, the student, and the institution.

The potential risk for increased liability will fall within a wide spectrum of low to high risk. Based upon case decisions in suits with transferable circumstances, most of the risk associated with democratic engagement activities will fall below a level of risk deemed too high to be beneficial. There will always be exceptions to this majority, and institutions must be prepared to mitigate when possible and prevent activities where the benefit of the activity clearly does not outweigh the benefit of the experience.

For example, the hypothetical administrator referenced previously considered a homelessness experiment for a classroom exercise where students sleep on the streets for one night and panhandle for money. In this scenario, the student would be minimally immersed in the life of a homeless person. If the faculty member instead expected a student to go undercover as a homeless person for an extended period of time, with extensive effort to assimilate into the homeless environment without disclosing the nature of the experiment, this exercise would be considered beyond the scope of reasonable risk on the spectrum. The student could be injured in countless ways, and the representation of the student as an actual homeless person would be excessive based upon the learning 
outcome for the class, and the university would, typically, not have the support necessary to keep the student safe during the activity, as a police department might.

It is the legal concept of the reasonable person which can help guide the determination of an activity that is just too far beyond the acceptable amount of risk. If the courts would find the activity to be beyond what the reasonable person would accept, then the institution should, responsibly, also find the activity beyond an acceptable level of risk because the benefit would no longer outweigh the cost.

\section{Policy Outline}

In this type of exploratory policy study, as noted in Chapter Two, current trends are observed, researched, and analyzed in anticipation of policy action that might be taken. By necessity, the exploration includes an analysis of the values underlying these

trends. Exploratory policy studies are especially applicable when the current trend being watched has a legal component, such as possible tort liability, as defined in Chapter Five of this study.

An exploratory policy study is similar to a prospective policy study in that both are anticipating future policy action and providing guidance as to courses of action. An exploratory study, however, tends to be more theoretical; a specific policy or policy topic has not already been proposed for adoption. As in this dissertation, the policymakers attempt to study the waters in certain areas, ascertaining the values surrounding those areas in an attempt to determine what future action they should take.

This dissertation follows Dunn's (1981) six-part policy analysis structure including the following elements: policy-relevant information, the policy claim, warrant, backing, rebuttal, and qualifier. 


\section{Policy-Relevant Information}

My analysis of democratic engagement, as noted, provided policy-relevant information through the collection of literature and the evaluation of case law as outlined in the four fact-gathering questions. The review of educational scholarship on engagement, as promised in the study methodology in Chapter Two, answers the questions, "What is civic engagement?" and "How is civic engagement currently being integrated into higher education?" and "Is higher education the appropriate venue for instruction on democratic engagement?" Additionally, case law is used in Chapter Five to answer the question, "Could an increase in civic engagement increase the legal liability for higher educational institutions?"

Dunn's six-part system for policy analysis is now used in this dissertation to evaluate and clarify democratic engagement policy:

\section{Policy Claim}

Democratic engagement is critical to the preservation of democracy in America, and because higher education is determined to be an ideal environment for civic learning, and because there is a compelling state interest which overrides potential increases in institutional risk and liability, democratic engagement as a priority in higher education should be adopted nationally.

\section{Warrant}

Because avoidance of all legal liability is not a top priority or deciding factor for all institutions of higher education, higher education institutions should adopt a democratic engagement policy. Additionally, due to the fact that preservation of 
democratic ideals is foundational in this country, democratic engagement programming should be supported and adopted by higher education institutions.

\section{Backing}

Backing for this policy recommendation includes: student benefit gained through civic education and benefits documented throughout this study for the nation, institutions, students, communities, and individual citizens. Ethical and moral decision-making skills for students are additional backing for support of this public policy agenda.

\section{Rebuttal}

The rebuttal to this policy recommendation is that there is no compelling state interest to engage students in democratic activities, nor to continue civics education past the K-12 level. Additionally, even if the policy claim is accepted that democratic engagement is needed, the rebuttal could be that the potential liability involved in democratic engagement programming surpasses the benefit or reward gained, resulting in a dismissal of the policy recommendation based upon the result of the balance test.

An additional, more base-level rebuttal, is that higher education should not be responsible for educating engaged citizens. Rather, this rebuttal clarifies that higher education is simply responsible for academic instruction and not for the development of students as responsible citizens.

\section{Qualifier}

Because a balance test is used in the creation of this policy recommendation, it is acknowledged that there may be cases where the liability of an institution is increased due to particular, case-by-case circumstances. However, the balance test process notes the case-by-case exceptions and provides for these situations while continuing to express 
certainty for the policy recommendation. Additionally, the legal concept of the reasonable person aids in the identification of activities just too far past the acceptable amount of risk, leading to those extreme, outlier activities which become unreasonable. Despite the potential liability increase for the institution in some cases, democratic engagement policy is necessary.

\section{Conclusion}

After examining the roots of civic engagement, educational scholarship about the topic, the mission of the college, and identifying the ways in which higher education is a good fit for civic engagement activities, I conclude that a democratic engagement program is necessary and appropriate for inclusion in the mission and curriculum for higher education institutions, despite the potential for increased legal liability.

Identifying a national call for engaged, educated citizens provides evidence of the need and desire of our nation's leaders to produce suitable, responsible, active leaders. The higher education system, as justified above, is the appropriate location for this type of training and preparation.

Values and morals should not be defined for students nor prescribed to them within this type of program, though preparing students to examine and understand morality and values determination is critical to the formation of future leaders who are prepared to engage in meaningful discussion. Morals and values are personal choices; however, the avoidance of discussion around these choices implies that morality and values issues are not of utmost importance. Just as it is possible to discuss religion and varying religious choices without prescribing specific religious beliefs or imposing beliefs upon another person, so is it possible to teach others how to choose values and 
make morally responsible decisions without imposing specifics about the right choice or the only choice.

By formally charging all institutions of higher education with the goal of implementing an effective democratic engagement program, the opportunity exists to develop highly impactful programming beyond the basic activities which many institutions now include in student life programming.

The inclusion of this effective programming exposes the college or university to legal and policy issues which require further examination and consideration. The study and examination of the K-12 system aids in the analysis of potential policy implications for the higher education system, as well as in setting precedent for required learning about democracy, social justice issues, and other issues included in democratic engagement programming. Formal inclusion of democratic engagement programming into higher education curriculum will also generate policy and legal issues for consideration, rather than simply offering extra-curricular opportunities.

A number of key actions are critical to the success and preservation of the democratic engagement movement including the following:

- Take a realistic perspective and understanding about the K-12 system's ability to truly prepare students for an adult life of engaged citizenship when the students are not developmentally prepared to learn and, most importantly, apply the concepts.

- Identify service as a mission of the university in terms of it being a priority, not simply mission statement lingo absent substance and action. 
- Create policy, both institutionally and from a federal or state level, supporting the inclusion of democratic engagement in higher education. Specifically, form policy which allows institutions the freedom to implement these activities without fear of overly litigious results by identifying a compelling state interest.

- Protect the democratic engagement movement from budget cuts, threatening political agendas, and outside funding issues through policy creation.

- Utilize the evidence of a compelling state interest to circumvent bureaucratic roadblocks.

- Educate faculty and administrators about the prioritization of democratic engagement activities in order to avoid the 'easy no' and the 'forgiveness, not permission' mindset.

- Stop shying away from topics involving morals and values, despite the potential for faculty to present biased opinions, by identifying the value to students gained through exposure to varying viewpoints. Focus, instead, on the critical evaluation of the content and methods of additional fact gathering.

- Recognize that institutions face increased liability in countless areas, for many reasons. Thousands of students reside on campus and regularly participate in potentially dangerous classroom activities, especially in lab settings. Increased liability is not new to the university; the activities simply need examined and considered in terms of risk mitigation. 
- Combat the ideology that privilege and wealth will guarantee our democracy's survival by re-educating Americans about civic duty.

Despite future obstacles, a number of important opportunities exist for higher education, and most importantly, students. The national need for an engaged, educated citizenry creates a dire need to improve and focus on the democratic engagement programming opportunities in higher education. Additionally, as Gutmann notes in her work on the democratic theory of education, "The policies that result from our democratic deliberations will not always be the right ones but they will be more enlightened - by the values and concerns of the many communities that constitute a democracy - than those that would be made by unaccountable educational experts" (1987, p. 11).

Dunn's policy analysis structure allows for the clear and concise democratic engagement policy recommendation as outlined in this dissertation, providing policyrelevant information, warrants, backing, rebuttals, and qualifiers to support the following claim: Democratic engagement is critical to the preservation of democracy in America, and because higher education is determined to be an ideal environment for civic learning, and because there is a compelling state interest which overrides potential increases in institutional risk and liability, democratic engagement as a priority in higher education should be adopted nationally. 


\section{REFERENCES}

Adams, J. (1776a). Letter to Zabdiel Adams. Founding.com: A Project of the Claremont Institute. Retrieved from http://www.founding.com/founders_library/pageID.2144/default.asp.

Adams, J. (1776b). Thoughts on Government. Founding.com: A Project of the Claremont Institute. Retrieved from http://www.founding.com/founders_library/pageID.2137/default.asp.

American Association of State Colleges and Universities State Relations and Policy Analysis Team. (2015). Top 10 higher education state policy issues for 2015. Policy Matters: A Higher Education Policy Brief. January 2015.

American Association of State Colleges and Universities [AASCU]. (n.d.). Retrieved March 22, 2015. ADP Publications. Retrieved from http://www.aascu.org/programs/ADP.

Association of American Colleges \& Universities (2011). Special Issue: Civic Engagement and Psychosocial Well-Being. Liberal Education. Spring, 97(2).

Association of American Colleges \& Universities. (2012). A crucible moment: College learning and democracy's future. A national call to action. Association of American Colleges and Universities.

Astin, A. (1998). The changing American college student: Thirty-year trends, 1966-1996. The Review of Higher Education. 21(1):115-135.

Augsburg College. (n.d.). Retrieved March, 22, 2015. Harry Boyte. Retrieved from http://www.augsburg.edu/sabo/contact/harry-boyte/.

Battistoni, R., Longo, N., Jayanandhan, S. (2009). Acting locally in a flat world: Global citizenship and the democratic practice of service-learning. Journal of Higher Education Outreach and Engagement. 13(2). 89.

Beach v. Univ. of Utah, 726 P.2d 413 (Utah 1986)

Beaumont, E. (2002). Reinvigorating the civic mission of American higher education: Ideals, challenges, and models of good practice. 
Bergquist, W. H., Pawlak, K., \& Bergquist, W. H. (2008). Engaging the six cultures of the academy: Revised and expanded edition of the four cultures of the academy (2nd ed.). San Francisco: Jossey-Bass.

Board of Trustees of Univ. of D.C. v. DiSalvo, 974 A.2d 868 (D.C. 2009) 17 Cal.3d 425

Bowen, G., Burton, C., Cooper, C., Cruz, L., McFadden, A., Reich, C., \& Wargo, M. (2011). Listening to the voices of today's undergraduates: Implications for teaching and learning. Journal of the Scholarship of Teaching and Learning, 11(3), 21-33.

Bowman, N. (2010). Promoting participation in a diverse democracy: A meta-analysis of college diversity experiences and civic engagement. Review of Educational Research, 81(1), 29-68.

Boyer, E., (1990). Scholarship reconsidered. Priorities for the professoriate. San Francisco: Jossey-Bass.

Boyer, E. (1996). The scholarship of engagement. Journal of Public Service and Outreach 1 (1): 11-20.

Brabant, M. \& Braid, D. (2009). The devil is in the details: Defining civic engagement. Journal of Higher Education Outreach and Engagement, 13(2), 59-87.

Brown. D. M. (2012). Hegemony and the Discourse of the Land Grant Movement: Historicizing as a Point of Departure. In G.A. Ludlow \& L. Worsham (Eds.), Education as Civic Engagement: Toward a More Democratic Society (pp. 7-48). New York, New York: Palgrave MacMillan.

Brown, J., Collins, A., \& Duguid, S. (1989). Situated cognition and the culture of learning. Educational Researcher. 18(1), 32-42.

Bruininks, R., Furco, A., Jones, R., Sommers, J. \& Konkle, E. (2015). Institutionalizing civic engagement at the University of Minnesota. In H. Boyte (Ed.), Democracy's education: Public work, citizenship, \& the future of colleges and universities (pp. 80-90).

Burns, James MacGregor. (1978). From Leadership: HarperCollins Publishers, Inc.

The Center for Information \& Research on Civic Learning and Engagement [CIRCLE]. (2006). Higher Education: Civic Mission \& Civic Effects. Retrieved from http://www.civicyouth.org/special-report-higher-education-civic-mission-civiceffects/.

The Center for Information \& Research on Civic Learning and Engagement [CIRCLE]. (2011). Guardians of Democracy. Retrieved from 
http://www.civicyouth.org/guardian-of-democracy-successor-report-to-the-civicmission-of-schools/

Coley, R. \& Sum, A. (2012). Fault lines in our democracy: Civic knowledge, voting behavior, and civic engagement in the United States.

Collins Dictionary. (n.d.) Retrieved March 30, 2015. Retrieved from http://www.collinsdictionary.com/.

Davidson v. Univ. of N. Carolina at Chapel Hill, 142 N.C. App. 544, 543 S.E.2d 920 (2001)

Dixon v. Alabama State Bd. of Ed., 294 F.2d 150 (5th Cir. 1961)

Dean, D. (2012). Class discussion and notes. EAF 468. Illinois State University.

Denham, T. J., \& Gadbow, N. (2002). Literature review: Factors affecting the development of generation $X$ and millennials. Societal factors affecting education. Nova Southeastern University.CIRCLE Interactive Map. (2014). [Interactive Map] State civic education at a glance. Retrieved from: http://www.civicyouth.org/statecivic-education-at-a-glance/.

Dewey, J. (1900). The school and society. Chicago, IL: University of Chicago.

Du Bois, W.E.B. (1903). The Talented Tenth. The Negro Problem: A Series of Articles by Representative Negroes of Today. New York: James Pott \& Co. 33-75. Reprinted by Arno Press, 1969.

Dunn, W. (1981). Public Policy Analysis: An Introduction. Englewood Cliff, N.J.: Prentice-Hall.

Edwards, A. (1994). In loco parentis: Alive and kicking, dead and buried, or rising phoenix? Association for the Study of Higher Education Annual Meeting, November 12, 1994. Tuscon, AZ.

Ehrlich, T. (2000). Civic responsibility and higher education. American Council on Education/Oryx press series on higher education.

Fish, S. (2008). Save the world on your own time. New York, NY: Oxford University Press.

Furek v. Univ. of Delaware, 594 A.2d 506 (Del. 1991)

Giddens, A. (1990) The consequences of modernity. Stanford, CA: Stanford University Press. 
Giles, D. E., Jr., \& Eyler, J. (1994). The theoretical roots of service-learning in John Dewey: Toward a theory of service-learning. Michigan Journal of Community Service Learning, 1(1), 77-85.

Giroux, H. A. (1999). Vocationalizing higher education: Schooling and the politics of corporate culture. College Literature, 26(3), 147-161.

Giroux, S.S. (2012). Race, Rhetoric, and the Contest over Civic Education. In G.A. Ludlow \& L. Worsham (Eds.), Education as Civic Engagement: Toward a More Democratic Society (pp. 7-48). New York, New York: Palgrave MacMillan.

Glannon, J. W. (2010). The law of torts: Examples \& Explanations. (4 ${ }^{\text {th }}$ ed.). New York, NY: Aspen Publishers.

Godsay, S., Henderson, W., Levine, P., Littenberg-Tobias, J. (2012). State civic education requirements: Fact sheet. The Center for Information \& Research on Civic Learning \& Engagement.

Gott v. Berea Coll., 156 Ky. 376, 161 S.W. 204 (1913)

Gunn, J. \& Lucaites, J. (2010). The contest of faculties: On discerning the politics of social engagement in the academy. Quarterly Journal of Speech. 96(4), 404-412.

Gurin, P., Nagda, B., \& Lopez, G. (2004). The benefits of diversity in education for democratic citizenship. Journal of Social Issues, 60(1), 17-34.

Gutmann, A. (1987). Democratic Education. Princeton, NJ: Princeton University Press.

Hartley, M. (2002). A Call to Purpose: Mission-Centered Change at Three Liberal Arts Colleges. New York, NY: RoutledgeFalmer.

Hartley, M. (2011). Idealism and Compromise and the Civic Engagement Movement. In Saltmarsh, J. \& Hartley, M. (Eds.), “To Serve a Larger Purpose”: Engagement for democracy and the transformation of higher education (27-48). Philadelphia, PA: Temple University Press.

Hendersot, K., Sperandio, J., (2009). Study abroad and development of global citizen identity and cosmopolitan ideals in undergraduates. Current Issues in Comparative Education 12(1). 45-55.

Howell v. Calvert, 268 Kan. 698, 1 P.3d 310 (2000)

Humphrey School of Public Affairs, University of Minnesota. (n.d.). Retrieved March 22, 2015. Harry Boyte. Retrieved from http://www.hhh.umn.edu/people/hboyte/. 
Imel, S. (2012). Civic engagement in the United States: Roots and branches. New Directions for Adult and Continuing Education, (135), 5-14.

Jefferson, T. (1818). Report to the Commissioners of the University of Virginia (The Rockfish Gap Report). Founding.com: A Project of the Claremont Institute. Retrieved from http://www.founding.com/founders_library/pageID.2361/default.asp.

Kahne, J., \& Middaugh, E. (2008). Democracy for some: The civic opportunity gap in high school. The Center for Information \& Research on Civic Learning and Engagement. Retrieved from http://www.civicyouth.org/PopUps/WorkingPapers/WP59Kahne.pdf.

Keenan, C. \& Carr D. (2010). Chapter 2: Getting Started. In J. Goldfinger \& J.W. Presley (Eds.), Educating Students for Political Engagement: A Guide to Implementation and Assessment for Colleges and Universities (pp. 5-9). Washington, D.C.: American Association of State Colleges and Universities.

Keller, George. (2004) Transforming a College. Baltimore, MD: Johns Hopkins University Press.

Kettering Foundation. (n.d.). Retrieved March 28, 2015. Our Focus. Retrieved from http://kettering.org/who-we-are/our-focus/.

Kezar, A. (2004). What is more important to effective governance: Relationships, trust, and leadership, or structures and formal processes? New Directions for Higher Education, (127), 35-46.

Kirkpatrick, S.A. and Locke, E.A. (1991). Leadership: Do Traits Matter? The Academy of Management Executive 5, No. 2, 48-60.

Kouzes, James M. (2003). Reprinted from Business leadership: A Jossey-Bass Reader (2003). San Francisco, CA: Jossey Bass, Inc.

Kouzes, James M. and Posner, Barry Z. (1993). "Leadership is a Relationship." From the book, Credibility, as reprinted in Business Leadership: A Jossey-Bass Reader (2003). San Francisco, CA: Jossey Bass, Inc.Kinsley, C. (1994). What is community service learning? Vital speeches, LXI (2).

Kozeracki, C. (2000). Service learning in the community college. Community College Review, 27(4), 54-71.

Legal Information Institute. (2014). Retrieved from https://www.law.cornell.edu/.

Leslie, D. (2003). "Governance" or "governing"? Retrieved from http://www.usc.edu/dept/chepa/gov/roundtable2003/leslie.pdf 
Levinson, M. (2007). The civic Achievement Gap. The Center for Information \& Research on Civic Learning and Engagement. Retrieved from http://www.civicyouth.org/PopUps/WorkingPapers/WP51Levinson.pdf

Lugg, E. (2012). Class discussion and notes. EAF 578. Illinois State University.

Lugg, E. (2014). Class notes. EAF 512. Illinois State University.

Lyons, A., McIlrath, L., Munch, R. (Eds.) (2012). Higher Education and Civic Engagement: Comparative Perspectives. New York, NY: Palgrave Macmillan.

Mehaffy, G. (2010). Forward: The Political Engagement Project - An Initiative of the American Democracy Project. In J. Goldfinger \& J.W. Presley (Eds.), Educating Students for Political Engagement: A Guide to Implementation and Assessment for Colleges and Universities (pp. 5-9). Washington, D.C.: American Association of State Colleges and Universities.

Mickelson, R., Nkomo, M. (2012). Integrated schooling, life course outcomes, and social cohesion in multiethnic democratic societies. Review of Research in Education, 36(1), 197-238.

Musil, C. (2003). Educating for citizenship. Peer Review, Spring, 4-8.

Nanus, Burt. (1992). "Why Does vision Matter?” from Hickman (1998). Leading Organizations: Perspectives for a New Era. London: Sage.

Nero v. Kansas State Univ., 253 Kan. 567, 861 P.2d 768 (1993)

Nie, N., Junn, J., \& Stehlik-Barry, K. (1996). Education and Democratic Citizenship in America. Chicago, IL: University of Chicago Press.

Obama, Barrack. (2015). State of the Union [National Address]. United States: Washington, D.C.

People ex rel. Pratt v. Wheaton Coll., 40 Ill. 186 (1866)

Putnam, W. (2008). Pocket Guide to Legal Research. Clifton Park, NY: Delmar, Cengage Learning.

Rhoades, G. (2003). Democracy and capitalism, academic style: Governance in contemporary higher education. Paper presented to the Governance Roundtable, Santa Fe, NM.

Robertson, E. (1992). Is Dewey's educational vision still viable? Review of Research in Education. v18, 335-381. 
Rudolph, F. (1962). The American College and University: A History. New York, NY: Alfred A. Knopf.

Saltmarsh, J. (2005). The civic promise of service-learning. Liberal Education, Spring, $50-55$.

Saltmarsh, J., \& Hartley, M. (Eds.). (2011). “To Serve a Larger Purpose”: Engagement for democracy and the transformation of higher education. Philadelphia, PA: Temple University Press.

Sandmann, L. (2006). Building a higher education network for community engagement. Journal of Higher Education Outreach and Engagement. 11(4): 41-54.

State v. Pendergrass, 19 N.C. 365 (1837)

Steffen, L. (1909). Sending a State to College.

Tarasoff v. Regents of Univ. of California, 17 Cal. 3d 425, 551 P.2d 334 (1976) U.S. Department of Education (2013, June 7). Fact Sheet: Redesigning America's High Schools. Retrieved from http://www.ed.gov/news/press-releases/fact-sheetredesigning-americas-high-schools.

Vedder. R (2011). The 6 Biggest Problems with Higher Ed. Retrieved from: http://centerforcollegeaffordability.org/archives/4653.

Wang, Y., Ye, F., Jackson, G., Rodgers, R., Jones, S. (2005). Development of student service-learning course survey (SSLCS) to measure service-learning course outcomes. Association for Institutional Research: IR Applications. Vol. 3.

Washington, G. (1795). Letter to the Commissioners of the District of Columbia. Founding.com: A Project of the Claremont Institute. Retrieved from http://www.founding.com/founders_library/pageID.2224/default.asp.

Webb v. Univ. of Utah, 2005 UT 80, 125 P.3d 906

Wellhausen v. Univ. of Kansas, 40 Kan. App. 2d 102, 189 P.3d 1181 (2008)

Westheimer, J., \& Kahne, J. (2004). What kind of citizen? The politics of educating for democracy. American Educational Research Journal, 41(2), 237-269.

Williams, J. J. (2012). History as a Challenge to the Idea of the University. In G.A. Ludlow \& L. Worsham (Eds.), Education as Civic Engagement: Toward a More Democratic Society (pp. 7-48). New York, New York: Palgrave MacMillan. 
Williams, R. L. (1991). The origins of federal support for higher education.

Wilson, W. (1896). Princeton in the nation's service. The Papers of Woodrow Wilson. Vol. 10.

Yale College Committee of the Corporation and the Academic Faculty. (1828). Reports on the Course of Instruction in Yale College. New Haven, CT: Hezekiah Howe.

Youniss, J. (2011). Service, public work, \& respectful public citizens. Liberal Education, Spring, 97(2). 28-33. 